\title{
Effective and safe proton pump inhibitor therapy in acid-related diseases - A position paper addressing benefits and potential harms of acid suppression
}

Carmelo Scarpignato ${ }^{* *}$, Luigi Gatta ${ }^{1,2}$, Angelo Zullo3 ${ }^{3}$ Corrado Blandizzi ${ }^{4}$, for the SIF-AIGO-FIMMG Group and on behalf of the Italian Society of Pharmacology, the Italian Association of Hospital Gastroenterologists, and the Italian Federation of General Practitioners

\begin{abstract}
Background: The introduction of proton pump inhibitors (PPIs) into clinical practice has revolutionized the management of acid-related diseases. Studies in primary care and emergency settings suggest that PPIs are frequently prescribed for inappropriate indications or for indications where their use offers little benefit. Inappropriate PPI use is a matter of great concern, especially in the elderly, who are often affected by multiple comorbidities and are taking multiple medications, and are thus at an increased risk of long-term PPI-related adverse outcomes as well as drug-to-drug interactions. Herein, we aim to review the current literature on PPI use and develop a position paper addressing the benefits and potential harms of acid suppression with the purpose of providing evidence-based guidelines on the appropriate use of these medications.

Methods: The topics, identified by a Scientific Committee, were assigned to experts selected by three Italian Scientific Societies, who independently performed a systematic search of the relevant literature using Medline/PubMed, Embase, and the Cochrane databases. Search outputs were distilled, paying more attention to systematic reviews and meta-analyses (where available) representing the best evidence. The draft prepared on each topic was circulated amongst all the members of the Scientific Committee. Each expert then provided her/his input to the writing, suggesting changes and the inclusion of new material and/or additional relevant references. The global recommendations were then thoroughly discussed in a specific meeting, refined with regard to both content and wording, and approved to obtain a summary of current evidence.

Results: Twenty-five years after their introduction into clinical practice, PPIs remain the mainstay of the treatment of acid-related diseases, where their use in gastroesophageal reflux disease, eosinophilic esophagitis, Helicobacter pylori infection, peptic ulcer disease and bleeding as well as, and Zollinger-Ellison syndrome is appropriate. Prevention of gastroduodenal mucosal lesions (and symptoms) in patients taking non-steroidal anti-inflammatory drugs (NSAIDs) or antiplatelet therapies and carrying gastrointestinal risk factors also represents an appropriate indication. On the contrary, steroid use does not need any gastroprotection, unless combined with NSAID therapy. In dyspeptic patients with persisting symptoms, despite successful H. pylori eradication, short-term PPI treatment could be attempted. Finally, addition of PPIs to pancreatic enzyme replacement therapy in patients with refractory steatorrhea may be worthwhile. (Continued on next page)
\end{abstract}

\footnotetext{
* Correspondence: scarpi@tin.it

${ }^{1}$ Clinical Pharmacology \& Digestive Pathophysiology Unit, Department of

Clinical \& Experimental Medicine, University of Parma, Maggiore University

Hospital, Cattani Pavillon, I-43125 Parma, Italy

Full list of author information is available at the end of the article
} 
(Continued from previous page)

Conclusions: Overall, PPIs are irreplaceable drugs in the management of acid-related diseases. However, PPI treatment, as any kind of drug therapy, is not without risk of adverse effects. The overall benefits of therapy and improvement in quality of life significantly outweigh potential harms in most patients, but those without clear clinical indication are only exposed to the risks of PPI prescription. Adhering with evidence-based guidelines represents the only rational approach to effective and safe PPI therapy.

Please see related Commentary: doi:10.1186/s12916-016-0724-1.

Keywords: Proton pump inhibitors, Antisecretory drugs, Efficacy, Safety, Appropriateness, Acid-related diseases

\section{Background}

The introduction of proton pump inhibitors (PPIs) into clinical practice has revolutionized the management of acidrelated diseases. Pharmacological acid suppression has been so successful in healing peptic ulcer (PU) and managing patients with gastroesophageal reflux disease (GERD) that elective surgery for ulcer disease has been virtually abolished and anti-reflux operations are today performed only in selected patients. Along the same lines, the incidence of non-steroidal anti-inflammatory drug (NSAID)-associated gastropathy has largely been reduced, despite the increased use of these medications in the aging population [1].

Despite the fact that PPIs are far from being the ideal antisecretory drugs [2] and that new longer-acting compounds with extended acid suppression are being developed [3-5], they remain, no doubt, the most effective currently available medications and are widely prescribed in all age populations. Healthcare providers are increasingly prescribing PPIs for prolonged, sometimes lifetime, use and there is growing concern for the potential adverse effects resulting from such long-term therapy $[6,7]$. Soon after the introduction of omeprazole, the first PPI, into the market, Jean Paul Galmiche, a leading French gastroenterologist, wrote a thoughtful article [8] anticipating that the unprecedented clinical efficacy of these drugs would have lead (patients and physicians alike) to addiction, and indeed, this is the case. Once on a PPI, the majority of patients stay on long-term PPIs, often indefinitely [9], especially the elderly [10].

Studies in primary care and emergency settings suggest that PPIs are frequently prescribed for inappropriate indications or for indications where their use offers little benefit [11]. Patients admitted to hospital frequently are started on PPIs, often inappropriately [12], and these medications are continued, following discharge, by primary care physicians. Indeed, inadequate recommendations for PPIs in discharge letters are quite frequent [13]. This prescription habit may lead to a continuation of PPI therapy in primary care, thereby unnecessarily increasing polypharmacy and the risk of adverse events as well as burdening the public health budget. In this connection, an Italian study [14] found that the persistence rate of PPI therapy is fairly high, after both appropriate and inappropriate prescriptions (62\% and $71 \%$, respectively). The general practitioners' attitude to continuing or discontinuing PPIs depends on their level of knowledge and their perceptions of hospital physicians' competence as well as the threshold to prescribing in hospitals [15].

The introduction of generic PPIs into the market has been followed by an increasing rate of PPI prescribing related to chronic treatments, unlicensed indications, and therapeutic substitutions [16]. Furthermore, since PPIs are now available over-the-counter [17], patients can have free access to them and for long periods of time, without seeking medical attention [18, 19]. Counseling is therefore important to ensure that patients understand that failure of symptoms to resolve or a rapid symptom relapse while taking a PPI is an indication to consult a physician. Furthermore, concerns about potential masking of a more serious pathology, such as malignancy, should not be overlooked [19].

Inappropriate PPI use is a matter of great concern, especially in the elderly, who are often affected by multiple comorbidities and are taking multiple medications, and are thus at an increased risk of long-term PPI-related adverse outcomes and drug-to-drug interactions (DDIs). There is indeed a strong relationship between the number of administered drugs and potential, clinically relevant DDIs [20], particularly in older adults [21]. As a consequence, the number of yearly papers reporting PPI-related adverse events and/or PPI-drug interactions has steadily increased over the past decade [22-25].

Together with inappropriate use, underuse is also matter of concern. For instance, despite all guidelines supporting the use of gastroprotection with PPIs in atrisk patients treated with NSAIDs [26-28], low prescription rates of gastroprotective medications have been reported, although these rates have increased progressively (for review see [28]). In Italy, three studies [29-31] reported a substantial misuse of gastroprotection in primary care. In particular, an underuse rate of $25-30 \%$ or an overuse (young patients without any concomitant risk factor) as high as $57.5 \%$ were observed. In addition, half PPI doses or ineffective $\mathrm{H}_{2}$-receptor antagonist $\left(\mathrm{H}_{2} \mathrm{RA}\right)$ treatment were prescribed in another $10 \%$ of subjects [30]. 
According to the data provided by the Organization for Economic Cooperation and Development [32], PPI use is widespread and currently increasing, especially in some European countries. Prescription rates have risen substantially, not only as a consequence of the replacement of $\mathrm{H}_{2} \mathrm{RAs}$ but also because of an expansion in the overall market. PPI utilization does not appear to be commensurate with prevalence of acid-related disease (particularly with GERD and NSAID-gastropathy) nor with prescribing guidelines, thus leading to significant incremental costs to both patients and national health systems. Inappropriate prescribing is therefore high and costly. In a US teaching hospital, the estimated cost of inpatient and outpatient inappropriate use of PPIs was $\$ 12,272$ and $\$ 59,272$, respectively [33]. This trend is also being observed in most industrialized countries and Italy is no exception.

Taking all the above considerations into account, the Italian Society of Pharmacology (SIF), the Italian Association of Hospital Gastroenterologists (AIGO), and the Italian Federation of General Practitioners (FIMMG) considered it wise to review the current literature on PPI use and to prepare a position paper addressing the benefits and potential risks of acid suppression with the aims of providing evidence-based guidelines for appropriate use of these medications.

\section{Methods}

The three scientific societies (SIF, AIGO, FIMMG), promoters of the endeavor, identified experts amongst their members in order to set-up the Scientific Committee, who defined the methodology to be followed in the preparation of the position paper.

The methodology adopted to process the recommendations consisted of four subsequent steps. In a meeting, held in Rome at the beginning of 2015, the Scientific Committee identified the following 13 clinically relevant areas on which primary care physicians and gastroenterologists are uncertain about how to prescribe PPIs in patients with acid-related diseases and where drug-misuse was found to be common:

1. GERD

2. Eosinophilic esophagitis (EoE)

3. H. pylori eradication and PU disease

4. Zollinger-Ellison syndrome (ZES)

5. Stress ulcer prophylaxis (SUP)

6. Dyspepsia

7. NSAID-associated gastrointestinal symptoms and lesions

8. Corticosteroid use

9. Antiplatelet or anticoagulant therapy

10. PU bleeding

11. Patients with cancer
12. Cirrhosis

13. Pancreatic disease

Since PPIs are often used long-term, the benefit-toharm balance of such therapy was also addressed.

Each selected topic was assigned to a given expert, who carried out an independent systematic search of the relevant literature using Medline/PubMed, Embase, and the Cochrane databases. Search outputs were distilled, paying more attention to systematic reviews and meta-analyses (where available) representing the best evidence.

For each topic, a draft was prepared and circulated amongst all the members of the Scientific Committee. Each expert then provided her/his input to the writing, suggesting changes and the inclusion of new material and/or additional relevant references. Following preparation of the revised draft, each topic was addressed to the Core Writing Group (CS, LG, AZ, $\mathrm{CB})$, who prepared the first draft of the full manuscript, which was examined in Bologna on June 2015. During the meeting, each single topic was thoroughly discussed and each statement concerning the summary of current evidence refined with regard to both content and wording.

The Core Writing Group then incorporated all the suggestions raised during the Bologna meeting and prepared the final draft. In doing so, an updated literature search was performed and the most recent evidence included. This revised document was then sent to Italian and International experts (see Acknowledgements section) for review. Any changes resulting from comments received by the external experts were made on the basis of scientific and editorial merit in order to produce the final version of the position paper.

\section{Results \\ PPIs for GERD}

\section{Summary of the current evidence}

PPIs represent the mainstay of medical treatment of esophageal manifestations of GERD; however, their benefits (if any) in extra-digestive GERD are still uncertain. Eight-week therapy with standard (once daily) dose PPIs can achieve healing of reflux esophagitis and symptom relief in more than $80 \%$ of patients with typical symptoms. When a functional investigation is added to a negative endoscopy in making the diagnosis, PPI efficacy in GERD and non-erosive reflux disease (NERD) appears comparable. Being a chronic, relapsing disease, GERD (as well as NERD) requires long-term PPI treatment, which can be continuous, intermittent or on-demand. Profound and individually tailored maximal acid suppression is needed in patients with Barrett's esophagus not only to control gastroesophageal reflux 
(GER) but also in the hope to achieve a chemopreventive effect against neoplastic transformation.

GER (i.e., the reflux of gastric contents into the esophagus) is a physiological phenomenon, occurring in everybody, especially after large and fat meals. Under physiological conditions, efficient esophageal clearing mechanisms return most of the refluxed material to the stomach and symptoms do not occur [34]. However, when the reflux of gastric contents is large or aggressive enough, it causes troublesome symptoms and/or complications and adversely affects health-related quality of life, giving rise to GERD [35]. The Montreal consensus subclassified the disease into esophageal and extra-esophageal syndromes, with established or proposed associations with GER [36]. Up to two-third of patients with esophageal symptoms have a macroscopically normal mucosa at endoscopy. Such patients are usually considered to have NERD [37, 38].

GERD is primarily a motor disorder and its pathogenesis is multifactorial. The main motility abnormalities include an impaired function of the lower esophageal sphincter, an abnormal esophageal clearance and a delayed gastric emptying in up to $40 \%$ of cases. The presence of hiatal hernia favors reflux, but this association is not mandatory. The ultimate consequence of the above motor abnormalities is the presence of acid in the wrong place (i.e., in contact with the esophageal mucosa) [39]. In addition, the amount of reflux increases markedly after meals in both healthy subjects and in GERD patients, an event almost exclusively due to the increase of transient (inappropriate) lower esophageal sphincter relaxations by food-induced gastric accommodation. Despite the buffering content of food, the $\mathrm{pH}$ of the material refluxed into the distal esophagus is acidic due to the presence of an "acid pocket", which occurs in both healthy subjects and GERD patients. It represents an area of unbuffered gastric acid that accumulates in the proximal stomach after meals and serves as a reservoir for acid reflux [40]. The abnormal esophageal exposure to acid, on the other hand, is not secondary to gastric acid hypersecretion, which has been documented in only a small subset of GERD patients [39]. All the above pathophysiological mechanisms are exaggerated in obese subjects $[41,42]$.

Since effective drugs capable of controlling the esophageal motor abnormalities are currently lacking, the mainstay of medical treatment for GERD are antisecretory drugs, which act indirectly by reducing the amount and concentration of gastric secretion available for reflux, thus lessening the aggressive power of the refluxed material [43]. PPIs also reduce the size of the acid pocket and increase the $\mathrm{pH}$ (from 1 to 4 ) of its content [40]. The clinical efficacy of these drugs has been clearly shown in many studies and the superiority of PPIs over $\mathrm{H}_{2} \mathrm{RAs}$ has been established beyond doubt [44]. The greater pharmacodynamic effect of PPIs depends on their ability to block the final step in the production of acid, regardless of the secretory stimulus. Moreover, PPIs are relatively more effective during the daytime than the nighttime and this leads to a better control of postprandial reflux events [44].

Eight-week therapy with standard (once daily) dose PPIs can achieve healing of reflux esophagitis in more than $80 \%$ of patients [45], a rate depending on the severity of mucosal lesions [46, 47]. This healing rate can be further improved by doubling the PPI dose [45]. Meta-analyses have shown that when compared to omeprazole, lansoprazole and pantoprazole, esomeprazole achieves the highest healing rates of reflux esophagitis in the short term $[46,48,49]$. The more favorable clinical benefit of esomeprazole appears negligible in less severe esophagitis (A \& B according to the Los Angeles classification [50,51]), but it might be important in more severe disease [48]. Vonoprazan, a member of the new generation reversible PPIs (called potassium-competitive acid blockers), is able to achieve higher intragastric $\mathrm{pH}$, effectively controlling both daytime and nighttime acid secretion [5]. As a consequence, it proved to be capable of healing almost $100 \%$ of severe (grades C and D) esophagitis [52], a benefit also maintained during the remission phase [53].

It is worth mentioning that currently available PPI regimens do not provide the same control of intragastric $\mathrm{pH}$, evaluated both in terms of mean $\mathrm{pH}$ over the 24 hours and percentage of time spent at $\mathrm{pH}>4$. This has been repeatedly demonstrated in patients with GERD [54-56] or taking NSAIDs [57]. A large metaanalysis [58], including 57 studies measuring intragastric $\mathrm{pH}$ after different PPI regimens, found that the relative potencies of the five compounds, compared to omeprazole, were $0.23,0.90,1.60$, and 1.82 for pantoprazole, lansoprazole, esomeprazole, and rabeprazole, respectively. This lack of pharmacodynamic equivalence should be taken into account when switching from a given PPI to another.

PPIs are effective in obtaining symptom relief in both erosive and non-erosive disease [59]. Their efficacy for the relief of regurgitation is, however, modest and considerably lower than that achieved for heartburn [60]. The myth that PPIs are less effective in NERD has recently been dispelled by a meta-analysis [61] showing that, when a functional investigation $(\mathrm{pH}$-metry or $\mathrm{pH}$ impedance recording) is added to a negative endoscopy to objectively confirm this condition, the estimated complete symptom response rate after PPI therapy is comparable to that observed in patients with erosive disease. 
However, NERD is an umbrella term, including at least four different patient subgroups [38], of whom only those where acid is implicated in symptom generation (i.e., true NERD and patients with acid hypersensitive esophagus) are clearly responsive to PPIs [62]. This is not the case of patients who are hypersensitive to nonacidic reflux or those with functional heartburn. According to Rome IV criteria [63], both acid hypersensitive esophagus (now called reflux hypersensitivity) and functional heartburn are functional gastrointestinal (GI) disorders, which should no longer be included in GERD. The lack of abnormal acid exposure and symptom-reflux association makes patients with functional heartburn not responsive to PPIs. This subgroup of subjects may benefit from visceral analgesics (e.g., antidepressants) [64].

Although not as frequent as previously suggested, PPIrefractory heartburn, occurring more commonly in NERD than in erosive disease, does nevertheless exist. Some $20 \%$ (range 15-27\%) of correctly diagnosed and appropriately treated patients do not respond to PPI therapy at standard doses [65]. To ascertain whether they are "truly" PPI-resistant, compliance and adherence to treatment should be checked. Indeed, PPIs are often taken inappropriately, with only $27 \%$ of GERD patients dosing their PPI correctly and only $12 \%$ dosing it optimally in a USA survey [66]. Although a standard PPI dose can occasionally control symptoms, nocturnal intragastric acidity often remains elevated (with nocturnal acid breakthrough, NAB) in these patients. A split regimen (either standard or double dose) of PPIs b.i.d. (before breakfast and before evening meal) provides superior acid control. In patients with persistent nocturnal symptoms, the addition of an $\mathrm{H}_{2} \mathrm{RA}$ at bedtime may be indicated to control NAB and associated esophageal acidification $[3,62,67,68]$, despite the likely development of tolerance to $\mathrm{H}_{2} \mathrm{RAs}$ [69]. The majority of patients, however, reported persistent improvement in GERD symptoms from night-time $\mathrm{H}_{2} \mathrm{RA}$ use [67]. To reduce the development of tolerance, on demand or cyclic dosing may be preferable, but this approach has not been specifically studied.

GERD and NERD are chronic, relapsing diseases. Six months after cessation of treatment, symptomatic relapse is rapid and frequent (i.e., in $90 \%$ of endoscopypositive and $75 \%$ of endoscopy-negative patients [70]). PPIs, both at a full and half dose, are able to maintain patients in remission, with a superior efficacy of the full dose $(\mathrm{NNT}=9.1)$ [71]. Esomeprazole $20 \mathrm{mg}$ is the only step-down dose PPI able to maintain a significantly higher proportion of GERD patients in symptomatic remission, as compared to lansoprazole $15 \mathrm{mg}[49,72]$ or pantoprazole $20 \mathrm{mg}$ [49].

Since PPIs do not correct the underlying pathophysiological motor abnormalities responsible for GERD, a continuous treatment is required to maintain all patients in remission. In the LOTUS trial [73], comparing longterm esomeprazole therapy with anti-reflux surgery (ARS), the estimated remission rate at 5 years was $92 \%$, higher than that reported with omeprazole in the SOPRAN study (57\%) [74]. However, while the PPI dose in the SOPRAN trial was fixed, in the LOTUS investigation, patients whose reflux symptoms were not adequately controlled by a standard maintenance regimen (i.e., esomeprazole, $20 \mathrm{mg} /$ day) were allowed to increase the dosage to $40 \mathrm{mg}$ once daily and then to $20 \mathrm{mg}$ twice daily. This dose titration may have contributed to the improved remission rate and suggests that long-term maintenance therapy should be individualized. Indeed, the number and severity of relapses are highly variable amongst patients. Infrequent reflux symptoms are less likely to be chronic and may respond to different management strategies. There are basically three different long-term approaches for GERD treatment with PPIs: continuous (i.e., every day), intermittent (i.e., cycles of daily PPI administration), or on-demand (i.e., symptomdriven) therapy, each selected on the basis of patients' clinical characteristics [75].

One third of patients, submitted to fundoplication, is reported to take acid-lowering compounds (mostly PPIs) after ARS, but only few studies have specified whether drug use was on a regular or occasional basis [76]. A meta-analysis of randomized controlled trials (RCTs) [77] found that - after ARS - $14 \%$ of patients still require antisecretory drugs. This figure increases with the duration of follow-up and up to one third of patients required antisecretory drugs after 10 years. The data from non-randomized studies [78], which are higher than the estimation provided by randomized studies (i.e., $20 \%$ of patients under acid suppression), are probably more representative of the current clinical practice.

Although medication use is often considered as an outcome measure for successful ARS, some studies have shown that antisecretory drug use does not correlate with true recurrent reflux in most patients [76] and does not necessarily indicate a failure of the procedure. A significant proportion of patients taking medications after operation are using them to relieve non-reflux symptoms and only one third of patients displays an abnormal esophageal exposure to acid after surgery [76]. Therefore, many patients take PPIs despite the lack of objective evidence of GERD on esophageal testing. The causes of persistent symptoms after surgery remain unclear. Non-GERD symptoms might be due to increased esophageal sensitivity while other symptoms (like bloating, early satiety and nausea) may be unmasked when reflux symptoms improve [79-81]. A careful selection of patients and thorough follow-up is needed to avoid unnecessary acid suppression in post-surgical patients. 
Before embarking on long-term treatment, an attempt to stop acid suppression must always be considered. Of the various interventions (patient's education, life-style modifications, abrupt withdrawal, and tapering), tapering is the more effective discontinuation strategy [82]. Abrupt withdrawal might be followed by rebound acid hypersecretion and exacerbation of symptoms [83]. Weight loss appears to be another strategy in obese/ overweight patients. Indeed, in one study, up to $54 \%$ of subjects compliant to a hypocaloric diet were able to stop PPI therapy, with an additional $32 \%$ being able to halve the dose [84]. All the above attempts should be considered also in patients who are already on longterm acid suppression.

Continuous maintenance therapy is indicated in patients with Barrett's esophagus of any mucosal length, owing to the potential chemopreventive activity of PPIs against neoplastic transformation, a property advocated by the American College of Gastroenterology (ACG) [85] and American Gastroenterological Association [86], but denied by the British Society of Gastroenterology guidelines [87]. Indeed, a recent meta-analysis of observational studies showed that PPI use is associated with a $71 \%$ reduction in risk of esophageal adenocarcinoma and/or high-grade dysplasia in this patient population (adjusted odds ratio $(\mathrm{OR})=0.29$ ) [88]. Despite a contrary opinion of the American Gastroenterological Association [86], current evidence suggests that standard PPI therapy is unable to normalize esophageal exposure to acid in the vast majority of patients with Barrett's esophagus. Profound and individually tailored maximal acid suppression is needed not only to control GER, but also in the hope to achieve a better chemopreventive effect [89].

In all those patients with GERD requiring long-term PPI therapy, $H$. pylori should be sought and - if present - eradicated, particularly in young patients. This approach, recommended by international guidelines $[90,91]$, is needed to prevent the development of atrophic gastritis or worsening of any preexisting one, with potential for neoplastic transformation [92]. However, in accordance with the Food and Drug Administration, ACG guidelines [93] do not recommend routine screening for or treatment of $H$. pylori infection in GERD patients (strong recommendation, low level of evidence).

Conversely from typical symptoms, the efficacy of PPIs on extra-esophageal manifestations of GERD is uncertain. This uncertainty could result, at least in part, from the available studies, which are not homogenous, with differences in patient selection, end-point considered, drug used, and regimen adopted. In addition, since extra-digestive symptoms may need higher PPI dose and clinical improvement may take a longer time to occur, only properly designed trials would be able to unravel a clinical response. Unfortunately, however, this has not always been the case.

The efficacy of PPIs in non-cardiac chest pain and extra-digestive GERD is disappointing. In these clinical conditions, PPIs are usually given twice daily and for extended periods (i.e., 3 or more months). However, evidence is often lacking and, where available, not strong enough to allow clear recommendations to be made.

With GERD being the most common and best-studied cause of non-cardiac chest pain, acid suppression is the initial pharmacological approach in this patient population. A systematic review showed that patients with endoscopic or $\mathrm{pH}$-monitoring evidence of GERD tend to improve, but not resolve, with PPI therapy, whereas GERD-negative patients display little or no response [60], a result confirmed by a more recent meta-analysis [94]. PPIs might also improve symptoms related to atrial fibrillation and other supraventricular arrhythmias, especially after meals, in patients with proven GERD [95].

Despite the negative conclusions of a Cochrane metaanalysis [96], a recent review [97] suggests that a therapeutic benefit for acid-suppressive therapy in patients with chronic cough cannot be dismissed, advocating a rigorous patient selection that could allow the identification of patient subgroups likely to be responsive. On the contrary, no systematic reviews and meta-analyses [98-103] found any significant clinical benefit of PPI therapy over placebo in reflux laryngitis.

Asthma and GERD can often coexist, with reflux disease being reported in 40-80\% of patients with asthma. While asthma medications can trigger GERD [104, 105], PPIs might, on the contrary, improve asthma control. Here, again, an early Cochrane review [106] showed no benefit of PPI therapy on nocturnal symptom score and lung function, but a recent meta-analysis [96] - by selecting the morning peak expiratory flow rate as the primary outcome - disclosed a benefit of PPIs over placebo, which was greater in patients with proven GERD.

Despite the widespread use of PPIs in dental practice to manage the oral manifestations of GERD [107], treatment of dental erosions represents the only objectively documented clinical use [108].

In summary, while PPIs are the mainstay of medical treatment for esophageal manifestations of GERD, their benefit in extra-digestive GERD remains uncertain. The complexity of patient presentation is matched by the challenge in appropriate diagnosis of reflux as the cause for patients' symptoms, which may also be related to other co-morbidities. Upper GI endoscopy and $\mathrm{pH}$ monitoring suffer from poor sensitivity, while laryngoscopy suffers from poor specificity in diagnosing reflux in this group of patients [109]. An empiric trial of PPIs could be the initial approach to diagnose and treat the potential underlying cause of these extra-esophageal 
symptoms. For those who improve with PPIs, GERD is presumed to be the etiology, but for those who do not respond, diagnostic testing with impedance and/or $\mathrm{pH}$ monitoring are reasonable to exclude continued acid or weakly acid reflux. In such cases, etiologies other than GERD may be pursued [109]. Difficult patients are best investigated and treated in referral centers.

\section{PPIs for eosinophilic esophagitis (EoE)}

\section{Summary of the current evidence}

PPIs are considered a first-line treatment in EoE. Other effective alternatives, such as dietary or topical corticosteroid therapy, should be used as second-line strategies, owing to long-term safety concerns (topical steroid therapy) and impairment of quality of life and nutritional inadequacy (dietary interventions). However, few data exist to guide specific recommendations on dose and duration of PPI initial therapy.

EoE is a chronic immune-mediated inflammatory disorder, defined symptomatically by esophageal dysfunction and histologically by esophageal eosinophil-predominant inflammation $[110,111]$. Originally thought to be a rare disease, its prevalence has greatly increased over the past 25 years. The allergic basis of EoE is supported by studies demonstrating that the underlying etiology for EoE is likely an aberrant "antigenic" or "immune" response, associated with consistent clinical and histologic abnormalities [112], and by their disappearance after antigen-free amino acid-based elemental diet [113].

It is important to emphasize that esophageal eosinophilia is a histological finding that requires interpretation in the clinical context and that esophageal eosinophilia alone does not define EoE; indeed, many other diseases have been associated with this histologic finding [114]. Although the presence of esophageal eosinophilia was first described in a subset of patients with GERD, it usually locates in the distal esophagus and never reaches the high density commonly observed in EoE, where it is associated with esophageal motor dysfunction, particularly dysphagia and food impaction [110, 111].

According to the ACG guidelines [115], PPI responsive esophageal eosinophilia (PPI-REE) should be diagnosed when patients have esophageal symptoms and histologic findings of esophageal eosinophilia, but demonstrate symptomatic and histologic response to PPIs. Originally categorized as a distinct clinical entity, PPI-REE is now considered a phenotype of EoE that is responsive to PPI therapy [110]. PPIs, therefore, no longer represent a diagnostic tool to distinguish between these two entities characterized by esophageal eosinophilia and symptoms, but a therapeutic option to be offered to patients with EoE. In this clinical setting, $\mathrm{pH}$ monitoring does not accurately predict response to PPI therapy [115], and similar remission rates have been documented in patients with both normal and pathologic $\mathrm{pH}$ monitoring [116]. In addition, symptom improvement is common with PPI therapy despite persistent eosinophilic infiltration [117].

A very recent meta-analysis [116], including 33 studies and 619 patients with EoE, found that PPI therapy led to a clinical response in $60.8 \%$ and histologic remission in $50.5 \%$ of patients. However, few data exist to guide specific recommendations on dosage and duration of PPI initial therapy. Retrospective data support the use of either once or twice daily use, but many of the PPI-REE studies used twice daily PPI dosing in the $20-40 \mathrm{mg}$ range of the several available PPIs [115], for which there is a trend (albeit non-significant) towards an increased effectiveness [116].

The reason for PPI responsiveness of this condition is not completely understood but could be due to other, non-antisecretory effects of PPIs [118], of which the anti-inflammatory action [119] is the most relevant one. In vitro and in vivo studies suggest that the antiinflammatory effects of PPI therapy rather than acid suppression alone may be responsible for this improvement through inhibition of the Th2-allergic pathway [120]. Indeed, like topical corticosteroids, PPIs downregulated cytokine expression [121]. Alternatively, the dilated intercellular spaces and consequent increased mucosal permeability, present in EoE [122], may allow allergen penetration, which triggers subsequent recruitment of eosinophils to the esophageal epithelium. Some studies have shown that dilated intercellular spaces could recover after short-term PPI treatment in GERD (for review see [123]), a finding recently reported in patients with PPI-REE [124].

In summary, due to their safety profile, ease of administration, and high response rates (up to $60 \%$ clinically), PPIs can be considered a first-line treatment for EoE. Recent data show that patients with EoE, responsive to topical steroids and diet, also respond to PPI treatment $[125,126]$. However, the former approaches might be set aside as second-line, owing to long-term safety concerns (topical corticosteroid therapy) and impairment of quality of life and/or nutritional inadequacy (dietary interventions) $[115,116,127]$.

PPIs for H. pylori eradication and peptic ulcer (PU) disease

\section{Summary of the current evidence}

PPIs represent a key component of any currently adopted regimens for $\mathrm{H}$. pylori eradication. The degree and duration of acid suppression influence the eradication rate. While almost all $\mathrm{H}$. pylori-positive ulcers are cured by $\mathrm{H}$. 
pylori eradication, H. pylori-negative and NSAID/aspirin-negative PUs need high dose PPIs to be healed and, often, lifelong acid suppression is required to prevent recurrence.

After the discovery by Warren and Marshall of the infectious etiology of PU disease in 1984 [128, 129], several lines of evidence confirmed that $H$. pylori eradication cures PU disease without the need for subsequent long-term maintenance antisecretory therapy [130-133], and can also be beneficial to other $H$. pylori-related diseases [90]. While previously used only to heal PUs, PPIs have become a key component of all the currently adopted eradication regimens [134], thus gaining a new role in the management of PU disease.

H. pylori is located within the gastric mucus layer, deep within the mucus-secreting glands of the antrum, attached to cells and even within cells, and is able to survive over a wide $\mathrm{pH}$ spectrum [134]. Since the survival capabilities of $H$. pylori within the stomach make its eradication difficult, several different drug combinations have been developed, with variable and inconsistent success, with no single therapy being effective worldwide. Therefore, the search for a new regimen to treat $H$. pylori infection still continues today [135].

An effective therapy should be able to eradicate the organism from each of these potential niches, which is an overwhelming task for any single antibiotic, whose in vitro susceptibility does not necessarily correlate with successful treatment in vivo. Since the very beginning, it was recognized that therapy with a single antibiotic leads to poor cure rates and various recipes were attempted, resulting in several effective combinations of antimicrobials, bismuth, and antisecretory drugs [136].

PPIs display several pharmacological actions that give them a place in the eradication regimens, namely:

1. They exert a direct antibacterial action against $H$. pylori $[137,138]$;

2. By increasing intra-gastric $\mathrm{pH}$, they allow the microorganism to reach the growth phase and become more sensitive to antibiotics such as amoxicillin and clarithromycin [139];

3. They increase antibiotic stability [140] and efficacy [141];

4. By reducing gastric emptying [142] and mucus viscosity [143], they increase the gastric residence time and mucus penetration of antimicrobials.

The mechanisms underlying the antibacterial activity of PPIs are complex and have been detailed in a comprehensive review [134]. These compounds are able to bind H. pylori cells and the bactericidal activity correlates with the degree of binding. Electron microscopy studies revealed - after exposure to a PPI - a significant change in the morphology of the microorganism, with appearance of coccoid forms (known to be degenerating organisms) [134]. PPIs are potent inhibitors of $H$. pylori urease at all $\mathrm{pH}$ values. This effect translates into significant reduction of ammonia production. Since this bacterial metabolite is important for development of mucosal inflammation and subsequent mucosal ulceration [144], patients receiving PPIs in combination with antimicrobials may have the additional benefit of reducing one of the potent inflammatory stimuli.

The inhibitory activity on $H$. pylori urease has been confirmed in vivo. As a consequence, PPI administration results in the inability to detect the microorganism, thus interfering with the urease-based diagnostic tests [90, 145]. The temporary inability to detect the presence of $H$. pylori is termed suppression and simply reflects a decrease in the number of bacteria below the limits of detection [145]. It is worth mentioning that the infection affects the degree and the duration of acid inhibition achieved by antisecretory drugs. Amongst the mechanisms by which the microorganism could modify the pH-rising effect of PPIs, the buffering of $H$. pylori-generated ammonia on gastric acid remains the most convincing one [69].

A large clinical trial (the $\mathrm{MACH}-2$ study) clearly showed that eradication rates achieved with two antibacterial agents (clarithromycin with either amoxicillin or metronidazole) are significantly lower than those achieved by the same two agents, given concomitantly with omeprazole [146]. These results were later confirmed by another RCT, where the combination of clarithromycin and tinidazole was evaluated with or without lansoprazole [147].

PPIs now represent the key component of any currently adopted regimens for $H$. pylori eradication, as recommended by Italian [148] and international guidelines [90, 149-151]. To be most effective, full dose PPIs should be given twice daily, concomitantly with antimicrobials as the mean intention-to-treat cure rates are greater in patients who use the high-dose PPI, compared with the standard-dose regimen $[152,153]$.

Eradication rates achieved with standard 1-week triple therapy (PPI-clarithromycin-amoxicillin) are dependent on CYP2C19 genotype [154]. Therefore, although any PPI can be selected, esomeprazole- and rabeprazolebased eradication regimens may show a better efficacy [155]. The biological plausibility of their superiority over other members of the PPI-class relies on their catabolism. Indeed, esomeprazole, the S-enantiomer of omeprazole, being - together with its metabolite (esomeprazole sulfone) - a powerful inhibitor of CYP2C19, does inhibit its own metabolism, rendering all subjects "slow 
metabolizers" [156]. This results in a more consistent acid suppression and might underline the slightly higher eradication rates reported with these PPIs [155]. Conversely from the other PPIs, the clearance of rabeprazole is much less dependent on CYP2C19 as it is predominantly metabolized non-enzymatically to rabeprazole thioether [157]. As a consequence, its antisecretory effect and the eradication rates of rabeprazole-based regimes are almost completely independent of genetic polymorphism [158]. As a matter of fact, a recent meta-analysis did show that, contrary to omeprazole and lansoprazole, the CYP2C19 genotype does not influence the eradication rate of esomeprazole- and rabeprazole-based therapies [159].

The importance of profound and long-lasting acid suppression for $H$. pylori eradication is illustrated by two studies showing a significantly higher intragastric $\mathrm{pH}$ and lower percent time spent at $\mathrm{pH}<4$ in patients successfully eradicated versus those who did not get rid of the bacterium [160, 161]. In addition, the eradication rate was higher in NAB-negative compared to NABpositive patients [160]. Controlling intra-gastric acidity is therefore needed to achieve the best eradication rates $[152,162]$. Indeed, some studies have shown that the use of high dose PPIs might result in high eradication rates even when one single antimicrobial agent is used [163-165]. The recent availability of more potent and longer-acting acid suppressants, namely vonoprazan [5], may facilitate the use of a dual therapy (i.e., acid suppressant plus amoxicillin) [166].

Although $H$. pylori infection remains the single most common cause of PUs, an increasing proportion of patients have H. pylori-negative ulcers [167]. The proportion is higher in the USA (and likely in Australia) than elsewhere, being only $4 \%$ in Italy [168]. Although the precise etiology of these ulcers is unknown, some are caused by the use of aspirin or NSAIDs [169]. Indeed, together, $H$. pylori infection and NSAID use account for approximately $90 \%$ of PU disease [170]. Patients with $H$. pylori-negative, NSAID/aspirin-negative (idiopathic) ulcers may have a more serious ulcer diathesis. While NSAID ulcers can be healed with PPIs (see below), idiopathic ulcers are likely to require longterm management with acid-suppressing drugs. PPIs are again the drugs of choice, although the optimal duration of treatment is undefined and might be lifelong [171].

\section{PPIs for Zollinger-Ellison syndrome (ZES)}

\section{Summary of the current evidence}

PPIs are the drugs of choice for the medical treatment of $Z E S$, but relatively high doses (3-4 times the standard dose) are required compared with those used in other acid-related conditions. Patients with complicated ZES (severe GERD, Billroth II resections, and multiple endocrine neoplasia type 1 (MEN-1) with untreated hyperparathyroidism) are more difficult to treat and usually benefit from twice-a-day PPI dosing. The intravenous route may be required initially. When curative tumor removal is not possible, antisecretory therapy must be continued indefinitely. Interruption of PPI treatment can have detrimental consequences.

ZES is a rare disorder characterized by the presence of a gastrin-producing tumor (gastrinoma), which leads to sustained hypersecretion of gastric acid and consequent PU disease (often with complications such as perforation, bleeding, etc.), diarrhea, or malabsorption. Gastrinomas usually develop in the non-beta islet cells of the pancreas or in the duodenal wall (40-90\%). Up to two-thirds are malignant. About $20-25 \%$ of cases are seen in patients with MEN-1 syndrome [172, 173]. Nevertheless, even rarer, ZES symptoms may arise from a cholecystokinin-producing tumor [174], because both cholecystokinin (CCK) and gastrin are full agonists for the gastrin- $\mathrm{CCK}_{2}$ receptor of the parietal cell, whose stimulation drives gastric acid secretion.

Although somatostatin analogues (octreotide or lanreotide) could be used to reduce serum gastrin and gastric acid secretion [175-177], initial treatment is aimed at controlling the hypersecretion of gastric acid with an antisecretory drug. Dose titration using gastric acid analysis is the ideal way to best determine the lowest effective dose of medical therapy. Indeed, giving enough medication just to control symptoms is not considered adequate, and it is important that acid secretion is reduced below $10 \mathrm{mEq} / \mathrm{h}$ (or below $5 \mathrm{mEq} / \mathrm{h}$ in the postsurgical stomach) to avoid ulcer recurrence and complications [178]. According to available guidelines [176, 177], a PPI is the drug of choice, but high doses (3-4 times the standard dose, once daily) are required compared with those used in other acid-related disorders. Patients with complicated ZES (severe GERD, Billroth II resections, and MEN-1 with untreated hyperparathyroidism, etc.) are more difficult to treat and may require twice-a-day PPI dosing. The intravenous route (e.g., pantoprazole $80 \mathrm{mg}$ every 8 hours [179]) may be required initially. Once symptoms have been controlled, the tumor can be investigated for surgical excision [178]. When curative removal is not possible, antisecretory therapy must be continued indefinitely. In patients who have undergone successful curative gastrinoma resection, PPIs may also be required because, in more than half of them, a hypersecretory state persists [180]. Interruption of PPI treatment (and consequent acid rebound) can have detrimental consequences, including severe peptic complications (strictures, perforations, etc.) [181]. Patient compliance to treatment 
is, therefore, crucial and should be regularly assessed. Over time, many patients could have the drug dose lowered [178].

The efficacy and safety of PPIs has revolutionized the management of ZES, so that total gastrectomy is no longer required. Long-term antisecretory treatment with PPIs has remained effective for more than 10 years, without development of tachyphylaxis or any doserelated adverse effect [182]. Even at the high doses required for patients with ZES, PPIs have a notable record of safety. An analysis of ZES patients can provide important insights into some of the safety issues, concerning long-term acid suppression [183].

\section{PPIs for stress ulcer prophylaxis (SUP)}

\section{Summary of the current evidence}

PPIs are the drugs of choice for acid suppression in SUP. The risk of bleeding in intensive care unit (ICU) is reduced by some $60 \%$ in patients receiving SUP compared with those treated with placebo or no prophylaxis. Routine prophylaxis, however, is not justified by current evidence. SUP should be withheld in the majority of hospitalized patients, unless they have multiple risk factors, since only those at risk of clinically important bleeding (CIB) are most likely to benefit from preventive strategies. Educating clinicians to follow SUP guidelines can improve the cost-effectiveness of PPI use in this clinical setting.

Stress-related mucosal disease (most commonly referred to as stress ulcer) is an acute condition that can be detected endoscopically in the majority (75-100 \%) of critically ill patients, within 24 hours of admission to an ICU. However, the incidence of CIB from stress ulcer in the ICU population is low, the pooled figure from the most recent trials being some $1 \%$ [184]. The incidence has improved substantially over recent decades, likely thanks to better overall ICU care. However, the mortality rate among patients with CIB was $48.5 \%$, which is significantly higher than that $(9.1 \%)$ of those without such bleeding [185], showing that stress-related mucosal disease can be a deadly condition.

Critically ill patients are at increased risk of developing stress-related mucosal disease and subsequent stress-ulcer bleeding as a result of both their underlying disease and therapeutic interventions. There are some well-established strong, independent risk factors for stress-related mucosal disease, respiratory failure and coagulopathy being the most relevant ones, with an OR of 15.6 and 4.3, respectively [184]. Other important factors include acute renal or hepatic failure, sepsis, hypotension, severe head or spinal cord injury, thermal injury involving more than $35 \%$ of the body surface area, acute lung injury, major surgery (lasting more than 4 hours), and history of GI bleeding [186].

Although no single study or meta-analysis has reported a decrease in the overall mortality related to SUP, guidelines from the American Society of Health-System Pharmacists [187] and Surviving Sepsis Campaign [188] recommend routine prophylaxis with acid suppressive therapy for high-risk patients. The rationale for this recommendation relies on the finding that important GI bleeding is strongly associated with prolonged ICU stay and increased mortality [189]. Indeed, three large meta-analyses found that the risk of bleeding in ICU is reduced by some $60 \%$ in patients receiving SUP compared with those treated with placebo or no prophylaxis [190-192]. Therefore, SUP has become the standard of care in the ICU, sometimes irrespective of the presence of risk factors. The benefit of SUP using real-world data is, however, not easy to estimate because of the lack of a control group.

$\mathrm{H}_{2}$ RAs have also been found effective in preventing CIB [186] and are the preferred acid lowering drugs in some ICUs [193] despite the efficacy of PPIs being significantly better. Over recent years, all meta-analyses [194-197] except one [198] confirmed the superior efficacy of this class of drugs. No studies showed a statistically significant difference in the rate of severe complications, such as nosocomial pneumonia, since these associations were not reported outcomes in any of the RCTs assessed. A recent observational study [199] found that PPI treatment for SUP in critically ill patients is associated with a risk of $C$. difficile infection higher than that observed with $\mathrm{H}_{2}$ RAs (6.7 \% vs. $1.8 \%$ ).

SUP should be withheld in the majority of hospitalized patients, unless they have multiple risk factors [184, 186]. Indeed, as outlined by current practice guidelines [187, 188], any risk factor different from those mentioned above does not independently predispose a patient to stress ulcer bleeding. Moreover, a recent meta-analysis suggests that patients receiving enteral nutrition may not require SUP [200]. On the other hand, its implementation might be associated with an increased risk of infectious complications, such as nosocomial pneumonia and C. difficile-associated diarrhea. Patients with liver cirrhosis may actually have an increased mortality rate if treated with PPIs [201].

Nevertheless, several studies demonstrate that, in many non-ICU patients lacking an indication for SUP, acid suppressive therapy is started upon hospital admission [202]. A recent study [203], while confirming that PPI use for SUP has spread inappropriately to low-risk patients, found that more than $50 \%$ of admitted PPI users were inadvertently prescribed a PPI at discharge, without a real medical need for acid suppression. 
In summary, PPIs represent the drugs of choice for acid suppression in SUP. However, routine prophylaxis is not justified by current evidence. Only patients at risk of CIB are likely to benefit from preventive strategies. Educating clinicians to follow SUP guidelines can improve the cost effectiveness of PPI use in this clinical setting.

\section{PPIs for dyspepsia}

\section{Summary of the current evidence}

PPI therapy in both uninvestigated and functional dyspepsia (FD) is widespread. Indeed, these drugs represent a key component of all the currently employed $\mathrm{H}$. pylori eradication regimens. The search for and eradication of the infection is the first line therapy in the young dyspeptic patient without alarm symptoms. In those patients with persisting symptoms despite successful eradication or naïve-uninfected patients with epigastric pain syndrome (EPS), short-term 4-8 week PPI treatment should be attempted. Finally, PPI co-therapy is indicated in patients with NSAID-associated dyspepsia, also with the aim of preventing GI events.

Dyspepsia is a common GI condition seen in clinical practice. It is not a single disease, but rather a complex of symptoms referable to the upper GI tract that often overlaps with other disease entities. In front of a patient with dyspeptic complaints, physicians should carefully evaluate the history and perform a physical examination in order to assume that symptoms arise from the upper GI tract [204]. If the patient is young ( $<45$ years), and there are no alarm symptoms, endoscopy and/or functional investigations are usually not performed, the condition is labeled as "uninvestigated" dyspepsia and treatment is empiric. On the contrary, if endoscopy does reveal a structural abnormality, management of dyspepsia relies on treatment of the underlying disease (e.g., PU, reflux esophagitis, or malignancy). When endoscopy is negative (which is the case in more than $70 \%$ of patients with dyspeptic symptoms), FD could be considered and, provided Rome IV criteria are fulfilled [205], the final diagnosis can be confirmed [204].

FD is characterized by a continuous or frequently recurring epigastric pain or discomfort centered in the upper abdomen for which no organic cause can be determined. According to the most updated Rome IV classification, dyspepsia is subdivided into postprandial distress syndrome (PDS, including fullness, early satiety, nausea) and epigastric pain syndrome (EPS, including epigastric pain or epigastric burning) [205]. However, symptom overlap with either GERD or irritable bowel syndrome is not infrequent [206, 207].

FD is widely prevalent in the general population - up to $15 \%$ in Italy [208] - so that FD patients are frequently managed in clinical practice by both general practitioners and gastroenterologists. Since the etiology of FD remains unclear and is probably heterogeneous, no definite single treatment is currently available for these patients [204]. Indeed, different therapeutic approaches have been proposed.

Since some drug classes (e.g., NSAIDs, calcium channel blockers, corticosteroids, ACE inhibitors, and methylxanthines) can induce dyspeptic symptoms [209], a careful evaluation of the current drug therapy is of paramount importance: dyspeptogenic medications should be withdrawn whenever possible. In patients with NSAID-associated dyspepsia, PPIs are effective and should be given also with the aim of preventing adverse GI events (see below).

The role of $H$. pylori in FD is supported by data from meta-analyses showing that $H$. pylori eradication resulted in a statistically significant benefit compared with placebo (relative risk of remaining dyspeptic 0.90; NNT =13) $[210,211]$. However, short-term benefit is often not evident since symptom relief becomes significant only some (up to 6) months after successful cure of the infection [212]. Furthermore, PPIs represent a key component of all the commonly used eradication regimens (triple, quadruple, sequential, concomitant or hybrid therapies).

It has been estimated that the H. pylori "test and treat" strategy is cost-effective in those regions where prevalence of the infection is $>20 \%$ [213], as in Italy, and that the advantage persists at long-term follow-up [214, 215]. Unfortunately, no predictive factors for clinical benefit have been identified, so that eradication treatments should be attempted in all dyspeptic patients. H. pylori should be investigated with either non-invasive tests or upper endoscopy, according to the age of the patient and the presence of alarm symptoms [148].

In patients with dyspeptic symptoms persisting despite successful eradication or naïve uninfected patients with EPS, PPI therapy can be attempted, an approach achieving a success rate of $34 \%(\mathrm{NNT}=10,95 \%$ confidence interval, 7-33) [216]. PPIs are particularly effective when overlapping reflux symptoms are present, while no significant benefit occurs in dyspeptic patients with PDS [217]. It is worth emphasizing that the effect of PPIs in FD occurs at standard doses and, since metaanalyses found no dose-response effect [216, 217], escalating the dose in non-responders to standard doses should not be considered. If breakthrough symptoms occur, antacids or alginate-containing formulations may be used [216]. Differentely from GERD, a long-term therapy with PPIs in FD is not indicated [217]. After successful treatment, a tapering strategy rather than abrupt discontinuation is preferred [217]. Although symptoms may recur in nearly $70 \%$ of patients within 1-year follow-up [82], re-starting treatment only in 
these patients is more advantageous than a continuous and expensive treatment, prescribed in all cases.

Dyspeptic symptoms are common in GERD patients, especially those with frequent reflux related symptoms. In these patients, epigastric pain, belching, bloating, and early satiety were found to improve on PPI therapy, conversely from nausea and vomiting, which did not benefit from acid suppression [218].

In addition to suppressing acid secretion, PPIs can also inhibit gastric motility and delay emptying rate [219] and, as a consequence, dyspeptic symptoms may actually be worsened by PPI therapy or, alternatively, new symptoms (especially postprandial fullness) may arise during treatment. If this is the case, patients could be switched to the $\mathrm{H}_{2} \mathrm{RAs}$, ranitidine or nizatidine, which, in addition to their antisecretory activity, display a cholinergic-like activity [219] and have been shown to accelerate gastric emptying [220]. On the other hand, a Cochrane metaanalysis [216] showed that $\mathrm{H}_{2}$ RAs are better than placebo in achieving symptom relief in patients with FD.

\section{PPIs for NSAID-associated symptoms and lesions}

\section{Summary of the current evidence}

Standard dose PPIs are indicated for patients taking non-selective NSAIDs at risk for upper GI complications (bleeding and perforation) and for those given selective cyclooxygenase (COX-2) inhibitors having had an episode of previous GI bleeding. In both non-selective and COX-2 selective NSAID users, PPI therapy reduces upper GI symptoms, in particular dyspepsia. However, NSAIDinduced adverse events in the lower GI tract are not prevented by PPIs.

NSAIDs are amongst the most widely used classes of drugs. Although they are very effective medications, their use is associated with a broad spectrum of adverse effects in the liver, kidney, cardiovascular (CV) system, skin, and gut [221]. GI adverse effects are the most common and include a wide clinical spectrum ranging from dyspepsia, heartburn, and abdominal discomfort to more serious events such as PU with life-threatening complications, including bleeding and perforation [222].

Since symptoms are not a reliable indicator of mucosal damage, it is important to identify factors that predict the risk of GI events in NSAID users. The risk factors for upper GI bleeding (UGIB) associated with NSAID use have been well defined by several studies [222]. Among them, the most important are prior history of complicated ulcer and age. Older age is common in NSAID users and those aged above 65 years carry a risk similar to those with a history of PU. Advancing age increases the risk by about $4 \%$ per year, probably because of the presence of other associated risk factors [223].
The presence of multiple risk factors greatly increases the risk of GI complications [222]. The role of $H$. pylori infection in patients taking NSAIDs and the potential benefit of eradication on upper GI risk in infected NSAID users has been controversial. However, eradication of associated $H$. pylori infection is beneficial when starting treatment with NSAIDs or aspirin, especially in the presence of an ulcer history [90, 224].

An often forgotten risk factor for upper GI complications is represented by drug combinations with NSAIDs [225]. While the role of steroids, antiplatelet drugs, and anticoagulants is long known, the synergistic effect of selective serotonin reuptake inhibitors (SSRIs) has until recently been overlooked. Over the past 15 years, several epidemiologic studies, summarized by three recent meta-analyses [226-228], have shown an association between SSRI use and the occurrence of UGIB, and found that this risk is further increased among patients, who concomitantly use NSAIDs [229, 230] and/or hold H. pylori infection [231], while it is lowered by concomitant PPI intake [227, 232]. The most plausible mechanisms underlying this detrimental effect include a marked decrease in serotonin platelet content, with consequent impairment of platelet aggregation in response to injury and prolongation of bleeding time as well as an increase in gastric acid secretion, with potential ulcerogenic activity [233, 234]. When given with NSAIDs, SSRIs may inhibit their metabolism, raising their blood levels and - through impairment of the hemostasis - may promote more severe bleeding. Since the concomitant use of both these drugs results in a significantly higher risk of UGIB than either drug alone $[229,230]$, this combination should be avoided whenever possible and, if unavoidable, adequate gastroprotection should be adopted from the very beginning [235].

GI symptoms usually develop within the first few days of starting a NSAID therapy and can actually occur with the first dose of the drug. Although some studies have suggested that the first 2 months of treatment represent the period of greatest risk for complications with a relative risk of $4.5 \%$, available evidence (from both RCTs and observational studies) shows that the risk of GI complications is constant over time, either during shortterm or long-term NSAID use [170]. Therefore, even a short course of NSAID therapy (e.g., for postoperative pain or acute musculoskeletal injury) carries a risk of GI complications similar to that of long-term treatment. As a consequence, prevention strategies should be implemented regardless of the duration of therapy, especially in patients with more than one risk factor (i.e., at high GI risk).

All RCTs have shown that PPIs are more effective than $\mathrm{H}_{2} \mathrm{RAs}$ in both preventing and treating gastroduodenal 
lesions [236]. The reasons underlying the superiority of this class of antisecretory drugs have been clarified by preclinical and clinical pharmacological studies indicating that degree and duration of acid inhibition are both important factors in determining their efficacy in the prevention of NSAID injury [237]. They also reduce upper GI symptoms associated with both COX-2 selective and nonselective NSAID use [236]. Due to the long half-life and entero-hepatic circulation of several NSAIDs, a split dose PPI might be useful; there is, however, no evidence for the clinical usefulness of this regimen.

COX-2 selective NSAIDs (often incorrectly referred to as coxibs ${ }^{1}$ ) have an improved upper GI safety profile compared to traditional (non-selective) compounds, as extensively shown in endoscopy and clinical outcome studies [238-240]. The evidence is strong, with consistent reductions in events of about $50 \%$ in large RCTs, meta-analyses of RCTs, and large observational studies in clinical practice [238]. Among patients with a prior ulcer bleed, treatment with a COX-2 inhibitor or an NSAID plus PPI is still associated with a clinically important risk of recurrent ulcer bleed (some $10 \%$ ) [222]. In these patients, the combination of a PPI and a COX-2 inhibitor reduces the risk of upper GI bleeding compared to that of COX-2 inhibitor alone [28, 236]. A very recent network meta-analysis indeed found that this drug combination represents the best strategy to prevent ulcer complications [241].

In addition to the upper GI tract, the NSAID-induced damage extends beyond the duodenum. Since NSAIDinduced intestinal injury involves non-acid-related mechanisms [222], co-administration of PPIs does not prevent NSAID-induced intestinal damage but might actually aggravate it $[28,170,242,243]$, most likely by inducing dysbiosis [244]. Furthermore, NSAID-associated lower GI bleeding is not prevented by PPI co-administration [245].

While the better upper GI safety of COX-2 selective agents over traditional NSAIDs is well established, their individual lower GI tolerability is less well evidenced and appears to differ. Both endoscopic and video-capsule studies have shown that celecoxib displays a better intestinal tolerability compared to an NSAID plus a PPI [28]. The good upper and lower GI safety profile was confirmed by the large CONDOR and GI-REASONS trials [28]. However, this benefit is partially lost when this COX-2 selective inhibitor is combined with a PPI [243].

On the other hand, over recent years, great attention has been focused on $\mathrm{CV}$ adverse effects of COX-2 selective inhibitors, which prompted a re-evaluation of the $\mathrm{CV}$ (and global) safety profile of traditional NSAIDs. Current evidence suggests that non-selective and COX-2 selective inhibitors display a similar incidence of these adverse effects, but with molecule-specific quantitative differences between the various drugs [246, 247].
NSAIDs are an essential part of the therapeutic armamentarium despite their well characterized GI and CV risk profiles. Physicians should not prescribe NSAIDs before taking a careful history and doing a physical examination so that they can acquire the information they need to balance risks and benefits for individual patients. When GI and/or CV risk factors are present, appropriate preventive strategies (i.e., COX-2 selective inhibitors and/or PPI use as well low-dose aspirin) should be implemented from the very beginning and compliance to treatment assessed regularly, especially in the elderly [222]. Finally, the appropriateness of an NSAID prescription should be emphasized, i.e., to control inflammation and pain, rather than to control pain alone [248]; only then can we hope to limit the expanding NSAID epidemic.

\section{PPIs for corticosteroid users}

\section{Summary of the current evidence}

Corticosteroid therapy does not cause damage to the gastroduodenal mucosa, but can enhance the GI risk associated with NSAID use. Therefore, unless patients taking corticosteroid therapy have a PU or are under concomitant NSAID therapy, mucosal protection with a PPI is not routinely indicated.

Contrary to NSAIDs, corticosteroids do not cause any direct injury to the gastroduodenal mucosa [249], and indeed some experimental evidence actually suggests a mucosal protective effect [250, 251]. These drugs may, however, increase the GI risk of NSAID therapy and may hamper the healing of idiopathic or iatrogenic ulcers [252]. The association between corticosteroid use and GI adverse events in patients with risk factors other than NSAID use remains controversial. Indeed, some studies reported an increased risk of PU complications in corticosteroid users, while other investigators failed to demonstrate such an association after adjustment for confounding factors [253-257]. A meta-analysis also failed to show any significant risk for gastric or duodenal ulcers in patients receiving corticosteroid treatment compared to controls [258]. It is worthwhile emphasizing that the design of the studies included in the meta-analysis was quite heterogeneous as was the type of patients selected (outpatients or inpatients, presence of comorbidity and co-therapy) as well as PU definition. However, a systematic review of available meta-analyses as well as of published case-control studies reached the same conclusion [259].

A more recent systematic review and meta-analysis of 159 studies, appeared between 1983 and 2013, on GI bleeding and perforation in corticosteroid users [260], found that corticosteroid therapy may increase the risk of GI events $(\mathrm{OR}=1.43)$ only in hospitalized patients. Here again, the diversity of GI bleeding definitions 
(widely varying from occult blood in stool to bleeding requiring transfusion or hospital stay) as well as the heterogeneity of the patients included do not allow drawing clinically relevant conclusions [260]. Taking these considerations into account, no evidence currently supports PPI therapy as prophylaxis for corticosteroid use in the absence of concomitant NSAID therapy.

In summary, PPI co-therapy is not routinely indicated in patients taking corticosteroids unless they have a history of PU or are taking NSAIDs. In hospitalized patients on corticosteroid therapy, prophylaxis against stress ulcers could be limited to those with a history of PU, clotting impairment or requiring mechanical ventilation for more than 48 hours [261]. Despite corticosteroids increase the risk of GI bleeding in patients with either diverticular disease of the colon or acute ischemic stroke [262, 263], PPI therapy is not expected to exert any preventive effect on eventual drug-induced GI bleeding in these patients.

\section{PPIs in patients taking anti-platelet or anti-coagulant therapy}

\section{Summary of the current evidence}

Standard dose PPI therapy is advised for gastroprotection in all patients on anti-platelet therapy who are at increased risk of gastrointestinal bleeding (age > 65 years or concomitant use of corticosteroids or anticoagulants or history of $P U)$. International Normalized Ratio monitoring is required when starting or stopping PPI therapy in vitamin $K$ antagonist users. In patients receiving clopidogrel or vitamin $K$ antagonists, choosing PPI lacking interference with the hepatic CYP450 enzymes might be preferred. No demonstrated interaction exists between PPIs and the novel oral anticoagulants.

Based on a documented efficacy, anti-platelet therapy (aspirin < $300 \mathrm{mg} /$ daily, ticlopidine $100 \mathrm{mg} /$ daily, clopidogrel $75 \mathrm{mg} /$ daily) is widely used for both primary and secondary prevention of $\mathrm{CV}$ and cerebrovascular ischemic events [264, 265]. However, anti-platelet drugs may cause adverse GI events (gastroduodenal ulcerations/erosions, overt bleeding, occult bleeding, and - only seldom - a perforation), with a definite probability of death, particularly in the elderly [266]. Therefore, gastroprotection is advised in those patients at increased GI risk during anti-platelet therapy. Increased risk factors include age above 65 years, concurrent use of steroid/anticoagulant therapy, or history of PU [222, 255, 267-269]. Presence of relevant comorbidities (heart failure, renal impairment, stroke, diabetes, on-going malignancy) and smoking are additional risk factors for both GI events and related mortality [255, 268-270]. Standard PPI-dose is the most effective gastroprotective therapy [271, 272]. Regrettably, PPI therapy is not effective in preventing bleeding lesions in either small intestine or colon induced by anti-platelet drugs, for which no protective strategies are today available [269, 273, 274].

A matter for concern is the interaction between PPIs and clopidogrel. Based on pharmacokinetic studies, PPI therapy reduces the efficacy of clopidogrel by interfering with the hepatic CYP2C19-based activation [275]. However, the clinical relevance of such a phenomenon is largely controversial. Indeed, a panel of experts of the European Society of Cardiology recently suggested that there is no conclusive evidence to discourage PPI use with clopidogrel due to a potential increased risk of ischemic events [276]. Further, the only prospective study (the COGENT trial) demonstrated that omeprazole significantly reduces the rate of composite GI events but did not show any increase in the composite $\mathrm{CV}$ events in patients at high CV risk [277]. Additionally, a recent meta-analysis [278], while confirming that the pharmacodynamic interaction between PPI and clopidogrel has no clinical significance, actually suggests that PPIs are a marker of increased CV risk in patients taking clopidogrel rather than a direct cause of worse outcomes. Nevertheless, PPIs that lack inhibition of CYP2C19 (i.e., pantoprazole or rabeprazole) might be preferred in clopidogrel users [276]. No significant interaction between PPIs and the new antiplatelet agents (prasugrel or ticagrelor) has been documented [276].

Co-administration of aspirin and clopidogrel is associated with synergistic effects in causing serious GI bleeding. Indeed, epidemiological studies have invariably shown that combination of two antiplatelet drugs produces significant excess risk of UGIB [225, 279]. PPI co-treatment is also effective in reducing the risk of UGIB in patients receiving dual antiplatelet therapy $[280,281]$. It is worthwhile mentioning that - among patients with dual antiplatelet therapy and PPI cotherapy - GI bleeding episodes are more frequent in the lower GI tract [282]; this changing pattern of bleeding likely reflects the success of gastroprotection [283].

Anticoagulants, either vitamin $\mathrm{K}$ antagonists or novel oral anticoagulants, including dabigatran, rivaroxaban and apixaban, do not cause gastroduodenal mucosa injury per se. These medications may, however, facilitate bleeding of pre-existing PUs. While gastroprotection is generally not advised, unless a concomitant anti-platelet or NSAID therapy is prescribed, a very recent retrospective cohort study found that PPI co-therapy is associated with reduced risk of warfarin-related upper GI bleeding. As expected, the risk reduction was greatest in patients also taking antiplatelet drugs and/or NSAIDs, but was still significant in those without concurrent use of these medications [284]. 
In patients under acid suppression because of gastroprotection or any acid-related disease, intensified International Normalized Ratio monitoring is recommended since PPIs may potentiate vitamin $K$ antagonistinduced anticoagulation, most likely due to facilitated gastric absorption of warfarin [276]. When acenocoumarol is used as an anticoagulant, some caution is needed when prescribing PPIs (in particular omeprazole, esomeprazole, and lansoprazole) because of potential DDIs [285]. No clinically significant interaction during PPI and novel oral anticoagulant co-administration occurs, so that dabigatran-related dyspepsia may be safely treated with PPIs [276].

\section{PPIs for PU bleeding}

\section{Summary of the current evidence}

Endoscopy is the mainstay of treatment of PU bleeding. However, PPI therapy - after endoscopic hemostasis - reduces the risk of re-bleeding, the requirement for surgery, and mortality in high-risk patients. Pre-endoscopic administration of a PPI can be useful in downgrading stigmata of recent hemorrhage, thereby reducing the need for endoscopic hemostatic procedures.

The goal of medical therapy for bleeding ulcers has been traditionally aimed to maintain a sustained intragastric $\mathrm{pH}$ ( $>6$ units), in order to promote platelet aggregation as well as clot formation and stability [286, 287]. Indeed, platelet function is impaired at low $\mathrm{pH}$ [288], and pepsin promotes clot lysis below pH 5 [289].

Although endoscopic therapy is able to achieve hemostasis in most patients, recurrent bleeding is not uncommon [290, 291]. Several meta-analyses [292-294] have shown that adjuvant treatment with a PPI after endoscopic hemostatic therapy reduces the risk of rebleeding and the requirement for surgery after ulcer bleeding but has no benefit on overall mortality, an effect seen only in Asian trials and in patients with active bleeding or a non-bleeding visible vessel. In addition, treatment with a PPI produces small, but potentially important, reductions in transfusion requirement and length of hospitalization [295, 296]. Although current guidelines [297-299] recommend a regimen of an intravenous (i.v.) bolus followed by a continuous infusion of PPIs, a recent meta-analysis [300] found that the efficacy of continuous and intermittent PPI therapies were comparable. Whether low-dose or oral PPIs can substitute high-dose PPIs after endoscopic hemostasis is controversial. In a recent meta-analysis from Taiwan [301], investigators concluded that low- and high-dose regimens were equivalent. However, they included trials with a small number of patients and patients with ulcers showing low-risk stigmata or even clean-base ulcers.
Similarly, some trials [302, 303] reported that the efficacy of oral PPIs is comparable to that of intravenous PPIs, but the results were combined from open-labeled trials with limited sample size. Furthermore, different oral regimens were combined together and compared with different intravenous regimens. It is also worth mentioning that most studies included in this setting have been performed in Asian patients [304].

Currently available PPIs are not able to maintain the intragastric $\mathrm{pH}$ above 6 for prolonged periods [305]. As a consequence, intravenous infusion has often been used in clinical studies. Intravenous esomeprazole is faster and more effective in raising intragastric $\mathrm{pH}$ than i.v. lansoprazole [306] or i.v. pantoprazole [307-309]. Even by the oral route, esomeprazole $40 \mathrm{mg}$, which provides the most effective control of intragastric $\mathrm{pH}$ amongst the class [54,55], achieves greater acid inhibition than intravenous pantoprazole $(40 \mathrm{mg} /$ daily) on both day 1 and day 5 [310]. The Peptic Ulcer Bleed study, involving 91 hospital emergency departments in 16 countries, showed that high-dose intravenous esomeprazole ( $80 \mathrm{mg}$, followed by $8 \mathrm{mg} / \mathrm{h}$ infusion, over 72 hours), given after successful endoscopic therapy to patients with high-risk stigmata of PU bleeding, reduced recurrent bleeding at 72 hours and had sustained clinical benefits for up to 30 days while patients were on maintenance oral esomeprazole (40 mg daily) [311].

PPI treatment, initiated prior to endoscopy in patients with upper GI bleeding, significantly reduces the proportion of patients with stigmata of recent hemorrhage at index endoscopy: pooled rates were $37.2 \%$ and $46.5 \%$, respectively (OR $=0.67)[312,313]$. Although there is no evidence that PPI treatment affects clinically important outcomes (mortality, re-bleeding, or need for surgery), pre-endoscopic (or even pre-hospital), oral or intravenous, administration of a PPI could downgrade high-risk stigmata of recent hemorrhage. This might increase the success of endoscopic hemostatic therapy and/or reduce the requirement for it.

\section{PPIs in patients with cancer}

\section{Summary of the current evidence}

In cancer patients, PPI use could be indicated to treat and/ or prevent chemotherapy-induced GERD and gastroduodenal ulceration, with accompanying symptoms. Patients with GI mucositis or dysphagia might also benefit from these drugs. Due to the low number or poor quality of the available studies, the evidence supporting these indications is low.

Amongst the adverse effects of cancer chemotherapy, GI symptoms are the most common and have the greatest impact on the quality of life [314-316]. Fewer than $20 \%$ of affected patients are referred to a GI specialist [317] since clear management algorithms and routine referral pathways are not in place 
due to limited research in this topic. As a consequence, some treatable symptom complexes go unrecognized and/or ineffective and potentially harmful treatments are prescribed. Sometimes, persistent symptoms do compromise or prevent ongoing anticancer treatment.

While several guidelines for management of the GI adverse effects of cancer chemotherapy do exist [318-324], only the European Society for Medical Oncology [318] and Multinational Association of Supportive Care in Cancer/International Society of Oral Oncology [324] clinical practice recommendations address gastroesophageal mucositis. Different types of cancer therapy alter the integrity of the GI mucosa [325] as well as the microbial flora that inhabit the oral cavity and the gut [326]. These treatments also affect the amount and composition of saliva [327]. In addition, they negatively impact on epithelial turnover and maturation, leading to impairment of the mucosal barrier [325]. Up to $40 \%$ of patients undergoing treatment with gemcitabine or S-1 (an oral pro-drug of 5-fluorouracil) for pancreatic cancer complained of GERD-related symptoms [328], and endoscopy revealed the presence of severe mucosal lesions (multiple gastric erosions, diffuse erosive gastritis, gastric or duodenal ulcer) in $46 \%$ of patients after a single cycle of chemotherapy (with cisplatin plus etoposide) [329]. Gastroduodenal ulcers are extremely frequent (up to $100 \%$ ) in patients submitted to hepatic intra-arterial chemotherapy [330, 331]. Even the more recent molecular-targeted agents are not devoid of GI adverse events [332]. For instance, ulceration and perforation of the stomach and bowel are well-known complications of bevacizumab (a humanized monoclonal antibody against vascular endothelial growth factor) [333, 334].

The rationale for acid suppression in patients undergoing cancer chemotherapy stems from the evidence that cytotoxic treatment damages the gastroesophageal mucosa, but does not affect the acid producing capacity of parietal cells. Therefore, mucosal damage may result - at least in part - from the effect of an aggressive acid-peptic secretion on an already damaged mucosa [335]. British guidelines [320] suggest PPI use amongst other therapeutic options - in the management of dysphagia and/or retching induced by cancer chemotherapy, but do not provide any indication about the dose and treatment duration. Acid suppression appears to be beneficial in the treatment of GI mucositis induced by chemotherapy [336] and radiation [337], while once daily PPIs seem to improve chemotherapyinduced GERD symptoms [328], but data are conflicting. Two large clinical trials $[338,339]$ have shown PPIs to be effective in the prevention of chemotherapy (cyclophosphamide methotrexate fluorouracil or 5fluorouracil)-induced gastroduodenal injury and in reducing the incidence of heartburn and epigastric pain.
In the more recent study [339], omeprazole was also highly effective in preventing delays in cancer treatment. No postponement of chemotherapy was required for patients treated with PPIs, while chemotherapy was delayed in some patients receiving placebo or an $\mathrm{H}_{2} \mathrm{RA}$.

Several other indications for PPI use in cancer patients have been suggested and/or proposed [340]; they include postoperative symptom relief in patients after gastric or esophageal resective surgery, prophylactic use in patients treated with NSAIDs as analgesics in cancer pain, acute management of upper GI bleeding in patients with proximal GI cancer, prophylactic use in patients treated with palliative upper GI endoscopic stenting, and prophylactic use in cancer patients who are at high risk for PU disease. However, most of the above indications have not been formally tested in specific, well-designed RCTs. In addition, even for those evaluated in clinical studies (i.e., chemotherapy-induced GERD symptoms or gastroduodenal ulceration), the evidence is low and often derives from single studies or single centers. Nevertheless, up to $73 \%$ of patients admitted to oncology or hematology units are treated with acid suppressants (PPIs or $\mathrm{H}_{2} \mathrm{RAs}$ ) [341, 342], mostly for SUP or unspecified gastroprotection.

The Globocan survey [343] indicates that, in 2012, approximately 32.6 million people were living with cancer (within 5 years of diagnosis). It is therefore astonishing and disappointing that thousands of studies, often dealing with trivial GI symptoms and spending billions of euros, have been performed while very few have evaluated the potential indications of PPIs in cancer to provide physicians with the best way to cope with the GI adverse effects of chemotherapy or radiotherapy and relieve the suffering of these difficult patients.

Besides the several potential and alleged indications of PPIs in cancer patients, increasing evidence suggests, for this class of drugs, an anti-tumor effect (through the selective induction of apoptosis as well as an anti-inflammatory effect) [344]. They also exert a protection of cancer cells from developing chemoor radiotherapeutic resistance [345]. Acidification of the extracellular compartment represents a conceivable mechanism of drug resistance in malignant cells. In addition, it drives proliferation and promotes invasion and metastasis [345]. Experimental evidence has shown that PPIs counteract tumor acidification (via inhibition of vacuolar $\mathrm{H}^{+}$ATPase) and restore sensitivity to anticancer drugs. Moreover, early clinical data have supported their role as add-on medications to anticancer treatments in patients with osteosarcoma or breast cancer [346]. A recent large epidemiological study (the SPORE program [347]) found that patients with head and neck tumors, taking acid suppressants, had significantly longer overall survival compared to those who did not. Specifically designed clinical trials 
are ongoing to better characterize the role of PPIs as new therapeutic agents in cancer treatment. Therefore, at the current status of present knowledge, PPI use as adjunct to cancer chemotherapy should not be performed outside a clinical trial.

\section{PPI use in cirrhosis}

\section{Summary of the current evidence}

PPI use in patients with liver cirrhosis must be very cautious since there is no evidence of benefit except for downgrading esophageal ulcers after sclerotherapy or banding of esophageal varices. There is also some evidence that their use could be associated with development of spontaneous bacterial peritonitis.

In clinical practice, PPI therapy is often used in cirrhotic patients, in the absence of acid-related disease, to prevent bleeding from hypertensive gastropathy [348]. This approach is not evidence-based and therefore not justified, also taking into account that acid secretion is markedly reduced in these patients [349].

A systematic review, performed in 2008, was unable to find any randomized clinical trials on acid-lowering drugs in the prevention of esophago-gastric variceal bleeding in cirrhotic patients. It is therefore not possible to establish whether these drugs are beneficial or harmful in this setting [350]. It is worth mentioning, however, that PPI use is associated with a microbiota shift and functional changes in the distal gut of patients with compensated cirrhosis, an effect that could drive or aggravate the pre-existing small intestine bacterial overgrowth $[351,352]$.

The only indication of PPIs, which is by the way weakly evidence-based, is the prevention and/or treatment of esophageal ulcers after sclerotherapy or variceal band ligation. The best available evidence supports the short-term use (maximum 10 days) of PPIs to reduce ulcer size, provided spontaneous ulcer healing is a concern. Practices such as high dose infusion and prolonged use should be discouraged until evidence of benefit becomes available [353].

When prescribing PPIs to cirrhotics, the benefit-toharm ratio must be carefully evaluated. Indeed, PPI therapy seems to be a risk factor for the onset of spontaneous bacterial peritonitis. A meta-analysis [354] showed that, compared to cirrhotic patients not receiving PPIs, those taking these drugs had an increased risk $(N=3815 ;$ OR $=3.15 ; 95 \%$ confidence interval, $2.09-4.74)$ of developing spontaneous bacterial peritonitis, an effect more evident in case-control studies than in cohort studies [355]. Another systematic review [356] also found an increased overall risk of bacterial infections $(\mathrm{OR}=1.98)$. A more recent case-control study discovered that PPI use in cirrhotic patients increases the risk of development of hepatic encephalopathy in a dose- dependent fashion [357]. All these analyses were mainly based on retrospective studies. The only large, multicenter, prospective trial [358] with PPIs dealt with spontaneous bacterial peritonitis and found acid suppression not associated with an increased risk. Further studies are therefore needed to better clarify these clinically relevant issues.

\section{PPIs for pancreatic diseases}

\section{Summary of the current evidence}

PPIs do not affect the clinical course of acute pancreatitis $(A P)$, such as the length of hospitalization and time to starting oral intake or pain relief and, as a consequence, they are not recommended routinely in this clinical setting. However, their use - as add-on medication to enzyme replacement therapy (ERT) - is indicated in patients with chronic pancreatitis (and other diseases characterized by exocrine pancreatic insufficiency), whose steatorrhea is refractory to ERT.

$\mathrm{AP}$ is one of the most common GI disorders, requiring acute hospitalization worldwide, with a reported annual incidence of $13-45$ cases per 100,000 persons [359]. AP is an inflammation of the pancreas; it is sometimes associated with a systemic inflammatory response that can impair the function of other organs or systems. The inflammation may subside spontaneously or may progress to necrosis of the pancreas and/or surrounding fatty tissue. The dysfunction may resolve or may progress to organ failure. As a consequence, there is a wide spectrum of disease from mild, where patients recover within a few days, to severe (10-15\%) with prolonged hospital stay, the need for critical care support, and a 15-20 \% risk of death [360, 361]. In Italy, AP is more commonly a mild disease with a biliary etiology and a low (5\%) overall mortality rate [362]. Whatever the cause, it should be recognized that AP is a systemic disease and not simply a disease of the pancreas. Thus, this common, potentially deadly, condition requires up-to-date evidence-based treatment.

AP is characterized by pancreatic and peripancreatic fat injury in part mediated by autodigestive enzymes. Excessive stimulation of the exocrine pancreas was long thought to worsen AP [363] and this represented the rationale for using inhibitors of exocrine pancreatic secretion (e.g., somatostatin and its analogs) as potential therapies for AP [364]. Along the same lines, antisecretory agents might be able - via inhibition of acid secretion and secretin release, due to duodenal acidification [365] - to contribute to the inhibition of pancreatic secretion.

Despite omeprazole being unable to inhibit amylase release from isolated pancreatic acini [366], pantoprazole appears capable of reducing tissue infiltration of inflammatory cells and acinar cell necrosis in rats with experimentally-induced 
pancreatitis [367], an action likely mediated by a reduced expression of inflammatory and adhesive proteins, key mediators in the pathogenesis of AP. The only clinical trial to date [368] found that treatment with pantoprazole does not affect the clinical course of AP such as the length of hospitalization, time to starting oral intake or pain relief. In addition, two retrospective studies found that PPI use does not affect clinical outcomes of patients with severe AP [369] or prevent post- endoscopic retrograde cholangiopancreatography pancreatitis [370]. As a consequence, most international guidelines on the management of AP do not even mention PPIs. The only exception is the Italian guideline [371], which clearly states that the routine use of PPIs is not recommended in patients with acute AP. This guideline and a former Japanese one [372] suggest that these drugs might be considered on a caseto-case basis, provided that specific indications, such as NSAID use, PU disease or bleeding, occur.

Chronic pancreatitis (CP) is a progressive, irreversible, fibro-inflammatory disease of the pancreas, in which the pancreatic secretory parenchyma is damaged and replaced by fibrous tissue, resulting in morphologic changes of the ducts and parenchyma. This process eventually culminates in permanent impairment of exocrine and endocrine function of the pancreas. The clinical manifestations of $\mathrm{CP}$ include abdominal pain as well as steatorrhea, weight loss, and malnutrition, all resulting from the loss of adequate enzyme and bicarbonate secretion [373, 374], and the so-called pancreatogenic diabetes, arising from loss of $\beta$-cell function $[375,376]$.

Chronic disabling pain, which poses a major detriment to the quality of life, is present in nearly $80-90 \%$ of patients with $\mathrm{CP}$. Although two meta-analyses found no real benefit of ERT [377], the role of pancreatic enzymes in mitigating abdominal pain still remains unclear and some experts recommend a 6-week trial of non-entericcoated pancreatic enzymes [378].

Together with pain, most patients with advanced $\mathrm{CP}$ will develop pancreatic insufficiency at some point, secondary to loss of pancreatic parenchyma. Pancreatic lipase secretion is lost faster than other secretions. It is well known that steatorrhea (due to decreased luminal hydrolysis of dietary fat) develops only when the lipase levels drop to less than $10 \%$ [379]. However, this does not minimize the importance of amylase and trypsin, which should be an integral part of pancreatic enzyme supplementation. Traditionally, ERT is indicated in patients with steatorrhea (fecal fat greater than $15 \mathrm{~g} /$ day) and weight loss [380]. Supplemental pancreatic enzymes alleviate diarrhea and maldigestion, associated with pancreatic exocrine insufficiency and also aid in maintaining normal nutrition, thus improving the quality of life [380].

Pancreatic enzymes in tablet form are susceptible to inactivation by stomach acid, therefore limiting their activity in the duodenum. The secretion of bicarbonate, which maintains an alkaline pancreatic juice, is dramatically reduced in most patients [380]. In addition, during the post-prandial period, the $\mathrm{pH}$ of the stomach and the upper small intestine is significantly decreased [381]. When postprandial $\mathrm{pH}$ in the small intestine becomes 4 or lower, bile acids precipitate and digestive enzymes (lipase in particular) lose their activities. Strategies to circumvent this include administering higher amounts of pancreatic enzymes and increasing gastric $\mathrm{pH}$ with the use of a PPI.

The favorable effects of antisecretory drugs on abolishing steatorrhea are primarily caused by reducing acid and volume of secretion. The end results of these actions are to elevate the $\mathrm{pH}$ in the stomach and duodenum, and facilitate the delivery and concentration of lipase in the duodenum. Another important effect is, however, the reduction of duodenal volume flow, which in turn increases the concentration of intraduodenal lipolytic activity [382]. Enteric-coated formulations protect pancreatic enzymes from the low $\mathrm{pH}$ in the stomach, allowing enzymes to maintain their potency when they reach the duodenum. Enteric-coated enzymes are indeed released in the duodenum, where the $\mathrm{pH}$ exceeds 5.5 units. Despite these formulations being resistant to breakdown by gastric acid, some studies have shown improvements in fat absorption when they are administered with concurrent acid suppression therapy [380].

The use of PPIs is recommended by international guidelines for $\mathrm{CP}$ and/or pancreatic exocrine insufficiency [383-391]. The Italian guidelines [384] clearly state that addition of PPIs is recommended only in patients with refractory steatorrhea and that acid suppression is not indicated in patients with an adequate response to ERT. These recommendations encompass the main diseases associated with exocrine pancreatic insufficiency (like acute pancreatitis, chronic pancreatitis, pancreatic cancer, cystic fibrosis, celiac disease, irritable bowel syndrome, etc.), defined as an inadequate pancreatic enzyme activity to digest food, generally due to either insufficient enzyme production, insufficient enzyme activation, or to early enzyme degradation [386, 392].

\section{Safety concerns with long-term PPI therapy}

\section{Summary of the current evidence}

Being very effective and considered very safe, PPIs are often prescribed inappropriately, especially in the elderly. The tolerability of PPIs is generally good, with an adverse event rate of 1-3\%. Some adverse effects are plausible and predictable; others are idiosyncratic, unpredictable, and rare. Overall, the benefits of PPI treatment outweigh the potential risks in most patients, who have a relevant and appropriate indication. 
Although overuse and misuse may challenge the safety profile, the tolerability of PPIs has been remarkably good. Adverse events generally occur at a rate of $1-3 \%$, without any significant differences among PPIs. Untoward effects most commonly include headaches, nausea, abdominal pain, constipation, flatulence, diarrhea, rash, and dizziness. Long-term studies indicate a tolerability profile similar to that found in short-term trials [22-25].

PPI-related adverse events involve the GI tract as well as other organs and systems. The majority of these events have been summarized in comprehensive reviews, to which the reader is referred [393-399]. The potential risks of long-term PPI therapy, along with the respective evidence summary, are outlined in Tables 1 and 2 .

Gastric $\mathrm{pH}$ is relevant for the absorption of several drugs and its modification by antisecretory therapy may significantly modify their pharmacokinetics [400]. PPIs also influence drug absorption and metabolism by interacting with adenosine triphosphate-dependent P-glycoprotein (e.g., inhibiting digoxin efflux) or with the CYP P450 enzyme system (e.g., decreasing simvastatin metabolism), thereby affecting both intestinal first-pass metabolism and hepatic clearance. A number of studies have shown that omeprazole (and, to a lesser extent, lansoprazole) carries a considerable potential for DDIs, since it has a high affinity for CYP2C19 and a somewhat lower affinity for CYP3A4. In contrast, pantoprazole and rabeprazole display a lower potential for DDIs [401, 402]. DDIs therefore represent a molecule-related effect rather than a class-effect [403].

These interactions are clinically relevant mostly for drugs with a narrow therapeutic index (e.g., diazepam, warfarin, antipsychotics, etc.) [401, 404]. In addition, PPI metabolism is very rapid in most Caucasian subjects (extensive metabolizers), so that their half-life ranges from only 0.5 to 2.1 hours [404]. Indeed, the prevalence of poor metabolizers, potentially at increased risk of drug interactions, is as low as $1.2-3.8 \%$ in Europe as compared to $23 \%$ in Asia [405]. This could explain why only few of the reported DDIs involving PPIs have been shown to be of clinical significance.

Recent studies have raised concerns about a possible adverse interaction between clopidogrel and PPIs (currently prescribed to patients who are receiving dual antiplatelet therapy to prevent upper GI bleeding) that could reduce the antithrombotic effect of the former and, therefore, lessen protection against $\mathrm{CV}$ events in high-risk patients.

Table 1 Concerns about long-term therapy with proton pump inhibitors (PPIs): Digestive System

Theoretical Concern

PPI-induced hypergastrinemia
Evidence Summary

- PPl-induced hypergastrinemia is enhanced in H. pylori-infected patients [448], where the antisecretory effect is increased

- No controlled human data support the increased risk of gastric cancer $[92,449]$

- More and higher quality studies are needed to confirm or refute any causal link with gastric cancer $[450,451]$

- No data support the increased risk of colorectal cancer [452]

- An increased frequency of fundic gland (inflammatory) polyps has been reported [451, 453]

- Rebound acid hypersecretion (and increased frequency of acid-related symptoms) is of uncertain clinical relevance [83]

- Despite unclear biological mechanism(s), two large observational studies [454, 455] reported conflicting results concerning the putative risk of pancreatic carcinoma in PPI users

Infectious consequences of long-term PPI-induced hypochlorhydria

- Growing evidence suggests that acid suppression increases the risk of enteric infections by C. difficile [456-458] and other pathogens [456, 459]

- Increased Candida infections in the mouth, esophagus, stomach, and upper small intestine of PPI users have been documented [460]

- PPI users are at increased risk of small intestinal bacterial overgrowth (SIBO) [461], while cirrhotic patients, taking these drugs, are at higher risk of spontaneous bacterial peritonitis [354, 355]

Non-infectious consequences of long-term PPI-induced hypochlorhydria

Dysbiosis

Consequences of long-term PPI-induced hypochlorhydria on electrolyte and nutrient absorption

Idiosyncratic reactions to PPIs was associated with an increased rate of subsequent diagnosis of celiac disease, but the biological
- According to a single case-control study [462], exposure to antisecretory drugs, including PPIs, plausibility is unclear

- Dysbiosis probably represents the most consistent adverse effect of PPIs, responsible - besides enteric infections and SIBO - for gas-related symptoms as well as aggravation of NSAID-enteropathy [463, 464]

- No consistent effects on calcium or iron absorption have been reported [394, 395]

- Severe symptomatic hyponatremia has been reported as a consequence of the syndrome of inappropriate ADH secretion [465]

- Data support an increased risk of developing significant $B_{12}$ deficiency [466], but this is a clinical concern only in elderly or malnourished patients

- Magnesium intestinal transport is inhibited by PPIs and may lead to rare but potentially life-threatening hypo-magnesiemia [467, 468]

- Lansoprazole-induced microscopic colitis has been described [469], with complete resolution after drug discontinuation; however, recent data suggest a class effect [470]

- Despite some case reports, epidemiological studies showing an association between PPI intake and acute pancreatitis have given conflicting results [44] 
Table 2 Concerns about long-term therapy with proton pump inhibitors (PPIs): Extra-digestive effects

\begin{tabular}{|c|c|}
\hline Theoretical Concern & Evidence Summary \\
\hline $\begin{array}{l}\text { Infectious consequences of long-term } \\
\text { PPI-induced hypochlorhydria }\end{array}$ & $\begin{array}{l}\text { - More and higher quality studies are needed to confirm or refute any causal link with } \\
\text { community-acquired pneumonia, especially in long-term users }[471,472]\end{array}$ \\
\hline $\begin{array}{l}\text { Bone consequences of long-term } \\
\mathrm{PPI} \text { therapy }\end{array}$ & $\begin{array}{l}\text { - PPI use is not associated with accelerated bone mineral density loss or osteoporosis [473], } \\
\text { which are thought to be the underlying biological explanation for the modest } \\
\text { increase in the risk of bone fracture [474-476] }\end{array}$ \\
\hline Dementia and Alzheimer's disease & $\begin{array}{l}\text { - Although, in a mouse model, very high-dose PPI use increased the level of } \beta \text {-amyloid in the brain [477] } \\
\text { human data linking these drugs to development of dementia are conflicting [478, 479] } \\
\text { - The risk of development of Alzheimer's disease in PPI users appears comparable to } \\
\text { that of any incident dementia [480] }\end{array}$ \\
\hline Delirium & $\begin{array}{l}\text { - PPIs were found to be an independent factor associated with development of delirium } \\
\text { in geriatric inpatients [481], likely reflecting poly-pharmacy and drug-to-drug interactions (DDIs) }\end{array}$ \\
\hline Acute myocardial infarction (AMI) & $\begin{array}{l}\text { - Since PPIs do not impair endothelial function [482], more and higher quality studies, } \\
\text { which have to be free from confounders [483], are needed to confirm [484, 485] or } \\
\text { refute }[277,278,408] \text { any causal link with AMl }\end{array}$ \\
\hline Idiosyncratic reactions to PPIs & $\begin{array}{l}\text { - PPIs appear to be the most common cause of drug-induced acute interstitial nephritis (AIN). } \\
\text { After PPI withdrawal and corticosteroid therapy, almost all patients recovered a normal } \\
\text { renal function [486, 487] } \\
\text { - There is a small but definite increase in risk of chronic kidney disease in long-term PPI users, } \\
\text { likely resulting from undiagnosed or residual PPI-induced AIN [487] } \\
\text { - Polymyositis and other myopathies, including the life-threatening condition of rhabdomyolysis, } \\
\text { have been described with all PPIs [488, 489] } \\
\text { - Immediate and delayed hypersensitivity to PPIs, with cross reactivity amongst the members } \\
\text { of the class, has been described [490] }\end{array}$ \\
\hline PPI-drug interactions & $\begin{array}{l}\text { - Acid suppression reduces absorption of levothyroxine, ketoconazole, itraconazole, atazanavir, } \\
\text { cefpodoxime, enoxacin, and dipyridamole while increasing that of nifedipine, digoxin, } \\
\text { and alendronate [400] } \\
\text { - Concomitant use of some PPIs with clopidogrel attenuates the antiplatelet effect of clopidogrel, } \\
\text { but may not be clinically relevant since there are no clinical differences in the risk for major } \\
\text { adverse CV events [401-403] } \\
\text { - Only a few drug interactions (e.g., with diazepam, warfarin, phenytoin, and methotrexate) } \\
\text { involving PPIs (mainly omeprazole and lansoprazole) are of clinical significance [401, 403] } \\
\text { - DDls may be more frequent in some patient populations (e.g., AIDS or cancer) [403] } \\
\text { - The degree of DDIs associated with PPIs and the respective clinical outcomes depend on } \\
\text { different factors such as genotype status of CYP enzymes, ethnicity, and drug regimen [403-405] }\end{array}$ \\
\hline
\end{tabular}

However, current evidence shows that, while concomitant use of some PPIs with clopidogrel does attenuate the antiplatelet effect of clopidogrel, this effect is unlikely to be clinically relevant [276, 278, 406, 407]. Conversely, denying PPIs to patients at GI risk would result in increased life-threatening GI bleeding [277, 408, 409].

PPIs are among the most widely used prescription drugs. Although alarms have been raised about their long-term safety, the preponderance of the evidence does not strongly support the concerns, publicized over the last few years and the benefit to harm ratio remains favorable.

The best available information on long-term safety of PPIs derives from the SOPRAN [74] and LOTUS [73] trials, comparing ARS with omeprazole or esomeprazole, respectively. Safety data were collected from patients during the 12-year period of the SOPRAN study $(n=298)$ and the 5 -year period of the LOTUS study $(n=514)$. Serious adverse events and changes in laboratory parameters were analyzed. Across both studies, serious adverse events were reported at a similar frequency in the PPI and ARS treatment groups. Laboratory results, including routine hematology and tests for liver enzymes, electrolytes, vitamin D, vitamin $\mathrm{B}_{12}$, folate, and homocysteine, showed no clinically relevant changes over time. The only expected difference concerned gastrin and chromogranin A levels, which were elevated in the PPI group, with the greatest increases observed in the first year [410]. Despite a continued proliferative drive on enterochromaffin-like cells during esomeprazole treatment, no dysplastic or neoplastic lesions were found [411].

Based on the quality of the overall evidence, the benefits of PPI treatment outweigh the potential risks in most patients, especially if PPI use is based on a relevant and appropriate indication $[6,44]$. On the contrary, patients treated without an appropriate therapeutic indication are only exposed to potential risks. Because PPIs are overprescribed in many patients, in particular for continued long-term use, the clinical effects should always be reviewed and justified attempts should be made to stop any therapy that may not be needed [397]. 


\section{Discussion}

PPIs remain the leading evidence-based therapy for acidrelated diseases, including GERD, PU disease, dyspepsia, NSAID-induced ulcer, $H$. pylori infection, and hypersecretory disorders such as ZES [1, 3, 4, 412, 413].

The strong evidence supporting PPI efficacy and a favorable safety profile has led to overuse of these drugs in many treatment arenas [11]. Surprisingly, despite more than 25 years of extensive literature addressing PPI therapy in upper GI disorders, inappropriate use remains consistently high both in hospital and in primary care [7]. In a recent US study [414], only $39 \%$ of inpatients' prescriptions were compliant to guidelines, with a difference between academic and non-academic hospitals (compliance being $50 \%$ vs. $29 \%$, respectively). Prophylaxis of upper GI bleeding in low risk patients was the most common indication for non-compliant prescriptions, while that of guideline compliant prescriptions was treatment of dyspepsia [414].

The questionable and inappropriate PPI use in the absence of documented evidence, supporting clear indications, is likely due to the perception that many physicians have about PPI safety, which makes them forget to assess the harms and benefits of (especially longterm) therapy [415]. Several studies (for a review see [11]) have shown that physicians frequently do not review and document PPI indications, which often results in their long-term or even indefinite continuation.

There are two main concerns pertaining to PPI overuse and misuse: drug expenditure, which has risen dramatically in recent years, even after the introduction of cheaper generic formulations [416], and growing safety concerns [393-399, 417]. Despite their concentration within the secretory canaliculi of the parietal cell and their pharmacologic selectivity [418], PPIs also have a "dark side" [419]. Sir William Osler once famously commented that no drug has a single effect and these secondary actions range from mildly inconvenient to frankly dangerous [420] - PPIs are no exception.

Non-judicious PPI use is a matter of great concern in the elderly, who often have multiple comorbidities, are taking multiple medications, and are thus at increased risk of long-term PPI-related adverse outcomes. PPI-related adverse events involve the GI tract as well as other organs and systems. The potential risks of long-term PPI therapy, along with the respective evidence summary, have been summarized in the Safety section. While some concerns about the possible adverse effects of PPIs (including an increased risk of gastric carcinoids, gastric carcinoma, decreased absorption of minerals and vitamins) have been raised since their introduction in the late 1980s, more recently, the number of publications dealing with PPIrelated adverse outcomes has steadily increased [393-398, 417]. It is worth mentioning, however, that the majority of studies are observational in nature and do not allow for establishing causality, but merely associations [421]. Residual bias is always a concern in observational studies, even after statistical adjustment, because all confounding factors cannot be recorded or even known. When effect sizes are small (relative risk/OR/hazard ratio $<2$ ), it is not possible to determine whether the association is valid or represents the result of residual bias [422]. Hazard ratios for PPI use and some reported adverse effects (e.g., dementia, chronic kidney disease, any fracture, or communityacquired pneumonia) were all $\leq 1.5$. Nevertheless, if a true causality exists, even small effect sizes can result in a meaningful risk for common interventions and conditions.

Despite PPIs carrying - like any other classes of drugs - some risks, they should not be denied to patients who are likely to benefit from them merely because of concerns about putative adverse effects. There is generally some equivalence between the acceptable burden of adverse effects and the severity of the illness being treated [420]. However, patients with acid-related diseases are often otherwise "healthy" subjects, who take drugs for a given condition. What level of undesirable effects would be acceptable for them and who will bear the cost of treating any ensuing iatrogenic disease? A number of simple and potentially effective preventive measures should be recommended for some (if not all) safety concerns in order to minimize them.

First of all, PPI therapy should be evidence based. Decisions on whether or not to initiate or continue PPI therapy should be sound and PPIs should only be prescribed when there is an appropriate clinical indication. Clinical guidelines can certainly help. In this Position Paper, we have reviewed the current available guidelines, together with the systematic reviews and meta-analyses used to generate them, and synthesized the knowledge in a number of statements (i.e., Summaries of the current evidence) and in Table 3.

Guidelines rely on both evidence and expert opinion; they are neither infallible nor a substitute for clinical judgment. They do, however, go beyond systematic reviews to recommend what should and should not be done in specific clinical circumstances. Despite guidelines being developed to improve quality of care received by patients, they have been criticized for recommending too little or too much, and even for providing reasons for national health systems or insurance payers to deny coverage [423]. Guidelines are often inflexible and can actually harm by leaving insufficient room for clinicians to tailor care to individual patient circumstances and medical history. What is best for patients overall, as recommended by guidelines, may be inappropriate for individuals [424]. Only evidencebased recommendations, which consider the balance between benefits and harms, and weigh these considerations using patient (rather than expert and societal) 
Table 3 Current indications of proton pump inhibitor (PPI) therapy

\begin{tabular}{|c|c|}
\hline Clinical setting & PPI dose and duration \\
\hline \multicolumn{2}{|l|}{ GERD } \\
\hline Erosive Esophagitis (A/B) & Standard dose PPI therapy for 8-12 weeks \\
\hline Erosive Esophagitis (C/D) & Double dose PPI therapy for 8-12 weeks \\
\hline NERD & Standard dose PPI therapy for 4-8 weeks \\
\hline Long-term Management (both GERD and NERD) & $\begin{array}{l}\text { Standard (or half) dose PPI maintenance (continuous, intermittent or on-demand, } \\
\text { depending on clinical characteristics of the patient) }\end{array}$ \\
\hline Barrett's Esophagus & Long-term individually-tailored PPI therapy \\
\hline Extra-digestive GERD & Standard or double-dose PPI therapy for at least 12 weeks \\
\hline Eosinophilic Esophagitis & Standard or double dose PPI therapy for 8-12 weeks \\
\hline H. pylori Eradication & Double dose, twice daily, PPI therapy for 7-14 days (in combination with antimicrobials) \\
\hline Non H. pylori-related PU disease & Standard dose PPI therapy for 4-8 weeks \\
\hline Zollinger-Ellison Syndrome & High-dose (eventually twice daily) long-term PPI therapy \\
\hline $\begin{array}{l}\text { Stress Ulcer Prophylaxis } \\
\text { in patients with risk factors }\end{array}$ & Standard PPI therapy by intravenous route only during ICU stay \\
\hline \multicolumn{2}{|l|}{ Dyspepsia } \\
\hline $\begin{array}{l}\text { Uninvestigated Dyspepsia in Patients younger } \\
\text { than } 45 \text { yrs }\end{array}$ & Standard or half-dose empiric PPI therapy for 4 weeks \\
\hline Functional Dyspepsia (EPS phenotype) & Standard or half dose PPI therapy for 4-8 weeks \\
\hline \multicolumn{2}{|l|}{ NSAID-gastropathy } \\
\hline $\begin{array}{l}\text { Prevention of gastro-duodenal lesions and } \\
\text { events }\end{array}$ & $\begin{array}{l}\text { Standard or half-dose PPI therapy, starting form the very first dose of NSAID in } \\
\text { patients at Gl risk }\end{array}$ \\
\hline Treatment of gastro-duodenal lesions & Standard dose PPI therapy for 8 weeks \\
\hline Steroid therapy & No need for gastroprotection unless used in combination with NSAIDs \\
\hline Anti-Platelet Therapy & $\begin{array}{l}\text { Standard dose PPI therapy, starting form the very first dose of antiplatelet agent } \\
\text { in patients at Gl risk }\end{array}$ \\
\hline Anti-Coagulant Therapy & No need for gastroprotection unless used in combination with antiplatelet therapy \\
\hline PU Bleeding & Intravenous bolus of $80 \mathrm{mg}$ of the available injectable PPIs, followed by $8 \mathrm{mg} / \mathrm{h}$ for 72 hours \\
\hline \multicolumn{2}{|l|}{ Cirrhosis } \\
\hline Hypertensive gastropathy & No need for acid suppression \\
\hline $\begin{array}{l}\text { Prevention or/and treatment of esophageal ulcers } \\
\text { after sclerotherapy or variceal band ligation }\end{array}$ & $\begin{array}{l}\text { Standard dose PPI therapy for } 10 \text { days (longer treatment should be avoided taking } \\
\text { into account the risk of spontaneous bacterial peritonitis) }\end{array}$ \\
\hline \multicolumn{2}{|l|}{ Pancreatic Diseases } \\
\hline Acute pancreatitis & No benefits from acid suppression \\
\hline Chronic pancreatitis & $\begin{array}{l}\text { Standard PPI therapy only in patients with steatorrhea, refractory to enzyme } \\
\text { replacement therapy }\end{array}$ \\
\hline
\end{tabular}

value, should be followed in everyday clinical practice. Taking these considerations into account, we have tried to distill the current evidence and provide physicians with clear patient-oriented recommendations, beyond cost and reimbursement issues. Medicine is a rapidly evolving field, however, and the validity of guidelines will not necessarily stand the test of time: indeed, today's assumptions may no longer be valid tomorrow. Healthcare providers should therefore stay tuned and constantly update their knowledge.

PPIs continue to be prescribed outside treatment guidelines. In Europe, the most common inappropriate use of PPI is for the prevention of gastric damage in co- therapy with agents that have a low gastrotoxicity, if any, or in patients without GI risk factors for significant gastroduodenal damage [30,31, 425-427] as well as in the prevention of stress-induced bleeding [14, 428-430]. PPIs are often started as an inpatient treatment and continued (often long-term) on discharge for non-indicated reasons [14, 431, 432].

PPIs are now available - at half the prescription dose as over-the-counter (OTC) medications, i.e., they can be purchased directly without prescription. Although the proportion of patients taking OTC PPIs internationally is unknown, it may well represent the majority of use globally. A recent US survey [433] found that $32 \%$ of patients 
with GERD symptoms were using OTC PPIs, with only $39 \%$ of consumers using them optimally, with better symptom relief. Besides patients, $50 \%$ of US gastroenterologists also use (i.e., suggest to patients) OTC PPIs [434]. Despite the vast majority of them (76\%) feeling that OTC brand name and generic formulations were equally effective (which is not always the case [435]), the majority of them recommended the brand medication [434].

The availability of OTC PPIs provides consumers with options other than antacids and $\mathrm{H}_{2} \mathrm{RAs}$ for selfmedication of acid-related symptoms. Prospective clinical trials have shown the efficacy of these drugs taken on demand or intermittently on GERD management, with potential for cost reduction [17]. Although guidelines for OTC use $[18,436]$ suggest a short course (2 week treatment) of PPIs in patients with typical complaints (acid and/or regurgitation), and without alarm symptoms, great potential for misuse and/or overuse does exist. Major concerns include management of patients in whom symptoms persist despite acid suppression, appropriate administration, and the potential masking for more serious pathology, like malignancy. Therefore, guidelines and position statements are not just for specialists and general practitioners but should be extended to clinical and community pharmacists as well as to patients.

PPIs are among the safest class of drugs. Although concerns have been raised on their long-term safety, the preponderance of evidence does not strongly support the concerns, publicized over the last few years, and the absolute risk is probably low. Some adverse effects are plausible and predictable; others are idiosyncratic, unpredictable, and rare. Based on the quality of the existing evidence, the benefits of PPI treatment outweigh the potential risks in most patients, especially if PPI use is based on a relevant and appropriate indication [6, 44]. Conversely, patients treated without an appropriate therapeutic indication are only exposed to potential risks and the benefit-to-harm balance becomes very low. Consequently, the overall focus should be on the appropriateness of PPI therapy and on a regular assessment of the need for continued PPI treatment.

Nearly all the adverse outcomes associated with PPIs occur among patients who receive long-term therapy; minimizing the duration of treatment by periodically reviewing a patient's need for acid-suppressive therapy could eliminate or substantially reduce the risk of adverse outcomes. Therefore, during continued long-term use, the clinical effects should always be reviewed and attempts be made to stop any therapy that may not be needed [397]. It is imperative to use the lowest dose of drug required to achieve the desired therapeutic goals. This may entail implementing discontinuation of treatment in asymptomatic patients as well as step-down [437, 438], intermittent [437, 439, 440], or on-demand PPI therapy [440-442] for maintenance of GERD. It should be emphasized, however, that PPI treatment in GERD is merely palliative in nature, since it does not address the underlying pathophysiology, something only ARS is able to achieve [443-445]. Therefore, in young fit patients needing continuous acid suppression, fundoplication should be considered. Intermittent or on-demand PPI therapy is not suitable for NSAID users, since the risk of serious GI events is constant in those patients with GI risk factors and can persist for some time after stopping therapy [170, 222].

Under the current situation of PPI misuse, opportunities do exist to increase appropriateness in order to enhance effectiveness and safety of drug therapy as well as minimize overall healthcare costs. As always, education is the key [7, 491]. Issuing guidelines and implementing them represent the most rational approach to the problem. Judicious surveillance of hospital use and prescription refills in the outpatient settings [416], with re-evaluation and justification for continued treatment, can minimize the potential for adverse effects and achieve cost saving. However, surveillance must be close and continuous since the attained benefits could be short lasting. Indeed, in a recent Canadian study [446], de-prescribing guidelines were associated with a decline in PPI use during the initial 6 months, but prescription patterns began to climb back to baseline afterwards.

\section{Conclusions}

Overall, PPIs are irreplaceable drugs in the management of acid-related diseases. However, PPI treatment - as any kind of drug therapy - is not without risk of adverse effects. The overall benefits of therapy and improvement in quality of life significantly outweigh potential risks in most patients, but those without clear clinical indication are only exposed to the risks of PPI prescription. Adhering to evidence-based guidelines represents the only rational approach to an effective and safe PPI therapy.

\section{Endnotes}

${ }^{1}$ The term "coxib" is being used in the medical/scientific literature as synonymous of "selective COX-2 inhibitor", which is not the case. The term "coxib" is a World Health Organization term used to describe a chemical class. It does not describe any pharmacological activity, nor indicate anything regarding COX-2 selectivity. Actually, there are members of the coxib family (e.g., SC-560) that selectively inhibit COX-1 [447].

\footnotetext{
Abbreviations

ACG: American College of Gastroenterology; AIDS: acquired

immunodeficiency syndrome; AIN: acute interstitial nephritis; AP: acute pancreatitis; AIGO: Italian Association of Hospital Gastroenterologists;

ARS: anti-reflux surgery; CIB: clinically important bleeding;

COX: cyclooxygenase; CYP 450: cytochrome P450; CP: chronic pancreatitis;

CV: cardiovascular; DDls: drug-to-drug interactions; EoE: eosinophilic
} 
esophagitis; EPS: epigastric pain syndrome; ERT: enzyme replacement therapy; FD: functional dyspepsia; FIMMG: Italian Federation of General Practitioners; GER: gastroesophageal reflux; GERD: gastroesophageal reflux disease; Gl: gastrointestinal; H. pylori: Helicobacter pylori; $\mathrm{H}_{2} \mathrm{RA}: \mathrm{H}_{2}$ receptor antagonist; ICU: intensive care unit; NAB: nocturnal acid breakthrough; NERD: non-erosive reflux disease; NNT: number needed to treat; NSAIDs: non-steroidal anti-inflammatory drugs; OTC: over-the-counter OR: odds ratio; PDS: Postprandial distress syndrome; PPIs: proton pump inhibitors; PPI-REE: proton pump inhibitor-responsive esophageal eosinophilia; PU: peptic ulcer; RCT: randomized controlled trial; SIF: Italian Society of Pharmacology; SSRIs: selective serotonin reuptake inhibitors; SIBO: small intestinal bacterial overgrowth; SUP: stress ulcer prophylaxis; UGIB: upper GI bleeding; ZES: Zollinger-Ellison syndrome

\section{Acknowledgements}

We are indebted to Professor Richard H Hunt (McMaster University, Hamilton, ON, CA) and Professor Jean Paul Galmiche (University of Nantes, France) for the critical reading of the manuscript and the very useful suggestions. We are also very grateful to all the National and International Experts (listed below), who kindly agreed to review the various statements of the Position Paper, contributing to the improvement of both contents and wording.

\section{Statement on}

GERD

Eosinophilic esophagitis

(Hospital General de Tomelloso,

Tomelloso, Spain)

- Professor Michael F. Vaezi

(Vanderbilt University Medical Center

Nashville, TN, USA)

Helicobacter pylori infection - Professor Thomas Borody

and PU disease

(Centre for Digestive Diseases, Australia)

- Professor Xavier Calvet (Autonomous

University of Barcelona, Spain)

- Professor Dino Vaira

(University of Bologna, Italy)

Zollinger-Ellison syndrome - Professor Joe Pisegna (University of

California at Los Angeles, USA)

- Professor Pierre Poitras

(University of Montreal, QC, Canada)

- Professor Jens F. Rehfeld

(University of Copenhagen, Denmark)

- Professor Philippe Ruszniewski

(University of Paris VII, Paris, France)

Stress ulcer prophylaxis

- Professor Francis KL Chan,

Chinese University, Hong Kong, China

- Professor Giustino Varrassi

(Schol of Medical Sciences,

LUdeS University, La Valletta, Malta)

Dyspepsia
- Professor Jan Tack (University of Leuven, Belgium)

- Professor Nick J Talley (University of

Newcastle, NSW, Australia)

\begin{tabular}{|c|c|}
\hline $\begin{array}{l}\text { NSAID-associated GI } \\
\text { symptoms and lesions }\end{array}$ & $\begin{array}{l}\text { - Professor Angel Lanas } \\
\text { (University of Zaragoza, Spain) } \\
\text { - Dr. Mario Guslandi (San Raffaele } \\
\text { University Hospital, Milan, Italy) } \\
\text { - Professor James Scheiman (University of } \\
\text { Michigan, Ann Arbor, MI, USA) }\end{array}$ \\
\hline Corticosteroid use & $\begin{array}{l}\text { - Professor Angel Lanas (University of } \\
\text { Zaragoza, Spain) } \\
\text { - Dr. Mario Guslandi (San Raffaele } \\
\text { University Hospital, Milan, Italy) } \\
\text { - Professor James Scheiman (University of } \\
\text { Michigan, Ann Arbor, MI, USA) }\end{array}$ \\
\hline $\begin{array}{l}\text { Anti-platelet or } \\
\text { anticoagulant therapy }\end{array}$ & $\begin{array}{l}\text { - Professor Xavier Calvet } \\
\text { (Autonomous University of Barcelona, Spain) } \\
\text { - Professor Angel Lanas } \\
\text { (University of Zaragoza, Spain) } \\
\text { - Professor James Scheiman (University of } \\
\text { Michigan, Ann Arbor, MI, USA) }\end{array}$ \\
\hline PU bleeding & $\begin{array}{l}\text { - Professor Francis KL Chan } \\
\text { (Chinese University, Hong Kong, China) } \\
\text { - Professor Xavier Calvet } \\
\text { (Autonomous University of Barcelona, Spain) } \\
\text { - Professor Guido Costamagna } \\
\text { (Catholic University, Rome, Italy) } \\
\text { - Professor Colin Howden, } \\
\text { (University of Tennessee, Health Science } \\
\text { Center, Memphis, TN, USA) }\end{array}$ \\
\hline Cancer & $\begin{array}{l}\text { - Dr. Renato Cannizzaro } \\
\text { (Oncology Reference Center, Aviano, Italy) } \\
\text { - Professor Stefano Cascinu (University of } \\
\text { Modena and Reggio Emilia, Italy) } \\
\text { - Professor Rajesh V. Lalla (UConn School } \\
\text { of Dental Medicine, Farmington, CT, USA) } \\
\text { - PD Dr. Maria Vehreschild } \\
\text { (First Department of Internal Medicine and } \\
\text { Center for Integrated Oncology, } \\
\text { University of Cologne, Germany) }\end{array}$ \\
\hline Cirrhosis & $\begin{array}{l}\text { - Professor Piero Amodio } \\
\text { (University of Padua, Italy) }\end{array}$ \\
\hline Pancreatic disease & $\begin{array}{l}\text { - Professor Luca Frulloni } \\
\text { (University of Verona, Italy) } \\
\text { - Professor Peter Alan Banks } \\
\text { (Harvard Medical School, Boston, MA, USA) }\end{array}$ \\
\hline Safety & $\begin{array}{l}\text { - Professor Colin Howden, (University of } \\
\text { Tennessee, Health Science Center, } \\
\text { Memphis, TN, USA) } \\
\text { - Professor George Triadafilopoulos } \\
\text { (Stanford University School of Medicine, } \\
\text { CA, USA) }\end{array}$ \\
\hline
\end{tabular}

The SIF-AIGO-FIMMG Group:

All members of the SIF-AIGO-FIMMG Committee (Antonio Balzano, Corrado Blandizzi, Alberto Chiriatti, Luigi Gatta, Anna Kohn, Gioacchino Leandro, Walter Marocco, Carmelo Scarpignato, Angelo Zullo) contributed to the refinement of the statements and helped to provide the best evidence for each of them.

\section{Authors' contributions}

CS initiated and led the development of the Position Paper with the active input of all the authors. CS, LG, AZ, and CB participated in the review process and in drafting the recommendations. CS and LG provided the methodological support. All the members of the Core Writing Group read and approved the final manuscript. The writing committee (CS, LG, AZ, and CB) accepts full responsibility for the content of this paper. 


\section{Competing interests}

The authors have received consulting and/or lecture fees from pharmaceutical companies (none marketing PPIs) and other organizations. The authors have received research support from charities and government sources at various times. No author has any direct stock-holding in any pharmaceutical company.

\section{Author details}

${ }^{1}$ Clinical Pharmacology \& Digestive Pathophysiology Unit, Department of Clinical \& Experimental Medicine, University of Parma, Maggiore University Hospital, Cattani Pavillon, I-43125 Parma, Italy. ${ }^{2}$ Gastroenterology \& Endoscopy Unit, Versilia Hospital, Azienda USL Toscana Nord Ovest, Lido di Camaiore, Italy. ${ }^{3}$ Division of Gastroenterology \& Digestive Endoscopy, Nuovo Regina Elena Hospital, Rome, Italy. ${ }^{4}$ Division of Pharmacology, Department of Clinical \& Experimental Medicine, University of Pisa, Pisa, Italy.

Received: 13 August 2016 Accepted: 14 October 2016 Published online: 09 November 2016

\section{References}

1. Scarpignato C, Pelosini I, Di Mario F. Acid suppression therapy: where do we go from here? Dig Dis. 2006;24:11-46.

2. Hunt RH. Review article: the unmet needs in delayed-release protonpump inhibitor therapy in 2005. Aliment Pharmacol Ther. 2005;22 Suppl 3:10-9.

3. Scarpignato C, Pelosini I. Review article: the opportunities and benefits of extended acid suppression. Aliment Pharmacol Ther. 2006;23 Suppl 2:23-34.

4. Scarpignato $\mathrm{C}$, Hunt $\mathrm{RH}$. Proton pump inhibitors: the beginning of the end or the end of the beginning? Curr Opin Pharmacol. 2008;8:677-84.

5. Hunt $\mathrm{RH}$, Scarpignato C. Potassium-competitive acid blockers (P-CABs): are they finally ready for prime time in acid-related disease? Clin Transl Gastroenterol. 2015;6, e119.

6. Vakil N. Prescribing proton pump inhibitors: is it time to pause and rethink? Drugs. 2012;72:437-45.

7. Lanas A. We are using too many PPIs, and we need to stop: A European perspective. Am J Gastroenterol. 2016;111:1085-6.

8. Galmiche JP. Traitement de l'oesophagite de reflux par les inhibiteurs de pompe à protons: de l'efficacité à la dépendance. Hépato-Gastro Oncol Digest. 1995;2:215-9.

9. Boath $\mathrm{EH}$, Blenkinsopp $\mathrm{A}$. The rise and rise of proton pump inhibitor drugs: patients' perspectives. Soc Sci Med. 1997;45:1571-9.

10. Pottegård A, Broe A, Hallas J, de Muckadell OBS, Lassen AT, Lødrup AB. Use of proton-pump inhibitors among adults: a Danish nationwide drug utilization study. Ther Adv Gastroenterol. 2016;9:671-8.

11. Heidelbaugh JJ, Kim AH, Chang R, Walker PC. Overutilization of protonpump inhibitors: what the clinician needs to know. Therap Adv Gastroenterol. 2012;5:219-32.

12. Gupta R, Garg P, Kottoor R, et al. Overuse of acid suppression therapy in hospitalized patients. South Med J. 2010;103:207-11.

13. Ahrens D, Chenot JF, Behrens G, Grimmsmann T, Kochen MM. Appropriateness of treatment recommendations for PPI in hospital discharge letters. Eur J Clin Pharmacol. 2010;66:1265-71.

14. Parente F, Cucino C, Gallus S, et al. Hospital use of acid-suppressive medications and its fall-out on prescribing in general practice: a 1-month survey. Aliment Pharmacol Ther. 2003;17:1503-6.

15. Wermeling M, Himmel W, Behrens G, Ahrens D. Why do GPs continue inappropriate hospital prescriptions of proton pump inhibitors? A qualitative study. Eur J Gen Pract. 2014;20:174-80.

16. Cammarota S, Bruzzese D, Sarnelli G, et al. Proton pump inhibitors prescribing following the introduction of generic drugs. Eur J Clin Invest. 2012;42:1068-78.

17. Inadomi JM, Fendrick AM. PPI use in the OTC era: who to treat, with what and for how long? Clin Gastroenterol Hepatol. 2005;3:208-15.

18. Haag $\mathrm{S}$, Andrews JM, Katelaris $\mathrm{PH}$, et al. Management of reflux symptoms with over-the-counter proton pump inhibitors: issues and proposed guidelines. Digestion. 2009;80:226-34.

19. Boardman HF, Delaney BC, Haag S. Partnership in optimizing management of reflux symptoms: a treatment algorithm for over-the-counter protonpump inhibitors. Curr Med Res Opin. 2015;31:1309-18.
20. Johnell K, Klarin I. The relationship between number of drugs and potential drug-drug interactions in the elderly: a study of over 600,000 elderly patients from the Swedish Prescribed Drug Register. Drug Saf. 2007;30:911-8.

21. Marengoni A, Pasina L, Concoreggi $C$, et al. Understanding adverse drug reactions in older adults through drug-drug interactions. Eur J Intern Med. 2014;25:843-6.

22. Blandizzi C, Scarpignato C. Gastrointestinal drugs. Side Eff Drugs Ann. 2011; 34:741-67.

23. Blandizzi C, Scarpignato C. Gastrointestinal drugs. Side Eff Drugs Ann. 2012; 35:555-78.

24. Blandizzi C, Scarpignato C. Gastrointestinal drugs. Side Eff Drugs Ann. 2014; 36:633-58.

25. Blandizzi C, Scarpignato C. Gastrointestinal drugs. Side Eff Drugs Ann. 2014; 37:539-60.

26. Pendleton A, Arden N, Dougados $M$, et al. EULAR recommendations for the management of knee osteoarthritis: report of a task force of the Standing Committee for International Clinical Studies Including Therapeutic Trials (ESCISIT). Ann Rheum Dis. 2000;59:936-44.

27. Schnitzer TJ. Update of ACR guidelines for osteoarthritis: role of the coxibs. J Pain Symptom Manage. 2002;23(4 Suppl):S24-30.

28. Scarpignato C, Lanas A, Blandizzi C, et al. Safe prescribing of non-steroidal antiinflammatory drugs in patients with osteoarthritis - An expert consensus addressing benefits as well as gastrointestinal and cardiovascular risks. BMC Med. 2015;13:55.

29. Bianco MA, Rotondano G, Buri L, Tessari F, Cipolletta L, Gas.Pro. Italian G. Gastro-protective strategies in primary care in Italy: the "Gas.Pro." survey. Dig Liver Dis. 2010;42:359-64.

30. Morini S, Zullo A, Oliveti D, et al. A very high rate of inappropriate use of gastroprotection for nonsteroidal anti-inflammatory drug therapy in primary care: a cross-sectional study. J Clin Gastroenterol. 2011;45:780-4.

31. Montagnani S, Tuccori M, Testi A, et al. Adherence with regulatory resolutions on prevention of NSAIDs-related gastrointestinal injury in Italy. Int J Clin Pharm. 2016:38:829-37.

32. OECD.Stat. http://stats.oecd.org/Index.aspx?DataSetCode=HEALTH_PHMC. Accessed on 4 July 2016.

33. Ladd AM, Panagopoulos G, Cohen J, Mar N, Graham R. Potential costs of inappropriate use of proton pump inhibitors. Am J Med Sci. 2014:347:446-51.

34. Kahrilas PJ. GERD pathogenesis, pathophysiology, and clinical manifestations. Cleve Clin J Med. 2003;70 Suppl 5:S4-19.

35. Dent J, Brun J, Fendrick AM, et al. An evidence-based appraisal of reflux disease management - the Genval Workshop Report. Gut. 1999;44 Suppl 2:S1-16.

36. Vakil N, van Zanten SV, Kahrilas P, Dent J, Jones R, Global Consensus Group. The Montreal definition and classification of gastroesophageal reflux disease: a global evidence-based consensus. Am J Gastroenterol. 2006;101: 1900-20.

37. Modlin IM, Hunt RH, Malfertheiner $P$, et al. Diagnosis and management of non-erosive reflux disease - the Vevey NERD Consensus Group. Digestion. 2009:80:74-88.

38. Savarino $E$, Zentilin $P$, Savarino V. NERD: an umbrella term including heterogeneous subpopulations. Nat Rev Gastroenterol Hepatol. 2013:10:371-80.

39. Boeckxstaens GE, Rohof WO. Pathophysiology of gastroesophageal reflux disease. Gastroenterol Clin North Am. 2014;43:15-25.

40. Kahrilas PJ, McColl K, Fox M, et al. The acid pocket: a target for treatment in reflux disease? Am J Gastroenterol. 2013;108:1058-64.

41. Anand G, Katz PO. Gastroesophageal reflux disease and obesity. Gastroenterol Clin North Am. 2010;39:39-46.

42. Chang P, Friedenberg F. Obesity and GERD. Gastroenterol Clin North Am. 2014:43:161-73.

43. Galmiche JP, Letessier E, Scarpignato C. Treatment of gastro-oesophageal reflux disease in adults. BMJ. 1998;316:1720-3.

44. Savarino V, Di Mario F, Scarpignato C. Proton pump inhibitors in GORD. An overview of their pharmacology, efficacy and safety. Pharmacol Res. 2009;59:135-53.

45. Khan M, Santana J, Donnellan C, Preston C, Moayyedi P. Medical treatments in the short term management of reflux oesophagitis. Cochrane Database Syst Rev. 2007;2, CD003244.

46. Edwards SJ, Lind T, Lundell L. Systematic review: Proton pump inhibitors (PPIs) for the healing of reflux oesophagitis - A comparison of esomeprazole with other PPIs. Aliment Pharmacol Ther. 2006;24:743-50.

47. Yuan $Y$, Vinh B, Hunt RH. Non-healed rate of moderate-severe (LA Classification Grade C and D) erosive esophagitis after 4-8 weeks proton pump inhibitors (PPIs): Evidence of an unmet need. Gastroenterology. 2009; 136 Suppl 1:A-440 
48. Gralnek IM, Dulai GS, Fennerty MB, Spiegel BM. Esomeprazole versus other proton pump inhibitors in erosive esophagitis: a meta-analysis of randomized clinical trials. Clin Gastroenterol Hepatol. 2006;4:1452-8.

49. Labenz J, Armstrong D, Leodolter A, Baldycheva I. Management of reflux esophagitis: does the choice of proton pump inhibitor matter? Int J Clin Pract. 2015;69:796-801.

50. Armstrong D, Bennett JR, Blum AL, et al. The endoscopic assessment of esophagitis: A progress report on observer agreement. Gastroenterology. 1996;111:85-92

51. Lundell LR, Dent J, Bennett JR, et al. Endoscopic assessment of oesophagitis: clinical and functional correlates and further validation of the Los Angeles classification. Gut. 1999;45:172-80.

52. Iwakiri $\mathrm{K}$, Umegaki E, Hiramatsu N, et al. A phase 3, randomized, doubleblind, multicenter study to evaluate the efficacy and safety of TAK-438 (20 mg once-daily) compared to lansoprazole (30 mg once-daily) in patients with erosive esophagitis. Gastroenterology. 2014;146:S-741.

53. Umegaki $\mathrm{E}$, Iwakiri $\mathrm{K}$, Hiramatsu $\mathrm{N}$, et al. A phase 3, randomized, doubleblind, multicenter study to evaluate the efficacy and safety of TAK-438 (10 mg or 20 mg Once-Daily) compared to lansoprazole (15 mg Once-Daily) in a 24-week maintenance treatment for healed erosive esophagitis. Gastroenterology. 2014;146:S-738.

54. Miner Jr P, Katz PO, Chen Y, Sostek M. Gastric acid control with esomeprazole, lansoprazole, omeprazole, pantoprazole, and rabeprazole: a five-way crossover study. Am J Gastroenterol. 2003;98:2616-20.

55. Rohss K, Lind T, Wilder-Smith C. Esomeprazole $40 \mathrm{mg}$ provides more effective intragastric acid control than lansoprazole $30 \mathrm{mg}$, omeprazole $20 \mathrm{mg}$, pantoprazole $40 \mathrm{mg}$ and rabeprazole $20 \mathrm{mg}$ in patients with gastrooesophageal reflux symptoms. Eur J Clin Pharmacol. 2004;60:531-9.

56. Miner $P$, Katz $P O$, Chen $Y$, Sostek $M$. Reanalysis of intragastric $\mathrm{pH}$ results based on updated correction factors for slimline[reg] and zinetics[trade] 24 single-use pH catheters. Am J Gastroenterol. 2006;101:404-5.

57. Goldstein JL, Miner Jr PB, Schlesinger PK, Liu S, Silberg DG. Intragastric acid control in non-steroidal anti-inflammatory drug users: comparison of esomeprazole, lansoprazole and pantoprazole. Aliment Pharmacol Ther. 2006;23:1189-96.

58. Kirchheiner J, Glatt S, Fuhr U, et al. Relative potency of proton-pump inhibitors-comparison of effects on intragastric pH. Eur J Clin Pharmacol. 2009:65:19-31.

59. Sigterman KE, van Pinxteren B, Bonis PA, Lau J, Numans ME. Short-term treatment with proton pump inhibitors, $\mathrm{H}_{2}$-receptor antagonists and prokinetics for gastro-oesophageal reflux disease-like symptoms and endoscopy negative reflux disease. Cochrane Database Syst Rev. 2013;5, CD002095.

60. Kahrilas PJ, Howden CW, Hughes N. Response of regurgitation to proton pump inhibitor therapy in clinical trials of gastroesophageal reflux disease. Am J Gastroenterol. 2011;106:1419-25.

61. Weijenborg PW, Cremonini F, Smout AJ, Bredenoord AJ. PPI therapy is equally effective in well-defined non-erosive reflux disease and in reflux esophagitis: a meta-analysis. Neurogastroenterol Motil. 2012;24:747-57.

62. Scarpignato C. Poor effectiveness of proton pump inhibitors in non-erosive reflux disease: the truth in the end! Neurogastroenterol Motil. 2012;24:697-704.

63. Aziz Q, Fass R, Gyawali CP, Miwa H, Pandolfino JE, Zerbib F. Esophageal disorders. Gastroenterology. 2016;150:1368-79.

64. Weijenborg PW, de Schepper HS, Smout AJ, Bredenoord AJ. Effects of antidepressants in patients with functional esophageal disorders or gastroesophageal reflux disease: a systematic review. Clin Gastroenterol Hepatol. 2015;13:251-9. e1.

65. Bytzer P, van Zanten SV, Mattsson H, Wernersson B. Partial symptomresponse to proton pump inhibitors in patients with non-erosive reflux disease or reflux oesophagitis - a post hoc analysis of 5796 patients. Aliment Pharmacol Ther. 2012;36:635-43.

66. Gunaratnam NT, Jessup TP, Inadomi J, Lascewski DP. Sub-optimal proton pump inhibitor dosing is prevalent in patients with poorly controlled gastro-oesophageal reflux disease. Aliment Pharmacol Ther. 2006:23:1473-7.

67. Rackoff A, Agrawal A, Hila A, Mainie I, Tutuian R, Castell DO. Histamine-2 receptor antagonists at night improve gastroesophageal reflux disease symptoms for patients on proton pump inhibitor therapy. Dis Esophagus. 2005;18:370-3

68. Wang Y, Pan T, Wang Q, Guo Z. Additional bedtime $\mathrm{H}_{2}$-receptor antagonist for the control of nocturnal gastric acid breakthrough. Cochrane Database Syst Rev. 2009;4, CD004275.
69. Scarpignato C. Antisecretory drugs, Helicobacter pylori infection and symptom relief in GORD: still an unexplored triangle. Dig Liver Dis. 2005;37:468-74.

70. Carlsson R, Dent J, Watts R, et al. Gastro-oesophageal reflux disease in primary care: an international study of different treatment strategies with omeprazole. International GORD Study Group. Eur J Gastroenterol Hepatol. 1998;10:119-24.

71. Donnellan C, Sharma N, Preston C, Moayyedi P. Medical treatments for the maintenance therapy of reflux oesophagitis and endoscopic negative reflux disease. Cochrane Database Syst Rev. 2005;2, CD003245.

72. Edwards SJ, Lind T, Lundell L. Systematic review of proton pump inhibitors for the maintenance of healed reflux oesophagitis. J Outc Resear. 2002;6:1-14.

73. Galmiche JP, Hatlebakk J, Attwood S, et al. Laparoscopic antireflux surgery vs esomeprazole treatment for chronic GERD: The LOTUS randomized clinical trial. JAMA. 2011;305:1969-77.

74. Lundell L, Miettinen P, Myrvold HE, et al. Comparison of outcomes twelve years after antireflux surgery or omeprazole maintenance therapy for reflux esophagitis. Clin Gastroenterol Hepatol. 2009:7:1292-8.

75. Bruley des Varannes S, Coron E, Galmiche JP. Short and long-term PPI treatment for GERD. Do we need more-potent anti-secretory drugs? Best Pract Res Clin Gastroenterol. 2010;24:905-21.

76. Contini S, Scarpignato C. Evaluation of clinical outcome after laparoscopic antireflux surgery in clinical practice: still a controversial issue. Minim Invasive Surg. 2011:2011:725472.

77. Yuan Y, Dattani ND, Scarpignato C, Hunt RH. Use of antisecretory medication after antireflux surgery for patients with gastroesophageal reflux disease (GERD): a systematic review of randomized control trials (RCTs). Am J Gastroenterol. 2009;104 Suppl 3:S25

78. Yuan Y, Dattani ND, Scarpignato C, Hunt RH. Use of antisecretory medication (ARM) after antireflux surgery (ARS) for patients with gastroesophageal reflux disease (GERD): a systematic review of nonrandomized studies. Gut. 2010;59 Suppl 1:A116-7.

79. Rohof WO, Bisschops R, Tack J, Boeckxstaens GE. Postoperative problems 2011: fundoplication and obesity surgery. Gastroenterol Clin North Am. 2011;40:809-21.

80. Richter JE. Gastroesophageal reflux disease treatment: side effects and complications of fundoplication. Clin Gastroenterol Hepatol. 2013;11:465-71.

81. Lin DC, Chun CL, Triadafilopoulos G. Evaluation and management of patients with symptoms after anti-reflux surgery. Dis Esophagus. 2015;28:1-10.

82. Haastrup P, Paulsen MS, Begtrup LM, Hansen JM, Jarbol DE. Strategies for discontinuation of proton pump inhibitors: a systematic review. Fam Pract. 2014;31:625-30

83. Lodrup AB, Reimer C, Bytzer P. Systematic review: symptoms of rebound acid hypersecretion following proton pump inhibitor treatment. Scand J Gastroenterol. 2013;48:515-22.

84. de Bortoli N, Guidi G, Martinucci I, et al. Voluntary and controlled weight loss can reduce symptoms and proton pump inhibitor use and dosage in patients with gastroesophageal reflux disease: a comparative study. Dis Esophagus. 2016;29:197-204.

85. Shaheen NJ, Falk GW, lyer PG, Gerson LB, American College of Gastroenterologists. ACG Clinical Guideline: diagnosis and management of Barrett's esophagus. Am J Gastroenterol. 2016;111:30-50.

86. Spechler SJ, Sharma P, Souza RF, Inadomi JM, Shaheen NJ. American Gastroenterological Association medical position statement on the management of Barrett's esophagus. Gastroenterology. 2011;140: 1084-91.

87. Fitzgerald RC, di Pietro M, Ragunath $K$, et al. British Society of Gastroenterology guidelines on the diagnosis and management of Barrett's oesophagus. Gut. 2014:63:7-42.

88. Singh S, Garg SK, Singh PP, Iyer PG, El-Serag HB. Acid-suppressive medications and risk of oesophageal adenocarcinoma in patients with Barrett's oesophagus: a systematic review and meta-analysis. Gut. 2014;63:1229-37.

89. Akiyama J, Bertele A, Brock C, et al. Benign and precursor lesions in the esophagus. Ann N Y Acad Sci. 2014;1325:226-41.

90. Malfertheiner P, Megraud F, O'Morain CA et al.; European Helicobacter and Microbiota Study Group and Consensus panel. Management of Helicobacter pylori infection - the Maastricht V/Florence Consensus Report. Gut 2016; doi: 10.1136/gutjnl-2016-312288.

91. World Gastroenterology Organisation Global Guidelines. GERD: Global Perspective on Gastroesophageal Reflux Disease. 2015. http://www. worldgastroenterology.org/guidelines/global-guidelines/gastroesophagealreflux-disease/gastroesophageal-reflux-disease-english [last Accessed 30 Oct 2016]. 
92. Lundell L, Vieth M, Gibson F, Nagy P, Kahrilas PJ. Systematic review: the effects of long-term proton pump inhibitor use on serum gastrin levels and gastric histology. Aliment Pharmacol Ther. 2015;42:649-63.

93. Katz PO, Gerson LB, Vela MF. Guidelines for the diagnosis and management of gastroesophageal reflux disease. Am J Gastroenterol. 2013;108:308-28.

94. Burgstaller JM, Jenni BF, Steurer J, Held U, Wertli MM. Treatment efficacy for non-cardiovascular chest pain: a systematic review and meta-analysis. PLoS One. 2014;9, e104722.

95. Roman C, Bruley des Varannes S, Muresan L, Picos A, Dumitrascu DL. Atrial fibrillation in patients with gastroesophageal reflux disease: a comprehensive review. World J Gastroenterol. 2014;20:9592-9.

96. Chang AB, Lasserson TJ, Gaffney J, Connor FL, Garske LA. Gastrooesophageal reflux treatment for prolonged non-specific cough in children and adults. Cochrane Database Syst Rev. 2011;1, CD004823.

97. Kahrilas PJ, Howden CW, Hughes N, Molloy-Bland M. Response of chronic cough to acid-suppressive therapy in patients with gastroesophageal reflux disease. Chest. 2013;143:605-12.

98. Sen P, Georgalas C, Bhattacharyya AK. A systematic review of the role of proton pump inhibitors for symptoms of laryngopharyngeal reflux. Clin Otolaryngol. 2006;31:20-4.

99. Qadeer MA, Colabianchi N, Strome M, Vaezi MF. Gastroesophageal reflux and laryngeal cancer: causation or association? A critical review. Am J Otolaryngol. 2006;27:119-28.

100. Gatta L, Vaira D, Sorrenti G, Zucchini S, Sama C, Vakil N. Meta-analysis: the efficacy of proton pump inhibitors for laryngeal symptoms attributed to gastro-oesophageal reflux disease. Aliment Pharmacol Ther. 2007;25:385-92.

101. Guo H, Ma H, Wang J. Proton pump inhibitor therapy for the treatment of laryngopharyngeal reflux: a meta-analysis of randomized controlled trials. J Clin Gastroenterol. 2016:50:295-300.

102. Wei C. A meta-analysis for the role of proton pump inhibitor therapy in patients with laryngopharyngeal reflux. Eur Arch Otorhinolaryngol. 2016; 273(11):3795-801.

103. Liu C, Wang H, Liu K. Meta-analysis of the efficacy of proton pump inhibitors for the symptoms of laryngopharyngeal reflux. Braz J Med Biol Res. 2016:49(7)

104. Harding SM. Gastroesophageal reflux, asthma, and mechanisms of interaction. Am J Med. 2001;111(Suppl 8A):8S-12.

105. Scarpignato C. Pharmacological bases of the medical treatment of gastroesophageal reflux disease. Dig Dis. 1988;6:117-48.

106. Gibson PG, Henry RL, Coughlan JL. Gastro-oesophageal reflux treatment for asthma in adults and children. Cochrane Database Syst Rev. 2003;2, CD001496.

107. Ranjitkar S, Smales RJ, Kaidonis JA. Oral manifestations of gastroesophageal reflux disease. J Gastroenterol Hepatol. 2012;27:21-7.

108. Wilder-Smith $\mathrm{CH}$, Wilder-Smith $\mathrm{P}$, Kawakami-Wong H, Voronets J, Osann K, Lussi A. Quantification of dental erosions in patients with GERD using optical coherence tomography before and after double-blind, randomized treatment with esomeprazole or placebo. Am J Gastroenterol. 2009;104:2788-95.

109. Hom C, Vaezi MF. Extra-esophageal manifestations of gastroesophageal reflux disease: diagnosis and treatment. Drugs. 2013;73:1281-95.

110. Molina-Infante J, Bredenoord AJ, Cheng E, et al. Proton pump inhibitorresponsive oesophageal eosinophilia: an entity challenging current diagnostic criteria for eosinophilic oesophagitis. Gut. 2016;65:524-31.

111. Kavitt RT, Hirano I, Vaezi MF. Diagnosis and treatment of eosinophilic esophagitis in adults. Am J Med. 2016;129:924-34.

112. Rothenberg ME. Biology and treatment of eosinophilic esophagitis. Gastroenterology. 2009;137:1238-49.

113. Kelly KJ, Lazenby AJ, Rowe PC, Yardley JH, Perman JA, Sampson HA. Eosinophilic esophagitis attributed to gastroesophageal reflux: improvement with an amino acid-based formula. Gastroenterology. 1995;109:1503-12.

114. Malagelada JR, Bazzoli F, Boeckxstaens G, et al. World Gastroenterology Organisation global guidelines: dysphagia - global guidelines and cascades update September 2014. J Clin Gastroenterol. 2015;49:370-8.

115. Dellon ES, Gonsalves N, Hirano I, Furuta GT, Liacouras CA, Katzka DA. ACG clinical guideline: Evidenced based approach to the diagnosis and management of esophageal eosinophilia and eosinophilic esophagitis (EoE). Am J Gastroenterol. 2013;108:679-92.

116. Lucendo AJ, Arias A, Molina-Infante J. Efficacy of proton pump inhibitor drugs for inducing clinical and histologic remission in patients with symptomatic esophageal eosinophilia: a systematic review and metaanalysis. Clin Gastroenterol Hepatol. 2016;14:13-22.

117. Molina-Infante J, Katzka DA, Gisbert JP. Review article: proton pump inhibitor therapy for suspected eosinophilic oesophagitis. Aliment Pharmacol Ther. 2013;37:1157-64.

118. Suzuki $H$, Hibi T. Novel effects other than antisecretory action and off-label use of proton pump inhibitors. Expert Opin Pharmacother. 2005;6:59-67.

119. Kedika RR, Souza RF, Spechler SJ. Potential anti-inflammatory effects of proton pump inhibitors: a review and discussion of the clinical implications. Dig Dis Sci. 2009;54:2312-7.

120. Molina-Infante J, Katzka DA. Proton-pump inhibitor-responsive esophageal eosinophilia. Curr Opin Gastroenterol. 2014;30:428-33.

121. Molina-Infante J, Rivas MD, Hernandez-Alonso M, et al. Proton pump inhibitorresponsive oesophageal eosinophilia correlates with downregulation of eotaxin-3 and Th2 cytokines overexpression. Aliment Pharmacol Ther. 2014:40:955-65.

122. Katzka DA, Ravi K, Geno DM, et al. Endoscopic mucosal impedance measurements correlate with eosinophilia and dilation of intercellular spaces in patients with eosinophilic esophagitis. Clin Gastroenterol Hepatol. 2015;13:1242-8.

123. van Malenstein $H$, Farre $R$, Sifrim D. Esophageal dilated intercellular spaces (DIS) and nonerosive reflux disease. Am J Gastroenterol. 2008;103:1021-8.

124. van Rhijn BD, Weijenborg PW, Verheij J, et al. Proton pump inhibitors partially restore mucosal integrity in patients with proton pump inhibitorresponsive esophageal eosinophilia but not eosinophilic esophagitis. Clin Gastroenterol Hepatol. 2014;12:1815-23.

125. Lucendo AJ, Arias A, Gonzalez-Cervera J, Olalla JM, Molina-Infante J. Dual response to dietary/topical steroid and proton pump inhibitor therapy in adult patients with eosinophilic esophagitis. J Allergy Clin Immunol. 2016;137:931-4.

126. Sodikoff J, Hirano I. Proton pump inhibitor-responsive esophageal eosinophilia does not preclude food-responsive eosinophilic esophagitis. J Allergy Clin Immunol. 2016;137:631-3.

127. Liacouras CA, Furuta GT, Hirano I, et al. Eosinophilic esophagitis: updated consensus recommendations for children and adults. J Allergy Clin Immunol. 2011;128:3-20.

128. Marshall BJ, Warren JR. Unidentified curved bacilli in the stomach of patients with gastritis and peptic ulceration. Lancet. 1984;1:1311-5.

129. Marshall BJ. The 1995 Albert Lasker Medical Research Award. Helicobacter pylori. The etiologic agent for peptic ulcer. JAMA. 1995;274:1064-6.

130. Leodolter A, Kulig M, Brasch H, Meyer-Sabellek W, Willich SN, Malfertheiner P. A meta-analysis comparing eradication, healing and relapse rates in patients with Helicobacter pylori-associated gastric or duodenal ulcer. Aliment Pharmacol Ther. 2001;15:1949-58.

131. Gisbert JP, Khorrami S, Carballo F, Calvet X, Gene E, Dominguez-Munoz JE. $H$. pylori eradication therapy vs. antisecretory non-eradication therapy (with or without long-term maintenance antisecretory therapy) for the prevention of recurrent bleeding from peptic ulcer. Cochrane Database Syst Rev. 2003:4, CD004062.

132. Ford AC, Delaney BC, Forman D, Moayyedi P. Eradication therapy in Helicobacter pylori positive peptic ulcer disease: systematic review and economic analysis. Am J Gastroenterol. 2004;99:1833-55.

133. Gisbert JP, Pajares JM. Systematic review and meta-analysis: is 1-week proton pump inhibitor-based triple therapy sufficient to heal peptic ulcer? Aliment Pharmacol Ther. 2005:21:795-804.

134. Scarpignato C, Pelosini I. Antisecretory drugs for eradication of Helicobacter pylori: antimicrobial activity and synergism with antimicrobial agents. Progr Basic Clin Pharmacol. 1999;11:135-78.

135. Gatta L, Vakil N, Vaira D, Scarpignato C. Global eradication rates for Helicobacter pylori infection: systematic review and meta-analysis of sequential therapy. BMJ. 2013;347:f4587.

136. Scarpignato C. Towards the ideal regimen for Helicobacter pylori eradication: the search continues. Dig Liver Dis. 2004;36:243-7.

137. Nakao M, Malfertheiner P. Growth inhibitory and bactericidal activities of lansoprazole compared with those of omeprazole and pantoprazole against Helicobacter pylori. Helicobacter. 1998;3:21-7.

138. Gatta L, Perna F, Figura N, et al. Antimicrobial activity of esomeprazole versus omeprazole against Helicobacter pylori. J Antimicrob Chemother. 2003;51:439-42

139. Scott D, Weeks D, Melchers K, Sachs G. The life and death of Helicobacter pylori. Gut. 1998;43 Suppl 1:S56-60.

140. Erah PO, Goddard AF, Barrett DA, Shaw PN, Spiller RC. The stability of amoxycillin, clarithromycin and metronidazole in gastric juice: relevance to 
the treatment of Helicobacter pylori infection. J Antimicrob Chemother. 1997;39:5-12.

141. Grayson ML, Eliopoulos GM, Ferraro MJ, Moellering Jr RC. Effect of varying $\mathrm{pH}$ on the susceptibility of Campylobacter pylori to antimicrobial agents. Eur J Clin Microbiol Infect Dis. 1989;8:888-9.

142. Parkman HP, Urbain JL, Knight LC, et al. Effect of gastric acid suppressants on human gastric motility. Gut. 1998;42:243-50.

143. Goddard AF, Spiller RC. The effect of omeprazole on gastric juice viscosity, pH and bacterial counts. Aliment Pharmacol Ther. 1996;10:105-9.

144. Lieber CS. Gastritis and Helicobacter pylori: forty years of antibiotic therapy. Digestion. 1997;58:203-10.

145. Attumi TA, Graham DY. Follow-up testing after treatment of Helicobacter pylori infections: cautions, caveats, and recommendations. Clin Gastroenterol Hepatol. 2011;9:373-5.

146. Lind T, Megraud F, Unge $P$, et al. The MACH2 study: role of omeprazole in eradication of Helicobacter pylori with 1-week triple therapies. Gastroenterology. 1999;116:248-53.

147. Wheeldon TU, Hoang TT, Phung DC, Bjorkman A, Granstrom M, Sorberg M. Helicobacter pylori eradication and peptic ulcer healing: the impact of deleting the proton pump inhibitor and using a once-daily treatment. Aliment Pharmacol Ther. 2003;18:93-100.

148. Zagari RM, Romano M, Ojetti V, et al. Guidelines for the management of Helicobacter pylori infection in Italy: The III Working Group Consensus Report 2015. Dig Liver Dis. 2015;47:903-12.

149. Hunt R, Fallone C, Veldhuyzan van Zanten S, et al. Canadian Helicobacter Study Group Consensus Conference: Update on the management of Helicobacter pylori - an evidence-based evaluation of six topics relevant to clinical outcomes in patients evaluated for H. pylori infection. Can J Gastroenterol. 2004;18:547-54.

150. Chey WD, Wong BC, Practice Parameters Committee of the American College of Gastroenterology. American College of Gastroenterology guideline on the management of Helicobacter pylori infection. Am J Gastroenterol. 2007;102:1808-25.

151. Fock KM, Katelaris P, Sugano K, et al. Second Asia-Pacific Consensus Guidelines for Helicobacter pylori infection. J Gastroenterol Hepatol. 2009; 24:1587-600.

152. Vallve M, Vergara M, Gisbert JP, Calvet X. Single vs. double dose of a proton pump inhibitor in triple therapy for Helicobacter pylori eradication: a metaanalysis. Aliment Pharmacol Ther. 2002;16:1149-56.

153. Sugimoto M, Graham DY. High-dose versus standard-dose PPI in triple therapy for Helicobacter pylori eradication. Nat Clin Pract Gastroenterol Hepatol. 2009;6:138-9.

154. Furuta T, Shirai N, Takashima M, et al. Effect of genotypic differences in CYP2C19 on cure rates for Helicobacter pylori infection by triple therapy with a proton pump inhibitor, amoxicillin, and clarithromycin. Clin Pharmacol Ther. 2001;69:158-68.

155. McNicholl AG, Linares PM, Nyssen OP, Calvet X, Gisbert JP. Meta-analysis: esomeprazole or rabeprazole vs. first-generation pump inhibitors in the treatment of Helicobacter pylori infection. Aliment Pharmacol Ther. 2012;36: 414-25.

156. McColl KE, Kennerley P. Proton pump inhibitors - differences emerge in hepatic metabolism. Dig Liver Dis. 2002;34:461-7.

157. Ishizaki T, Horai Y. Review article: cytochrome P450 and the metabolism of proton pump inhibitors - emphasis on rabeprazole. Aliment Pharmacol Ther. 1999:13 Suppl 3:27-36.

158. Padol S, Yuan Y, Thabane M, Padol IT, Hunt RH. The effect of CYP2C19 polymorphisms on $\mathrm{H}$. pylori eradication rate in dual and triple first-line PPI therapies: a meta-analysis. Am J Gastroenterol. 2006;101:1467-75.

159. Tang HL, Li Y, Hu YF, Xie HG, Zhai SD. Effects of CYP2C19 loss-of-function variants on the eradication of $\mathrm{H}$. pylori infection in patients treated with proton pump inhibitor-based triple therapy regimens: a meta-analysis of randomized clinical trials. PLoS One. 2013;8:e62162.

160. Kim JI, Park SH, Kim JK, Chung IS, Chung KW, Sun HS. The effects of nocturnal acid breakthrough on Helicobacter pylori eradication. Helicobacter. 2002;7:331-6.

161. Sugimoto M, Furuta $T$, Shirai $N$, et al. Evidence that the degree and duration of acid suppression are related to Helicobacter pylori eradication by triple therapy. Helicobacter. 2007;12:317-23.

162. Ford A, Moayyedi P. How can the current strategies for Helicobacter pylori eradication therapy be improved? Can J Gastroenterol. 2003;17(Suppl B): $36 \mathrm{~B}-40$.
163. Miehlke S, Mannes GA, Lehn N, Hele C, Stolte M, Bayerdorffer E. An increasing dose of omeprazole combined with amoxycillin cures Helicobacter pylori infection more effectively. Aliment Pharmacol Ther. 1997; 11:323-9.

164. Zullo A, Ridola L, Francesco VD, et al. High-dose esomeprazole and amoxicillin dual therapy for first-line Helicobacter pylori eradication: a proof of concept study. Ann Gastroenterol. 2015;28:448-51.

165. Yang JC, Lin CJ, Wang HL, et al. High-dose dual therapy is superior to standard first-line or rescue therapy for Helicobacter pylori infection. Clin Gastroenterol Hepatol. 2015;13:895-905.

166. Furuta T, Sahara S, Ichikawa $H$, et al. Dual therapy with vonoprazan and amoxicillin is as effective as standard PPI-based triple therapy with amoxicillin and clarithromycin or metronidazole in Japan. Gastroenterology. 2016;150:S877

167. McColl KE. Helicobacter pylori negative ulcer disease. Dig Liver Dis. 2000; 32:125-7

168. Sbrozzi-Vanni A, Zullo A, Di Giulio E, et al. Low prevalence of idiopathic peptic ulcer disease: an Italian endoscopic survey. Dig Liver Dis. 2010;42: 773-6.

169. Malfertheiner P, Chan FKL, McColl KEL. Peptic ulcer disease. Lancet. 2009; 374:1449-61.

170. Hunt RH, Lanas A, Stichtenoth DO, Scarpignato C. Myths and facts in the use of anti-inflammatory drugs. Ann Med. 2009;41:423-37.

171. McColl KE. How I, manage H. pylori-negative, NSAID/aspirin-negative peptic ulcers. Am J Gastroenterol. 2009;104:190-3.

172. Jensen RT, Niederle B, Mitry E, et al. Gastrinoma (duodenal and pancreatic). Neuroendocrinology. 2006;84:173-82.

173. Ito T, Igarashi $H$, Jensen RT. Zollinger-Ellison syndrome: recent advances and controversies. Curr Opin Gastroenterol. 2013;29:650-61.

174. Rehfeld JF, Federspiel B, Bardram L. A neuroendocrine tumor syndrome from cholecystokinin secretion. N Engl J Med. 2013;368:1165-6.

175. Brandi ML, Gagel RF, Angeli A, et al. Guidelines for diagnosis and therapy of MEN type 1 and type 2. J Clin Endocrinol Metab. 2001;86:5658-71.

176. Jensen RT, Cadiot G, Brandi ML, et al. ENETS Consensus Guidelines for the management of patients with digestive neuroendocrine neoplasms: functional pancreatic endocrine tumor syndromes. Neuroendocrinology. 2012;95:98-119.

177. Thakker RV, Newey PJ, Walls GV, et al. Clinical practice guidelines for multiple endocrine neoplasia type 1 (MEN1). J Clin Endocrinol Metab. 2012; 97:2990-3011.

178. Wilcox CM, Hirschowitz BI. Treatment strategies for Zollinger-Ellison syndrome. Expert Opin Pharmacother. 2009;10:1145-57.

179. Lew EA, Pisegna JR, Starr JA, et al. Intravenous pantoprazole rapidly controls gastric acid hypersecretion in patients with Zollinger-Ellison syndrome. Gastroenterology. 2000;118:696-704.

180. Ojeaburu JV, Ito T, Crafà P, Bordi C, Jensen RT. Mechanism of acid hypersecretion post curative gastrinoma resection. Dig Dis Sci. 2011;56:139-54

181. Poitras P, Gingras MH, Rehfeld JF. The Zollinger-Ellison syndrome: dangers and consequences of interrupting antisecretory treatment. Clin Gastroenterol Hepatol. 2012;10:199-202

182. Nieto JM, Pisegna JR. The role of proton pump inhibitors in the treatment of Zollinger-Ellison syndrome. Expert Opin Pharmacother. 2006;7:169-75.

183. Jensen RT. Consequences of long-term proton pump blockade: insights from studies of patients with gastrinomas. Basic Clin Pharmacol Toxicol. 2006;98:4-19.

184. Bardou M, Quenot JP, Barkun A. Stress-related mucosal disease in the critically ill patient. Nat Rev Gastroenterol Hepatol. 2015;12:98-107.

185. Faisy C, Guerot E, Diehl JL, Iftimovici E, Fagon JY. Clinically significant gastrointestinal bleeding in critically ill patients with and without stressulcer prophylaxis. Intensive Care Med. 2003;29:1306-13.

186. Quenot JP, Thiery N, Barbar S. When should stress ulcer prophylaxis be used in the ICU? Curr Opin Crit Care. 2009:15:139-43.

187. ASHP Therapeutic Guidelines on Stress Ulcer Prophylaxis. ASHP Commission on Therapeutics and approved by the ASHP Board of Directors on November 14, 1998. Am J Health Syst Pharm. 1999;56:347-79.

188. Dellinger RP, Levy MM, Rhodes A, et al. Surviving Sepsis Campaign: international guidelines for management of severe sepsis and septic shock, 2012. Intensive Care Med. 2013:39:165-228.

189. Cook DJ, Griffith LE, Walter SD, et al. The attributable mortality and length of intensive care unit stay of clinically important gastrointestinal bleeding in critically ill patients. Crit Care. 2001;5:368-75. 
190. Cook DJ, Reeve BK, Guyatt GH, et al. Stress ulcer prophylaxis in critically ill patients. Resolving discordant meta-analyses. JAMA. 1996;275:308-14.

191. Krag M, Perner A, Wetterslev J, Wise MP, Hylander MM. Stress ulcer prophylaxis versus placebo or no prophylaxis in critically ill patients. A systematic review of randomised clinical trials with meta-analysis and trial sequential analysis. Intensive Care Med. 2014;40:11-22.

192. Liu B, Liu S, Yin A, Siddiqi J. Risks and benefits of stress ulcer prophylaxis in adult neurocritical care patients: a systematic review and meta-analysis of randomized controlled trials. Crit Care. 2015;19:409.

193. Daley RJ, Rebuck JA, Welage LS, Rogers FB. Prevention of stress ulceration: current trends in critical care. Crit Care Med. 2004;32:2008-13.

194. Pongprasobchai S, Kridkratoke S, Nopmaneejumruslers C. Proton pump inhibitors for the prevention of stress-related mucosal disease in critically-ill patients: a meta-analysis. J Med Assoc Thai. 2009;92:632-7.

195. Alhazzani W, Alenezi F, Jaeschke RZ, Moayyedi P, Cook DJ. Proton pump inhibitors versus histamine 2 receptor antagonists for stress ulcer prophylaxis in critically ill patients: a systematic review and meta-analysis. Crit Care Med. 2013;41:693-705

196. Barkun AN, Bardou M, Pham CQ, Martel M. Proton pump inhibitors vs. histamine 2 receptor antagonists for stress-related mucosal bleeding prophylaxis in critically ill patients: a meta-analysis. Am J Gastroenterol. 2012;107:507-20.

197. Alshamsi F, Belley-Cote E, Cook D, et al. Efficacy and safety of proton pump inhibitors for stress ulcer prophylaxis in critically ill patients: a systematic review and meta-analysis of randomized trials. Crit Care. 2016;20:120.

198. Lin PC, Chang CH, Hsu PI, Tseng PL, Huang YB. The efficacy and safety of proton pump inhibitors vs histamine-2 receptor antagonists for stress ulcer bleeding prophylaxis among critical care patients: a meta-analysis. Crit Care Med. 2010;38:1197-205.

199. Ro Y, Eun CS, Kim HS, et al. Risk of Clostridium difficile infection with the use of a proton pump inhibitor for stress ulcer prophylaxis in critically ill patients. Gut Liver. 2016;10:581-6.

200. Marik PE, Vasu T, Hirani A, Pachinburavan M. Stress ulcer prophylaxis in the new millennium: a systematic review and meta-analysis. Crit Care Med. 2010;38:2222-8.

201. Buendgens L, Koch A, Tacke F. Prevention of stress-related ulcer bleeding at the intensive care unit: Risks and benefits of stress ulcer prophylaxis. World J Crit Care Med. 2016:5:57-64.

202. Gardner TB, Robertson DJ. Stress ulcer prophylaxis in non-critically ill patients: less may be more. Am J Gastroenterol. 2006;101:2206-8.

203. Shin S. Evaluation of costs accrued through inadvertent continuation of hospital-initiated proton pump inhibitor therapy for stress ulcer prophylaxis beyond hospital discharge: a retrospective chart review. Ther Clin Risk Manag. 2015;11:649-57.

204. Talley NJ, Ford AC. Functional dyspepsia. N Engl J Med. 2015;373:1853-63.

205. Stanghellini V, Chan FKL, Hasler WL, et al. Gastroduodenal disorders. Gastroenterology. 2016;150:1380-92.

206. Wang A, Liao X, Xiong $L$, et al. The clinical overlap between functional dyspepsia and irritable bowel syndrome based on Rome III criteria. BMC Gastroenterol. 2008:8:43.

207. Noh YW, Jung HK, Kim SE, Jung SA. Overlap of erosive and non-erosive reflux diseases with functional gastrointestinal disorders according to Rome III criteria. J Neurogastroenterol Motil. 2010;16:148-56.

208. Zagari RM, Law GR, Fuccio L, et al. Epidemiology of functional dyspepsia and subgroups in the Italian general population: an endoscopic study. Gastroenterology. 2010;138:1302-11.

209. Hallas J, Bytzer P. Screening for drug related dyspepsia: an analysis of prescription symmetry. Eur J Gastroenterol Hepatol. 1998;10:27-32.

210. Moayyedi P, Soo S, Deeks J, et al. Eradication of Helicobacter pylori for nonulcer dyspepsia. Cochrane Database Syst Rev. 2006;2, CD002096.

211. Moayyedi P. Helicobacter pylori eradication for functional dyspepsia: What are we treating? Comment on "Helicobacter pylori eradication in functional dyspepsia". Arch Intern Med. 2011;171:1936-7.

212. Sugano K, Tack J, Kuipers EJ, et al. Kyoto global consensus report on Helicobacter pylori gastritis. Gut. 2015;64:1353-67.

213. Lacy BE, Talley NJ, Locke 3rd GR, et al. Review article: current treatment options and management of functional dyspepsia. Aliment Pharmacol Ther. 2012;36:3-15.

214. Lassen AT, Hallas J, de Muckadell OB S. Helicobacter pylori test and eradicate versus prompt endoscopy for management of dyspeptic patients: 6.7 year follow up of a randomised trial. Gut. 2004;53:1758-63.
215. Harvey RF, Lane JA, Nair P, et al. Clinical trial: prolonged beneficial effect of Helicobacter pylori eradication on dyspepsia consultations - the Bristol Helicobacter Project. Aliment Pharmacol Ther. 2010;32:394-400.

216. Moayyedi P, Soo S, Deeks J, Delaney B, Innes M, Forman D. Pharmacological interventions for non-ulcer dyspepsia. Cochrane Database Syst Rev. 2006;4, CD001960.

217. Moayyedi P, Delaney BC, Vakil N, Forman D, Talley NJ. The efficacy of proton pump inhibitors in nonulcer dyspepsia: a systematic review and economic analysis. Gastroenterology. 2004;127:1329-37.

218. Gerson LB, Kahrilas PJ, Fass R. Insights into gastroesophageal reflux disease-associated dyspeptic symptoms. Clin Gastroenterol Hepatol. 2011;9:824-33.

219. Scarpignato C, Pelosini I, Contini S. What is the effect of acid suppression with proton pump inhibitors on esophageal and gastric motility? In: Giuli R et al. Editor. The Duodenogastroesophageal Reflux - From the Duodenum to the Trachea: 125 Questions, 125 Answers. John Libbey Eurotext; 2006. pp. 262-71.

220. McCallum RW, Zarling EJ, Goetsch AC, et al. Multicenter, double-blind, placebo-controlled crossover study to assess the acute prokinetic efficacy of nizatidine-controlled release (150 and $300 \mathrm{mg}$ ) in patients with gastroesophageal reflux disease. Am J Med Sci. 2010;340:259-63.

221. Aronson JK. Meyler's side effects of analgesic and anti-inflammatory drugs. Amsterdam: Elsevier; 2010.

222. Scarpignato C, Hunt RH. Nonsteroidal antiinflammatory drug-related injury to the gastrointestinal tract: clinical picture, pathogenesis, and prevention. Gastroenterol Clin North Am. 2010;39:433-64.

223. Laine L, Bombardier C, Hawkey CJ, et al. Stratifying the risk of NSAID-related upper gastrointestinal clinical events: results of a double-blind outcomes study in patients with rheumatoid arthritis. Gastroenterology. 2002;123:1006-12.

224. Vergara M, Catalan M, Gisbert JP, Calvet X. Meta-analysis: role of Helicobacter pylori eradication in the prevention of peptic ulcer in NSAID users. Aliment Pharmacol Ther. 2005;21:1411-8.

225. Masclee GM, Valkhoff VE, Coloma PM, et al. Risk of upper gastrointestinal bleeding from different drug combinations. Gastroenterology. 2014;147:784-92.

226. Anglin R, Yuan Y, Moayyedi P, Tse F, Armstrong D, Leontiadis Gl. Risk of upper gastrointestinal bleeding with selective serotonin reuptake inhibitors with or without concurrent nonsteroidal anti-inflammatory use: a systematic review and meta-analysis. Am J Gastroenterol. 2014;109:811-9.

227. Jiang HY, Chen $\mathrm{HZ}, \mathrm{Hu} X \mathrm{XJ}$, et al. Use of selective serotonin reuptake inhibitors and risk of upper gastrointestinal bleeding: a systematic review and meta-analysis. Clin Gastroenterol Hepatol. 2015;13:42-50.

228. Laporte $S$, Chapelle $C$, Caillet $P$, et al. Bleeding risk under selective serotonin reuptake inhibitor (SSRI) antidepressants: a meta-analysis of observational studies. Pharmacol Res. 2016. Ahead of print. doi: 10.1016/j. phrs.2016.08.017.

229. Loke YK, Trivedi AN, Singh S. Meta-analysis: gastrointestinal bleeding due to interaction between selective serotonin uptake inhibitors and non-steroidal anti-inflammatory drugs. Aliment Pharmacol Ther. 2008;27:31-40.

230. Oka Y, Okamoto K, Kawashita N, Shirakuni Y, Takagi T. Meta-analysis of the risk of upper gastrointestinal hemorrhage with combination therapy of selective serotonin reuptake inhibitors and non-steroidal anti-inflammatory drugs. Biol Pharm Bull. 2014;37:947-53.

231. Dall M, de Muckadell OB S, Moller Hansen J, Wildner-Christensen M, Touborg Lassen A, Hallas J. Helicobacter pylori and risk of upper gastrointestinal bleeding among users of selective serotonin reuptake inhibitors. Scand J Gastroenterol. 2011:46:1039-44.

232. Targownik LE, Bolton JM, Metge CJ, Leung S, Sareen J. Selective serotonin reuptake inhibitors are associated with a modest increase in the risk of upper gastrointestinal bleeding. Am J Gastroenterol. 2009; 104:1475-82

233. Andrade C, Sandarsh S, Chethan KB, Nagesh KS. Serotonin reuptake inhibitor antidepressants and abnormal bleeding: a review for clinicians and a reconsideration of mechanisms. J Clin Psychiatry. 2010;71:1565-75

234. de Abajo FJ. Effects of selective serotonin reuptake inhibitors on platelet function: mechanisms, clinical outcomes and implications for use in elderly patients. Drugs Aging. 2011;28:345-67.

235. Targownik LE. Are we worried enough about selective serotonin receptor inhibitors and upper gastrointestinal bleeding? Clin Gastroenterol Hepatol. 2015;13:51-4 
236. Rostom A, Moayyedi P, Hunt R, Canadian Association of Gastroenterology Consensus Group. Canadian consensus guidelines on long-term nonsteroida anti-inflammatory drug therapy and the need for gastroprotection: benefits versus risks. Aliment Pharmacol Ther. 2009;29:481-96.

237. Scarpignato C, Pelosini I. Prevention and treatment of non-steroidal anti-inflammatory drug-induced gastro-duodenal damage: rationale for the use of antisecretory compounds. Ital J Gastroenterol Hepatol. 1999; 31 Suppl 1:S63-72.

238. Moore RA, Derry S, Phillips CJ, McQuay HJ. Nonsteroidal anti-inflammatory drugs (NSAIDs), cyxlooxygenase-2 selective inhibitors (Coxibs) and gastrointestinal harm: review of clinical trials and clinical practice. BMC Musculoskelet Disord. 2006;7:79.

239. Rostom A, Muir K, Dube C, et al. Gastrointestinal safety of cyclooxygenase-2 inhibitors: a Cochrane Collaboration systematic review. Clin Gastroenterol Hepatol. 2007;5:818-28.

240. Blandizzi C, Tuccori M, Colucci R, et al. Role of coxibs in the strategies for gastrointestinal protection in patients requiring chronic non-steroidal antiinflammatory therapy. Pharmacol Res. 2009;59:90-100.

241. Yuan JQ, Tsoi KK, Yang M, et al. Systematic review with network metaanalysis: comparative effectiveness and safety of strategies for preventing NSAID-associated gastrointestinal toxicity. Aliment Pharmacol Ther. 2016; 43:1262-75.

242. Fujimori S, Takahashi Y, Tatsuguchi A, Sakamoto C. Omeprazole increased small intestinal mucosal injury in two of six disease-free cases evaluated by capsule endoscopy. Dig Endosc. 2014;26:676-9.

243. Washio E, Esaki M, Maehata Y, et al. Proton pump inhibitors increase incidence of nonsteroidal anti-inflammatory drug-induced small bowel injury: a randomized placebo-controlled trial. Clin Gastroenterol Hepatol. 2016;14:809-15. e1.

244. Marlicz W, Loniewski I, Grimes DS, Quigley EM. Nonsteroidal antiinflammatory drugs, proton pump inhibitors, and gastrointestinal injury: contrasting interactions in the stomach and small intestine. Mayo Clin Proc. 2014:89:1699-709.

245. Nagata N, Niikura R, Aoki T, et al. Effect of proton-pump inhibitors on the risk of lower gastrointestinal bleeding associated with NSAIDs, aspirin, clopidogrel, and warfarin. J Gastroenterol. 2015;50:1079-86.

246. Trelle S, Reichenbach S, Wandel S, et al. Cardiovascular safety of non-steroidal anti-inflammatory drugs: network meta-analysis. BMJ. 2011;342:C7086.

247. Collaboration CatNTC, Bhala N, Emberson J, et al. Vascular and upper gastrointestinal effects of non-steroidal anti-inflammatory drugs: metaanalyses of individual participant data from randomised trials. Lancet. 2013; 382:769-79.

248. Hunt RH, Choquette D, Craig BN, et al. Approach to managing musculoskeletal pain: acetaminophen, cyclooxygenase-2 inhibitors, or traditional NSAIDs? Can Fam Physician. 2007:53:1177-84.

249. Martinek J, Hlavova K, Zavada F, et al. "A surviving myth" - corticosteroids are still considered ulcerogenic by a majority of physicians. Scand J Gastroenterol. 2010;45:1156-61

250. Filaretova L. Gastroprotective role of glucocorticoids during NSAID-induced gastropathy. Curr Pharm Des. 2013;19:29-33.

251. Filaretova L. The hypothalamic-pituitary-adrenocortical system: Hormonal brain-gut interaction and gastroprotection. Auton Neurosci. 2006;125: 86-93.

252. Guslandi M. Steroid ulcers: any news? World J Gastrointest Pharmacol Ther. 2013;4:39-40.

253. Luo JC, Chang FY, Lin HY, et al. The potential risk factors leading to peptic ulcer formation in autoimmune disease patients receiving corticosteroid treatment. Aliment Pharmacol Ther. 2002;16:1241-8.

254. Hernandez-Diaz S, Rodriguez LA. Steroids and risk of upper gastrointestinal complications. Am J Epidemiol. 2001;153:1089-93.

255. Weil J, Langman MJ, Wainwright $P$, et al. Peptic ulcer bleeding: accessory risk factors and interactions with non-steroidal anti-inflammatory drugs. Gut. 2000;46:27-31.

256. Messer J, Reitman D, Sacks HS, Smith Jr H, Chalmers TC. Association of adrenocorticosteroid therapy and peptic-ulcer disease. N Engl J Med. 1983; 309:21-4.

257. Piper JM, Ray WA, Daugherty JR, Griffin MR. Corticosteroid use and peptic ulcer disease: role of nonsteroidal anti-inflammatory drugs. Ann Intern Med. 1991;114:735-40.

258. Conn HO, Poynard T. Corticosteroids and peptic ulcer: meta-analysis of adverse events during steroid therapy. J Intern Med. 1994;236:619-32.
259. Dorlo TP, Jager NG, Beijnen JH, Schellens JH. Concomitant use of proton pump inhibitors and systemic corticosteroids. Ned Tijdschr Geneeskd. 2013; 157:A5540.

260. Narum S, Westergren T, Klemp M. Corticosteroids and risk of gastrointestinal bleeding: a systematic review and meta-analysis. BMJ Open. 2014;4, e004587.

261. Cook DJ, Fuller HD, Guyatt GH, et al. Risk factors for gastrointestinal bleeding in critically ill patients. Canadian Critical Care Trials Group. N Engl J Med. 1994;330:377-81.

262. Jansen A, Harenberg S, Grenda U, Elsing C. Risk factors for colonic diverticular bleeding: a Westernized community based hospital study. World J Gastroenterol. 2009;15:457-61.

263. Ogata T, Kamouchi M, Matsuo R, et al. Gastrointestinal bleeding in acute ischemic stroke: recent trends from the Fukuoka stroke registry. Cerebrovasc Dis Extra. 2014;4:156-64.

264. Weisman SM, Graham DY. Evaluation of the benefits and risks of low-dose aspirin in the secondary prevention of cardiovascular and cerebrovascular events. Arch Intern Med. 2002;162:2197-202.

265. US Preventive Services Task Force. Aspirin for the prevention of cardiovascular disease: U.S. Preventive Services Task Force recommendation statement. Ann Intern Med. 2009;150:396-404.

266. Zullo A, Hassan C, Campo SM, Morini S. Bleeding peptic ulcer in the elderly: risk factors and prevention strategies. Drugs Aging. 2007;24:815-28.

267. Lanas A, Garcia-Rodriguez LA, Arroyo MT, et al. Risk of upper gastrointestinal ulcer bleeding associated with selective cyclo-oxygenase-2 inhibitors, traditional non-aspirin non-steroidal anti-inflammatory drugs, aspirin and combinations. Gut. 2006;55:1731-8.

268. Garcia Rodriguez LA, Lin KJ, Hernandez-Diaz S, Johansson S. Risk of upper gastrointestinal bleeding with low-dose acetylsalicylic acid alone and in combination with clopidogrel and other medications. Circulation. 2011;123: 1108-15.

269. Sostres C, Gargallo CJ, Lanas A. Nonsteroidal anti-inflammatory drugs and upper and lower gastrointestinal mucosal damage. Arthritis Res Ther. 2013; 15 Suppl 3:S3.

270. Ahsberg K, Hoglund P, Stael von Holstein C. Mortality from peptic ulcer bleeding: the impact of comorbidity and the use of drugs that promote bleeding. Aliment Pharmacol Ther. 2010;32:801-10.

271. Ibanez L, Vidal X, Vendrell L, Moretti U, Laporte JR, Spanish-Italian Collaborative Group for the Epidemiology of Gastrointestinal Bleeding. Upper gastrointestinal bleeding associated with antiplatelet drugs. Aliment Pharmacol Ther. 2006;23:235-42.

272. Schjerning Olsen AM, Lindhardsen J, Gislason GH, et al. Impact of proton pump inhibitor treatment on gastrointestinal bleeding associated with non-steroidal anti-inflammatory drug use among post-myocardial infarction patients taking antithrombotics: nationwide study. BMJ. 2015; 351:h5096.

273. Shiotani A, Murao T, Fujita Y, et al. Novel single nucleotide polymorphism markers for low dose aspirin-associated small bowel bleeding. PLoS One. 2013;8, e84244.

274. Lanas A, Carrera-Lasfuentes P, Arguedas Y, et al. Risk of upper and lower gastrointestinal bleeding in patients taking nonsteroidal anti-inflammatory drugs, antiplatelet agents, or anticoagulants. Clin Gastroenterol Hepatol. 2014;13:906-12.

275. Chen M, Wei JF, Xu YN, Liu XJ, Huang DJ. A meta-analysis of impact of proton pump inhibitors on antiplatelet effect of clopidogrel. Cardiovasc Ther. 2012;30:e227-33.

276. Agewall S, Cattaneo M, Collet JP, et al. Expert position paper on the use of proton pump inhibitors in patients with cardiovascular disease and antithrombotic therapy. Eur Heart J. 2013;34:1708-13.

277. Vaduganathan M, Cannon CP, Cryer BL, et al. Efficacy and safety of protonpump inhibitors in high-risk cardiovascular subsets of the COGENT trial. Am Jed. 2016;129:1002-5.

278. Cardoso RN, Benjo AM, DiNicolantonio JJ, et al. Incidence of cardiovascular events and gastrointestinal bleeding in patients receiving clopidogrel with and without proton pump inhibitors: an updated meta-analysis. Open Heart. 2015;2, e000248

279. Hallas J, Dall M, Andries A, et al. Use of single and combined antithrombotic therapy and risk of serious upper gastrointestinal bleeding: population based case-control study. BMJ. 2006;333:726

280. Lin KJ, Hernandez-Diaz S, Garcia Rodriguez LA. Acid suppressants reduce risk of gastrointestinal bleeding in patients on antithrombotic or antiinflammatory therapy. Gastroenterology. 2011;141:71-9. 
281. Trenk D. Proton pump inhibitors for prevention of bleeding episodes in cardiac patients with dual antiplatelet therapy - between Scylla and Charybdis? Int J Clin Pharmacol Ther. 2009;47:1-10.

282. Casado Arroyo R, Polo-Tomas M, Roncales MP, Scheiman J, Lanas A. Lower $\mathrm{Gl}$ bleeding is more common than upper among patients on dual antiplatelet therapy: long-term follow-up of a cohort of patients commonly using PPI co-therapy. Heart. 2012;98:718-23.

283. Chan FK, Leung Ki EL, Wong GL, et al. Risks of bleeding recurrence and cardiovascular events with continued aspirin use after lower gastrointestinal hemorrhage. Gastroenterology. 2016;151:271-7.

284. Ray WA, Chung CP, Murray KT, et al. Association of proton pump inhibitors with reduced risk of warfarin-related serious upper gastrointestinal bleeding Gastroenterology. 2016. Ahead of print

285. Teichert M, van Noord C, Uitterlinden AG, et al. Proton pump inhibitors and the risk of overanticoagulation during acenocoumarol maintenance treatment. Br J Haematol. 2011;153:379-85.

286. Berstad A. Does profound acid inhibition improve haemostasis in peptic ulcer bleeding? Scand J Gastroenterol. 1997;32:396-8.

287. Geus WP. Are there indications for intravenous acid-inhibition in the prevention and treatment of upper GI bleeding? Scand J Gastroenterol. 2000:232:10-20.

288. Green Jr FW, Kaplan MM, Curtis LE, Levine PH. Effect of acid and pepsin on blood coagulation and platelet aggregation. A possible contributor prolonged gastroduodenal mucosal hemorrhage. Gastroenterology. 1978; 74:38-43.

289. Patchett SE, Enright H, Afdhal N, O'Connell W, O'Donoghue DP. Clot lysis by gastric juice: an in vitro study. Gut. 1989;30:1704-7

290. Barkun AN, Bardou M, Kuipers EJ, et al. International consensus recommendations on the management of patients with nonvariceal upper gastrointestinal bleeding. Ann Intern Med. 2010;152:101-13.

291. Andriulli A, Annese V, Caruso N, et al. Proton-pump inhibitors and outcome of endoscopic hemostasis in bleeding peptic ulcers: a series of metaanalyses. Am J Gastroenterol. 2005;100:207-19.

292. Zed PJ, Loewen PS, Slavik RS, Marra CA. Meta-analysis of proton pump inhibitors in treatment of bleeding peptic ulcers. Ann Pharmacother. 2001;35:1528-34.

293. Leontiadis GI, Sharma VK, Howden CW. Proton pump inhibitor treatment for acute peptic ulcer bleeding. Cochrane Database Syst Rev. 2006;1, CD002094.

294. Zhang YS, Li Q, He BS, Liu R, Li ZJ. Proton pump inhibitors therapy vs H2 receptor antagonists therapy for upper gastrointestinal bleeding after endoscopy: a meta-analysis. World J Gastroenterol. 2015;21:6341-51.

295. Leontiadis Gl, Sharma VK, Howden CW. Systematic review and metaanalysis: proton-pump inhibitor treatment for ulcer bleeding reduces transfusion requirements and hospital stay - results from the Cochrane Collaboration. Aliment Pharmacol Ther. 2005;22:169-74.

296. Leontiadis Gl, Sharma VK, Howden CW. Proton pump inhibitor therapy for peptic ulcer bleeding: Cochrane collaboration meta-analysis of randomized controlled trials. Mayo Clin Proc. 2007:82:286-96.

297. Sung JJ, Chan FK, Chen M, et al. Asia-Pacific Working Group consensus on non-variceal upper gastrointestinal bleeding. Gut. 2011;60:1170-7.

298. Laine L, Jensen DM. Management of patients with ulcer bleeding. Am J Gastroenterol. 2012;107:345-60.

299. Gralnek IM, Dumonceau JM, Kuipers EJ, et al. Diagnosis and management of nonvariceal upper gastrointestinal hemorrhage: European Society of Gastrointestinal Endoscopy (ESGE) Guideline. Endoscopy. 2015;47:a1-46.

300. Sachar H, Vaidya K, Laine L. Intermittent vs continuous proton pump inhibitor therapy for high-risk bleeding ulcers: a systematic review and meta-analysis. JAMA Intern Med. 2014;174:1755-62.

301. Wang $\mathrm{CH}, \mathrm{Ma} \mathrm{MH}$, Chou HC, et al. High-dose vs non-high-dose proton pump inhibitors after endoscopic treatment in patients with bleeding peptic ulcer: a systematic review and meta-analysis of randomized controlled trials. Arch Intern Med. 2010;170:751-8.

302. Tsoi KK, Hirai HW, Sung JJ. Meta-analysis: comparison of oral vs. intravenous proton pump inhibitors in patients with peptic ulcer bleeding. Aliment Pharmacol Ther. 2013;38:721-8.

303. Jian Z, Li H, Race NS, Ma T, Jin H, Yin Z. Is the era of intravenous proton pump inhibitors coming to an end in patients with bleeding peptic ulcers? Meta-analysis of the published literature. Br J Clin Pharmacol. 2016;82:880-9.

304. Lau JY, Barkun A, Fan DM, Kuipers EJ, Yang YS, Chan FK. Challenges in the management of acute peptic ulcer bleeding. Lancet. 2013;381:2033-43.

305. Freston J, Chiu YL, Pan WJ, Lukasik N, Taubel J. Effects on 24-hour intragastric $\mathrm{pH}$ : a comparison of lansoprazole administered nasogastrically in apple juice and pantoprazole administered intravenously. Am J Gastroenterol. 2001;96:2058-65.

306. Pisegna JR, Sostek MB, Monyak JT, Miner Jr PB. Intravenous esomeprazole $40 \mathrm{mg}$ vs. intravenous lansoprazole $30 \mathrm{mg}$ for controlling intragastric acidity in healthy adults. Aliment Pharmacol Ther. 2008;27:483-90.

307. Wilder-Smith $\mathrm{CH}$, Rohss $\mathrm{K}$, Bondarov $\mathrm{P}$, Hallerback $\mathrm{B}$, Svedberg LE, Ahlbom H. Esomeprazole $40 \mathrm{mg}$ i.v. provides faster and more effective intragastric acid control than pantoprazole $40 \mathrm{mg}$ i.v.: results of a randomized study. Aliment Pharmacol Ther. 2004;20:1099-104.

308. Piccoli F, Ory G, Hadengue A, Beglinger C, Degen L. Effect of intravenous esomeprazole $40 \mathrm{mg}$ and pantoprazole $40 \mathrm{mg}$ on intragastric $\mathrm{pH}$ in healthy subjects. A prospective, open, randomised, two-way cross-over comparative study. Arzneimittelforschung. 2007;57:654-8.

309. Hartmann D, Eickhoff A, Damian U, Riemann JF, Schilling D. Effect of intravenous application of esomeprazole $40 \mathrm{mg}$ versus pantoprazole $40 \mathrm{mg}$ on 24-hour intragastric pH in healthy adults. Eur J Gastroenterol Hepatol. 2007:19:133-7.

310. Armstrong D, Bair D, James C, Tanser L, Escobedo S, Nevin K. Oral esomeprazole vs. intravenous pantoprazole: a comparison of the effect on intragastric pH in healthy subjects. Aliment Pharmacol Ther. 2003; 18:705-11.

311. Sung JJ, Barkun A, Kuipers EJ, et al. Intravenous esomeprazole for prevention of recurrent peptic ulcer bleeding: a randomized trial. Ann Intern Med. 2009;150:455-64.

312. Dorward S, Sreedharan A, Leontiadis Gl, Howden CW, Moayyedi P, Forman D. Proton pump inhibitor treatment initiated prior to endoscopic diagnosis in upper gastrointestinal bleeding. Cochrane Database Syst Rev. 2006;4, CD005415.

313. Sreedharan A, Martin J, Leontiadis Gl, et al. Proton pump inhibitor treatment initiated prior to endoscopic diagnosis in upper gastrointestinal bleeding. Cochrane Database Syst Rev. 2010;7, CD005415.

314. Mitchell EP. Gastrointestinal toxicity of chemotherapeutic agents. Semin Oncol. 2006;33:106-20.

315. Di Fiore F, Van Cutsem E. Acute and long-term gastrointestinal consequences of chemotherapy. Best Pract Res Clin Gastroenterol. 2009;23:113-24.

316. Boussios S, Pentheroudakis G, Katsanos K, Pavlidis N. Systemic treatmentinduced gastrointestinal toxicity: incidence, clinical presentation and management. Ann Gastroenterol. 2012;25:106-18.

317. Andreyev J. Gastrointestinal complications of pelvic radiotherapy: are they of any importance? Gut. 2005;54:1051-4.

318. Peterson DE, Bensadoun RJ, Roila F. Management of oral and gastrointestinal mucositis: ESMO clinical recommendations. Ann Oncol. 2009;20 Suppl 4:174-7.

319. Worthington HV, Clarkson JE, Bryan G, et al. Interventions for preventing oral mucositis for patients with cancer receiving treatment. Cochrane Database Syst Rev. 2011;4, CD000978.

320. Andreyev HJ, Davidson SE, Gillespie C, Allum WH, Swarbrick E. Practice guidance on the management of acute and chronic gastrointestinal problems arising as a result of treatment for cancer. Gut. 2012;61:179-92.

321. McGuire DB, Fulton JS, Park J, et al. Systematic review of basic oral care for the management of oral mucositis in cancer patients. Support Care Cancer. 2013;21:3165-77.

322. Vehreschild MJ, Vehreschild JJ, Hubel K, et al. Diagnosis and management of gastrointestinal complications in adult cancer patients: evidence-based guidelines of the Infectious Diseases Working Party (AGIHO) of the German Society of Hematology and Oncology (DGHO). Ann Oncol. 2013;24:1189-202

323. Andreyev J, Ross P, Donnellan C, et al. Guidance on the management of diarrhoea during cancer chemotherapy. Lancet Oncol. 2014;15:447-60.

324. Lalla RV, Bowen J, Barasch A, et al. MASCC/ISOO clinical practice quidelines for the management of mucositis secondary to cancer therapy. Cancer. 2014;120:1453-61.

325. Blijlevens NM, Donnelly JP, De Pauw BE. Mucosal barrier injury: biology, pathology, clinical counterparts and consequences of intensive treatment for haematological malignancy: an overview. Bone Marrow Transplant. 2000; 25:1269-78.

326. Touchefeu $Y$, Montassier $E_{1}$ Nieman $K$, et al. Systematic review: the role of the gut microbiota in chemotherapy- or radiation-induced gastrointestinal mucositis - current evidence and potential clinical applications. Aliment Pharmacol Ther. 2014;40:409-21.

327. Chaveli-Lopez B. Oral toxicity produced by chemotherapy: A systematic review. J Clin Exp Dent. 2014;6:e81-90. 
328. Uwagawa T, Misawa T, lida T, et al. Proton-pump inhibitor as palliative care for chemotherapy-induced gastroesophageal reflux disease in pancreatic cancer patients. J Palliat Med. 2010;13:815-8.

329. Sartori S, Nielsen I, Maestri A, Beltrami D, Trevisani L, Pazzi P. Acute gastroduodenal mucosal injury after cisplatin plus etoposide chemotherapy. Clinical and endoscopic study. Oncology. 1991;48:356-61.

330. Doria Jr MI, Doria LK, Faintuch J, Levin B. Gastric mucosal injury after hepatic arterial infusion chemotherapy with floxuridine. A clinical and pathologic study. Cancer. 1994;73:2042-7.

331. Ravizza D, Fazio N, Fiori G, et al. latrogenic gastroduodenal ulcers during hepatic intra-arterial chemotherapy. Hepatogastroenterology. 2003;50:49-53.

332. Loriot Y, Perlemuter G, Malka D, et al. Drug insight: gastrointestinal and hepatic adverse effects of molecular-targeted agents in cancer therapy. Nat Clin Pract Oncol. 2008:5:268-78.

333. Abu-Hejleh T, Mezhir JJ, Goodheart MJ, Halfdanarson TR. Incidence and management of gastrointestinal perforation from bevacizumab in advanced cancers. Curr Oncol Rep. 2012;14:277-84.

334. Tol J, Cats A, Mol L, et al. Gastrointestinal ulceration as a possible side effect of bevacizumab which may herald perforation. Invest New Drugs. 2008;26:393-7.

335. Steer CB, Harper PG. Gastro-oesophageal complications in patients receiving cancer therapy: the role of proton pump inhibitors. Eur J Gastroenterol Hepatol. 2002;14 Suppl 1:S17-21.

336. Xie YL, Huang QC. Advances in prevention and treatment of chemotherapyinduced gastrointestinal mucositis with proton pump inhibitors. World Chin J Digestology. 2014;22:642-7.

337. Eguchi K, Suzuki M, Ida S, et al. Successful treatment of radiation-induced mucositis with proton pump inhibitor administration: A report of two laryngeal cancer cases. Auris Nasus Larynx. 2016. Ahead of print. http://dx.doi.org/10.1016/j.anl.2016.05.006.

338. Sartori S, Trevisani L, Nielsen I, Tassinari D, Abbasciano V. Misoprostol and omeprazole in the prevention of chemotherapy-induced acute gastroduodenal mucosal injury. A randomized, placebo-controlled pilot study. Cancer. 1996;78:1477-82

339. Sartori S, Trevisani L, Nielsen I, Tassinari D, Panzini I, Abbasciano V. Randomized trial of omeprazole or ranitidine versus placebo in the prevention of chemotherapy-induced gastroduodenal injury. J Clin Oncol. 2000;18:463-7

340. Triadafilopoulos G, Roorda AK, Akiyama J. Indications and safety of proton pump inhibitor drug use in patients with cancer. Expert Opin Drug Saf. 2013;12:659-72.

341. Mercadante S, David F, Riina S, Girelli D. Injustifiable use of gastroprotection in advanced cancer patients. Palliat Med. 2007;21:631-3.

342. McCaleb RV, Gandhi AS, Clark SM, Clemmons AB. Clinical outcomes of acid suppressive therapy use in hematology/oncology patients at an Academic Medical Center. Ann Pharmacother. 2016;50:541-7.

343. WHO: Globocan 2012. Estimated cancer incidence, mortality and prevalence worldwide in 2012. http://globocan.iarc.fr/Pages/fact_sheets_cancer.aspx [last Accessed 30 Oct 2016].

344. Lugini L, Federici $C$, Borghi $M$, et al. Proton pump inhibitors while belonging to the same family of generic drugs show different anti-tumor effect. J Enzyme Inhib Med Chem. 2016;31:538-45.

345. Taylor S, Spugnini EP, Assaraf YG, Azzarito T, Rauch C, Fais S. Microenvironment acidity as a major determinant of tumor chemoresistance: proton pump inhibitors (PPIs) as a novel therapeutic approach. Drug Resist Updat. 2015;23:69-78.

346. Fais S. Evidence-based support for the use of proton pump inhibitors in cancer therapy. J Transl Med. 2015;13:368.

347. Papagerakis S, Bellile E, Peterson LA, et al. Proton pump inhibitors and histamine 2 blockers are associated with improved overall survival in patients with head and neck squamous carcinoma. Cancer Prev Res. 2014;7: 1258-69.

348. Lodato F, Azzaroli F, Di Girolamo M, et al. Proton pump inhibitors in cirrhosis: tradition or evidence based practice? World J Gastroenterol. 2008; 14:2980-5.

349. Savarino V, Mela GS, Zentilin P, et al. Evaluation of 24-hour gastric acidity in patients with hepatic cirrhosis. J Hepatol. 1996;25:152-7.

350. Yang J, Guo Z, Wu Z, Wang Y. Antacids for preventing oesophagogastric variceal bleeding and rebleeding in cirrhotic patients. Cochrane Database Syst Rev. 2008;2, CD005443.
351. Gupta A, Dhiman RK, Kumari S, et al. Role of small intestinal bacterial overgrowth and delayed gastrointestinal transit time in cirrhotic patients with minimal hepatic encephalopathy. J Hepatol. 2010;53:849-55.

352. Bajaj JS, Cox IJ, Betrapally NS, et al. Systems biology analysis of omeprazole therapy in cirrhosis demonstrates significant shifts in gut microbiota composition and function. Am J Physiol Gastrointest Liver Physiol. 2014;307:G951-7.

353. Lo EA, Wilby KJ, Ensom MH. Use of proton pump inhibitors in the management of gastroesophageal varices: a systematic review. Ann Pharmacother. 2015:49:207-19.

354. Deshpande A, Pasupuleti $V$, Thota P, et al. Acid-suppressive therapy is associated with spontaneous bacterial peritonitis in cirrhotic patients: a meta-analysis. J Gastroenterol Hepatol. 2013;28:235-42.

355. Yu T, Tang $Y$, Jiang $L$, Zheng $Y$, Xiong $W$, Lin L. Proton pump inhibitor therapy and its association with spontaneous bacterial peritonitis incidence and mortality: A meta-analysis. Dig Liver Dis. 2016:48:353-9.

356. Xu HB, Wang HD, Li CH, et al. Proton pump inhibitor use and risk of spontaneous bacterial peritonitis in cirrhotic patients: a systematic review and meta-analysis. Genet Mol Res. 2015;14:7490-501.

357. Tsai CF, Chen MH, Wang YP, et al. Proton pump inhibitors increase risk for hepatic encephalopathy in patients with cirrhosis in population study. Gastroenterology. 2016. Ahead of print.

358. Terg R, Casciato P, Garbe C, et al. Proton pump inhibitor therapy does not increase the incidence of spontaneous bacterial peritonitis in cirrhosis: $\mathrm{A}$ multicenter prospective study. J Hepatol. 2015;62:1056-60.

359. Yadav D, Lowenfels AB. The epidemiology of pancreatitis and pancreatic cancer. Gastroenterology. 2013;144:1252-61.

360. Working Party of the British Society of Gastroenterology, Association of Surgeons of Great Britain and Ireland, Pancreatic Society of Great Britain and Ireland, Association of Upper GI Surgeons of Great Britain and Ireland. UK guidelines for the management of acute pancreatitis. Gut. 2005;54 Suppl 3:iii1-9.

361. Banks PA, Bollen TL, Dervenis C, et al. Classification of acute pancreatitis 2012: revision of the Atlanta classification and definitions by international consensus. Gut. 2013;62:102-11.

362. Cavallini G, Frulloni L, Bassi C, et al. Prospective multicentre survey on acute pancreatitis in Italy (Prolnf-AISP): results on 1005 patients. Dig Liver Dis. 2004;36:205-11.

363. Pandol SJ, Saluja AK, Imrie CW, Banks PA. Acute pancreatitis: bench to the bedside. Gastroenterology. 2007;132:1127-51.

364. Kambhampati S, Park W, Habtezion A. Pharmacologic therapy for acute pancreatitis. World J Gastroenterol. 2014;20:16868-80.

365. Chey WY, Chang TM. Secretin: historical perspective and current status. Pancreas. 2014;43:162-82.

366. Cai J, Zhou W, Luo HS, Peng LV. Effect of proton pump inhibitor on amylase release from isolated pancreatic acini. In Vitro Cell Dev Biol Anim. 2007:43:25-7.

367. Hackert T, Tudor S, Felix K, et al. Effects of pantoprazole in experimental acute pancreatitis. Life Sci. 2010;87:551-7.

368. Yoo JH, Kwon $\mathrm{C}-\mathrm{I}$, Yoo K-H, et al. Effect of proton pump inhibitor in patients with acute pancreatitis - pilot study. Korean J Gastroenterol. 2012;60:362.

369. Murata A, Ohtani M, Muramatsu K, Matsuda S. Effects of proton pump inhibitor on outcomes of patients with severe acute pancreatitis based on a national administrative database. Pancreatology. 2015;15:491-6.

370. Abdelfatah MM, Nayfe R, El Zoghbi M, Gallegos P, Shill M, Kandil H. Proton pump inhibitors impact on post-endoscopic retrograde cholangiopancreatography pancreatitis. Pancreas. 2015;44:680-1.

371. Pezzilli R, Zerbi A, Campra D, et al. Italian Association for the Study of the Pancreas (AISP). Consensus guidelines on severe acute pancreatitis. Dig Liver Dis. 2015:47:532-43.

372. Takeda K, Takada T, Kawarada Y, et al. JPN Guidelines for the management of acute pancreatitis: medical management of acute pancreatitis. J Hepatobiliary Pancreat Surg. 2006;13:42-7.

373. Majumder S, Chari ST. Chronic pancreatitis. Lancet. 2016;387:1957-66.

374. Braganza JM, Lee SH, McCloy RF, McMahon MJ. Chronic pancreatitis. Lancet. 2011:377:1184-97.

375. Rickels MR, Bellin M, Toledo FG, et al. Detection, evaluation and treatment of diabetes mellitus in chronic pancreatitis: recommendations from PancreasFest 2012. Pancreatology. 2013;13:336-42.

376. Meier JJ, Giese A. Diabetes associated with pancreatic diseases. Curr Opin Gastroenterol. 2015;31:400-6. 
377. Brown A, Hughes M, Tenner S, Banks PA. Does pancreatic enzyme supplementation reduce pain in patients with chronic pancreatitis: a metaanalysis. Am J Gastroenterol. 1997;92:2032-5.

378. Lieb 2nd JG, Forsmark CE. Review article: pain and chronic pancreatitis. Aliment Pharmacol Ther. 2009;29:706-19.

379. Fieker A, Philpott J, Armand M. Enzyme replacement therapy for pancreatic insufficiency: present and future. Clin Exp Gastroenterol. 2011;4:55-73.

380. Dominguez-Munoz JE. Chronic pancreatitis and persistent steatorrhea: what is the correct dose of enzymes? Clin Gastroenterol Hepatol. 2011;9:541-6.

381. Geus WP, Eddes EH, Gielkens HA, Gan KH, Lamers CB, Masclee AA. Postprandial intragastric and duodenal acidity are increased in patients with chronic pancreatitis. Aliment Pharmacol Ther. 1999;13:937-43.

382. DiMagno EP. Gastric acid suppression and treatment of severe exocrine pancreatic insufficiency. Best Pract Res Clin Gastroenterol. 2001;15:477-86.

383. Anthony $\mathrm{H}$, Collins $\mathrm{CE}$, Davidson $\mathrm{G}$, et al. Pancreatic enzyme replacement therapy in cystic fibrosis: Australian guidelines. Pediatric Gastroenterological Society and the Dietitians Association of Australia. J Paediatr Child Health. 1999:35:125-9.

384. Frulloni L, Falconi M, Gabbrielli A, et al. Italian consensus guidelines for chronic pancreatitis. Dig Liver Dis. 2010;42 Suppl 6:S381-406.

385. Toouli J, Biankin AV, Oliver MR, Pearce CB, Wilson JS, Wray NH. Management of pancreatic exocrine insufficiency: Australasian Pancreatic Club recommendations. Med J Aust. 2010;193:461-7.

386. Pezzilli R, Andriulli A, Bassi C, et al. Exocrine pancreatic insufficiency in adults: a shared position statement of the Italian Association for the Study of the Pancreas. World J Gastroenterol. 2013;19:7930-46.

387. Hoffmeister A, Mayerle J, Beglinger C, et al. English language version of the S3-consensus guidelines on chronic pancreatitis: definition, aetiology, diagnostic examinations, medical, endoscopic and surgical management of chronic pancreatitis. Z Gastroenterol. 2015;53:1447-95.

388. de-Madaria E, Abad-Gonzalez A, Aparicio JR, et al. The Spanish Pancreatic Club's recommendations for the diagnosis and treatment of chronic pancreatitis: part 2 (treatment). Pancreatology. 2013;13:18-28.

389. Delhaye M, Van Steenbergen W, Cesmeli E, et al. Belgian consensus on chronic pancreatitis in adults and children: statements on diagnosis and nutritional, medical, and surgical treatment. Acta Gastroenterol Belg. 2014;77:47-65.

390. Gheorghe C, Seicean A, Saftoiu A, et al. Romanian guidelines on the diagnosis and treatment of exocrine pancreatic insufficiency. J Gastrointestin Liver Dis. 2015;24:117-23.

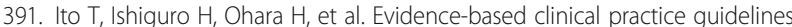
for chronic pancreatitis 2015. J Gastroenterol. 2016;51:85-92.

392. Berry AJ. Pancreatic enzyme replacement therapy during pancreatic insufficiency. Nutr Clin Pract. 2014;29:312-21.

393. Thomson AB, Sauve MD, Kassam N, Kamitakahara H. Safety of the long-term use of proton pump inhibitors. World J Gastroenterol. 2010;16:2323-30.

394. Ito T, Jensen RT. Association of long-term proton pump inhibitor therapy with bone fractures and effects on absorption of calcium, vitamin B12, iron, and magnesium. Curr Gastroenterol Rep. 2010;12:448-57.

395. Sheen E, Triadafilopoulos G. Adverse effects of long-term proton pump inhibitor therapy. Dig Dis Sci. 2011;56:931-50.

396. Chen J, Yuan YC, Leontiadis Gl, Howden CW. Recent safety concerns with proton pump inhibitors. J Clin Gastroenterol. 2012;46:93-114.

397. Johnson DA, Oldfield 4th EC. Reported side effects and complications of long-term proton pump inhibitor use: dissecting the evidence. Clin Gastroenterol Hepatol. 2013:11:458-64.

398. de la Coba OC, Arguelles Arias F, Martin de Argila de Prados C, et al. Protonpump inhibitors adverse effects: a review of the evidence and position statement by the Sociedad Espanola de Patologia Digestiva. Rev Esp Enferm Dig. 2016;108:207-24.

399. Mossner J. The indications, applications, and risks of proton pump inhibitors. Dtsch Arztebl Int. 2016;113:477-83.

400. Lahner E, Annibale B, Delle FG. Systematic review: impaired drug absorption related to the co-administration of antisecretory therapy. Aliment Pharmacol Ther. 2009:29:1219-29.

401. Blume H, Donath F, Warnke A, Schug BS. Pharmacokinetic drug interaction profiles of proton pump inhibitors. Drug Saf. 2006;29:769-84.

402. Wedemeyer RS, Blume H. Pharmacokinetic drug interaction profiles of proton pump inhibitors: an update. Drug Saf. 2014;37:201-11.

403. Yucel E, Sancar M, Yucel A, Okuyan B. Adverse drug reactions due to drugdrug interactions with proton pump inhibitors: assessment of systematic reviews with AMSTAR method. Expert Opin Drug Safe. 2016;15:223-36.
404. Shi S, Klotz U. Proton pump inhibitors: an update of their clinical use and pharmacokinetics. Eur J Clin Pharmacol. 2008;64:935-51.

405. Desta Z, Zhao X, Shin JG, Flockhart DA. Clinical significance of the cytochrome P450 2C19 genetic polymorphism. Clin Pharmacokinet. 2002;41:913-58.

406. Leontiadis GI, Yuan Y, Howden CW. The interaction between proton pump inhibitors and clopidogrel and upper gastrointestinal bleeding. Gastrointest Endosc Clin N Am. 2011;21:637-56.

407. Madanick RD. Proton pump inhibitor side effects and drug interactions: much ado about nothing? Cleve Clin J Med. 2011;78:39-49.

408. Bhatt DL, Cryer BL, Contant CF, et al. Clopidogrel with or without omeprazole in coronary artery disease. N Engl J Med. 2010;363:1909-17.

409. Vaduganathan $M$, Bhatt $D L$, Cryer BL, et al. Proton-pump inhibitors reduce gastrointestinal events regardless of aspirin dose in patients requiring dual antiplatelet therapy. J Am Coll Cardiol. 2016;67:1661-71.

410. Attwood SE, Ell C, Galmiche JP, et al. Long-term safety of proton pump inhibitor therapy assessed under controlled, randomised clinical trial conditions: data from the SOPRAN and LOTUS studies. Aliment Pharmacol Ther. 2015;41:1162-74.

411. Fiocca R, Mastracci L, Attwood SE, et al. Gastric exocrine and endocrine cell morphology under prolonged acid inhibition therapy: results of a 5-year follow-up in the LOTUS trial. Aliment Pharmacol Ther. 2012;36:959-71.

412. Huang JQ, Hunt RH. Eradication of Helicobacter pylori infection in the management of patients with dyspepsia and non-ulcer dyspepsia. Yale J Biol Med. 1998;71:125-33.

413. Schubert ML, Peura DA. Control of gastric acid secretion in health and disease. Gastroenterology. 2008;134:1842-60.

414. Eid SM, Boueiz A, Paranji S, Mativo C, Landis R, Abougergi MS. Patterns and predictors of proton pump inhibitor overuse among academic and nonacademic hospitalists. Intern Med. 2010;49:2561-8.

415. Yang YX, Metz DC. Safety of proton pump inhibitor exposure. Gastroenterology. 2010;139:1115-27.

416. Heidelbaugh JJ, Goldberg KL, Inadomi JM. Magnitude and economic effect of overuse of antisecretory therapy in the ambulatory care setting. Am J Manag Care. 2010;16:e228-34.

417. Heidelbaugh JJ, Goldberg KL, Inadomi JM. Overutilization of proton pump inhibitors: a review of cost-effectiveness and risk. Am J Gastroenterol. 2009; 104 Suppl 2:S27-32

418. Shin JM, Vagin O, Munson K, Kidd M, Modlin IM, Sachs G. Molecular mechanisms in therapy of acid-related diseases. Cell Mol Life Sci. 2008;65:264-81.

419. Nealis TB, Howden CW. Is there a dark side to long-term proton pump inhibitor therapy? Am J Ther. 2008;15:536-42.

420. Flower R. The Osler Lecture 2012: 'Pharmacology 2.0, medicines, drugs and human enhancement'. QJM. 2012;105:823-30.

421. Jepsen P, Johnsen SP, Gillman MW, Sorensen HT. Interpretation of observational studies. Heart. 2004;90:956-60.

422. Laine L. Clinical Practice. Upper gastrointestinal bleeding due to a peptic ulcer. N Engl J Med. 2016;374:2367-76.

423. Steinbrook R. Guidance for guidelines. N Engl J Med. 2007:356:331-3.

424. Woolf SH, Grol R, Hutchinson A, Eccles M, Grimshaw J. Clinical guidelines: potential benefits, limitations, and harms of clinical guidelines. BMJ. 1999; 318:527-30

425. Dries AM, Richardson P, Cavazos J, Abraham NS. Therapeutic intent of proton pump inhibitor prescription among elderly nonsteroidal antiinflammatory drug users. Aliment Pharmacol Ther. 2009:30:652-61.

426. Lanas A, Boers M, Nuevo J. Gastrointestinal events in at-risk patients starting non-steroidal anti-inflammatory drugs (NSAIDs) for rheumatic diseases: the EVIDENCE study of European routine practice. Ann Rheum Dis. 2015;74:675-81.

427. Pasina L, Urru SA, Mandelli S, Giua C, Minghetti P. Evidence-based and unlicensed indications for proton pump inhibitors and patients' preferences for discontinuation: a pilot study in a sample of Italian community pharmacies. J Clin Pharm Ther. 2016:41:220-3.

428. Issa IA, Soubra O, Nakkash H, Soubra L. Variables associated with stress ulcer prophylaxis misuse: a retrospective analysis. Dig Dis Sci. 2012;57:2633-41.

429. Hong MT, Monye LC, Seifert CF. Acid suppressive therapy for stress ulcer prophylaxis in noncritically ill patients. Ann Pharmacother. 2015;49:1004-8.

430. Redfern RE, Brown M, Karhoff KL, Middleton JL. Overuse of acid-suppression therapy at an urban tertiary hospital. South Med J. 2015;108:732-8.

431. Grube RR, May DB. Stress ulcer prophylaxis in hospitalized patients not in intensive care units. Am J Health Syst Pharm. 2007;64:1396-400.

432. Meli M, Malta R, Aprea $L$, et al. Proton pump inhibitor use in a university teaching hospital [in Italian]. Italian J Med. 2012;6:202-9. 
433. Sheikh I, Waghray A, Waghray N, Dong C, Wolfe MM. Consumer use of over-the-counter proton pump inhibitors in patients with gastroesophageal reflux disease. Am J Gastroenterol. 2014;109:789-94.

434. Menees SB, Guentner A, Chey SW, Saad R, Chey WD. How do US gastroenterologists use over-the-counter and prescription medications in patients with gastroesophageal reflux and chronic constipation? Am J Gastroenterol. 2015;110:1516-25.

435. Blandizzi C, Scarpignato C. Generic drugs in gastroenterology. Critical issues in bioequivalence and inference in therapeutic equivalence. Ther Perspect. 2014;17:1-43.

436. Holtmann G, Bigard MA, Malfertheiner P, Pounder R. Guidance on the use of over-the-counter proton pump inhibitors for the treatment of GERD. Int J Clin Pharm. 2011:33:493-500.

437. Galmiche JP, Stephenson K. Treatment of gastroesophageal reflux disease in adults: an individualized approach. Dig Dis. 2004;22:148-60.

438. Lee TJ, Fennerty MB, Howden CW. Systematic review: is there excessive use of proton pump inhibitors in gastro-oesophageal reflux disease? Aliment Pharmacol Ther. 2004;20:1241-51.

439. Bardhan KD. Intermittent and on-demand use of proton pump inhibitors in the management of symptomatic gastroesophageal reflux disease. Am J Gastroenterol. 2003;98:540-8.

440. Zacny J, Zamakhshary M, Sketris I, Veldhuyzen van Zanten S. Systematic review: the efficacy of intermittent and on-demand therapy with histamine $\mathrm{H}_{2}$-receptor antagonists or proton pump inhibitors for gastro-oesophageal reflux disease patients. Aliment Pharmacol Ther. 2005;21:1299-312.

441. Pace F, Tonini M, Pallotta S, Molteni P, Porro GB. Systematic review: maintenance treatment of gastro-oesophageal reflux disease with proton pump inhibitors taken 'on-demand'. Aliment Pharmacol Ther. 2007;26:195-204.

442. Metz DC, Inadomi JM, Howden CW, van Zanten SJ, Bytzer P. On-demand therapy for gastroesophageal reflux disease. Am J Gastroenterol. 2007;102: 642-53.

443. Contini S, Scarpignato C. Endoscopic treatment of gastro-oesophageal reflux disease (GORD): a systematic review. Dig Liver Dis. 2003;35:818-38.

444. Lundell L. Surgical therapy of gastro-oesophageal reflux disease. Best Pract Res Clin Gastroenterol. 2010;24:947-59.

445. Worrell SG, Greene CL, DeMeester TR. The state of surgical treatment of gastroesophageal reflux disease after five decades. J Am Coll Surg. 2014;219: 819-30.

446. Thompson W, Hogel M, Li Y, et al. Effect of a proton pump inhibitor deprescribing guideline on drug usage and costs in long-term care. J Am Med Dir Assoc. 2016;17:673. e1-4.

447. Wallace JL. Selective cyclooxygenase-2 inhibitors: after the smoke has cleared. Dig Liver Dis. 2002;34:89-94.

448. Moss SF, Playford RJ, Ayesu K, Li SK, Calam J. pH-dependent secretion of gastrin in duodenal ulcer disease: effect of suppressing Helicobacter pylori. Digestion. 1992;52:173-8

449. Eslami L, Nasseri-Moghaddam S. Meta-analyses: does long-term PPI use increase the risk of gastric premalignant lesions? Arch Iran Med. 2013;16:449-58.

450. Ahn JS, Eom CS, Jeon CY, Park SM. Acid suppressive drugs and gastric cancer: a meta-analysis of observational studies. World J Gastroenterol. 2013;19:2560-8.

451. Tran-Duy A, Spaetgens B, Hoes AW, de Wit NJ, Stehouwer CD. Use of proton pump inhibitors and risks of fundic gland polyps and gastric cancer: systematic review and meta-analysis. Clin Gastroenterol Hepatol. 2016. Ahead of print. doi: 10.1016/j.cgh.2016.05.018.

452. Robertson DJ, Larsson H, Friis S, Pedersen L, Baron JA, Sorensen HT. Proton pump inhibitor use and risk of colorectal cancer: a population-based, casecontrol study. Gastroenterology. 2007;133:755-60.

453. Free Martin FC, Chenevix-Trench G, Yeomans ND. Systematic review with meta-analysis: fundic gland polyps and proton pump inhibitors. Aliment Pharmacol Ther. 2016:44:915-25.

454. Bradley MC, Murray LJ, Cantwell MM, Hughes CM. Proton pump inhibitors and histamine-2-receptor antagonists and pancreatic cancer risk: a nested case-control study. Br J Cancer. 2012;106:233-9.

455. Lai SW, Sung FC, Lin CL, Liao KF. Use of proton pump inhibitors correlates with increased risk of pancreatic cancer: a case-control study in Taiwan. Kuwait Med J. 2014:46:44-8.

456. Bavishi C, Dupont HL. Systematic review: the use of proton pump inhibitors and increased susceptibility to enteric infection. Aliment Pharmacol Ther. 2011;34:1269-81.

457. Zacharioudakis IM, Zervou FN, Pliakos EE, Ziakas PD, Mylonakis E. Colonization with toxinogenic C. difficile upon hospital admission, and risk of infection: a systematic review and meta-analysis. Am J Gastroenterol. 2015;110:381-90.

458. Tleyjeh IM, Bin Abdulhak AA, Riaz M, et al. Association between proton pump inhibitor therapy and Clostridium difficile infection: a contemporary systematic review and meta-analysis. PLoS One. 2012;7, e50836.

459. Leonard J, Marshall JK, Moayyedi P. Systematic review of the risk of enteric infection in patients taking acid suppression. Am J Gastroenterol. 2007;102: 2047-56.

460. Daniell HW. Acid suppressing therapy as a risk factor for Candida esophagitis. Dis Esophagus. 2016;29:479-83.

461. Lo WK, Chan WW. Proton pump inhibitor use and the risk of small intestinal bacterial overgrowth: a meta-analysis. Clin Gastroenterol Hepatol. 2013;11: 483-90.

462. Lebwohl B, Spechler SJ, Wang TC, Green PH, Ludvigsson JF. Use of proton pump inhibitors and subsequent risk of celiac disease. Dig Liver Dis. 2014;46:36-40.

463. Freedberg DE, Lebwohl B, Abrams JA. The impact of proton pump inhibitors on the human gastrointestinal microbiome. Clin Lab Med. 2014; 34:771-85.

464. Scarpignato C, Bertelé A. Effect of proton pump inhibitors on gut microbiota. Biotascope. 2016. In press.

465. Liamis G, Milionis H, Elisaf M. A review of drug-induced hyponatremia. Am J Kidney Dis. 2008;52:144-53.

466. Jung SB, Nagaraja V, Kapur A, Eslick GD. Association between vitamin B 12 deficiency and long-term use of acid-lowering agents: a systematic review and meta-analysis. Intern Med J. 2015;45:409-16.

467. Cheungpasitporn W, Thongprayoon C, Kittanamongkolchai W, et al. Proton pump inhibitors linked to hypomagnesemia: a systematic review and metaanalysis of observational studies. Ren Fail. 2015;37:1237-41.

468. Park CH, Kim EH, Roh YH, Kim HY, Lee SK. The association between the use of proton pump inhibitors and the risk of hypomagnesemia: a systematic review and meta-analysis. PLoS One. 2014;9, e112558.

469. Capurso G, Marignani M, Attilia F, et al. Lansoprazole-induced microscopic colitis: an increasing problem? Results of a prospective case-series and systematic review of the literature. Dig Liver Dis. 2011; 43:380-5

470. Tong J, Zheng Q, Zhang C, Lo R, Shen J, Ran Z. Incidence, prevalence, and temporal trends of microscopic colitis: a systematic review and metaanalysis. Am J Gastroenterol. 2015;110:265-76.

471. Lambert AA, Lam JO, Paik JJ, Ugarte-Gil C, Drummond MB, Crowell TA. Risk of community-acquired pneumonia with outpatient proton-pump inhibitor therapy: a systematic review and meta-analysis. PLoS One. 2015;10, e0128004.

472. Eom CS, Jeon CY, Lim JW, Cho EG, Park SM, Lee KS. Use of acid-suppressive drugs and risk of pneumonia: a systematic review and meta-analysis. CMAJ. 2011:183:310-9.

473. Lau AN, Tomizza M, Wong-Pack M, Papaioannou A, Adachi JD. The relationship between long-term proton pump inhibitor therapy and skeletal frailty. Endocrine. 2015;49:606-10.

474. Targownik LE, Lix LM, Metge CJ, Prior HJ, Leung S, Leslie WD. Use of proton pump inhibitors and risk of osteoporosis-related fractures. CMAJ. 2008;179: 319-26.

475. Ngamruengphong S, Leontiadis Gl, Radhi S, Dentino A, Nugent K. Proton pump inhibitors and risk of fracture: a systematic review and meta-analysis of observational studies. Am J Gastroenterol. 2011;106:1209-18.

476. Yu EW, Bauer SR, Bain PA, Bauer DC. Proton pump inhibitors and risk of fractures: a meta-analysis of 11 international studies. Am J Med. 2011;124: 519-26.

477. Badiola N, Alcalde V, Pujol A, et al. The proton-pump inhibitor lansoprazole enhances amyloid beta production. PLoS One. 2013;8, e58837.

478. Booker A, Jacob LE, Rapp M, Bohlken J, Kostev K. Risk factors for dementia diagnosis in German primary care practices. Int Psychogeriatr. 2016;28: 1059-65.

479. Gomm W, von Holt K, Thome F, et al. Association of proton pump inhibitors with risk of dementia: a pharmacoepidemiological claims data analysis. JAMA Neurol. 2016;73:410-6.

480. Haenisch B, von Holt K, Wiese B, et al. Risk of dementia in elderly patients with the use of proton pump inhibitors. Eur Arch Psychiatry Clin Neurosci. 2015:265:419-28.

481. Otremba I, Wilczynski K, Szewieczek J. Delirium in the geriatric unit: proton-pump inhibitors and other risk factors. Clin Interv Aging. 2016: 11:397-405. 
482. Ghebremariam YT, Cooke JP, Khan F, et al. Proton pump inhibitors and vascular function: A prospective cross-over pilot study. Vasc Med. 2015;20: 309-16.

483. Chan JL, El-Serag HB. Is proton pump inhibitor use associated with risk of myocardial infarction? Gastroenterology. 2016;150:526-7.

484. Shah NH, LePendu P, Bauer-Mehren A, et al. Proton pump inhibitor usage and the risk of myocardial infarction in the general population. PLoS One. 2015;10, e0124653.

485. Turkiewicz A, Vicente RP, Ohlsson H, Tyden P, Merlo J. Revising the link between proton-pump inhibitors and risk of acute myocardial infarction-a case-crossover analysis. Eur J Clin Pharmacol. 2015;71:125-9.

486. Sierra F, Suarez M, Rey M, Vela MF. Systematic review: proton pump inhibitor-associated acute interstitial nephritis. Aliment Pharmacol Ther. 2007;26:545-53.

487. Moledina DG, Perazella MA. PPIs and kidney disease: from AIN to CKD. J Nephrol. 2016;29(5):611-6. doi:10.1007/s40620-016-0309-2.

488. Clark DW, Strandell J. Myopathy including polymyositis: a likely class adverse effect of proton pump inhibitors? Eur J Clin Pharmacol. 2006;62:473-9.

489. Duncan SJ, Howden CW. Proton pump inhibitors and risk of rhabdomyolysis: a comprehensive review. Drug Saf. 2016. In press.

490. Bergmann M, Guignard B, Ribi C. Hypersensitivity to proton pump inhibitors. Rev Med Suisse. 2012:8:830-5.

491. Savarino V, Dulbecco P, de Bortoli $N$ et al. The appropriate use of proton pump inhibitors (PPIs): Need for a reappraisal. Eur J Intern Med. 2016; doi:10. 1016/j.jejim.2016.10.007. 